Florida International University FIU Digital Commons

6-25-2014

\title{
The Relation of Steroid Hormones and Personality Factors to Financial Performance and Risk-Taking Behavior
}

Fernando M. Patterson

Florida International University, fpatt001@fiu.edu

DOI: $10.25148 /$ etd.FI14071112

Follow this and additional works at: https://digitalcommons.fiu.edu/etd

\section{Recommended Citation}

Patterson, Fernando M., "The Relation of Steroid Hormones and Personality Factors to Financial Performance and Risk-Taking Behavior" (2014). FIU Electronic Theses and Dissertations. 1448.

https://digitalcommons.fiu.edu/etd/1448 


\title{
FLORIDA INTERNATIONAL UNIVERSITY
}

Miami, Florida

\section{THE RELATION OF STEROID HORMONES AND PERSONALITY FACTORS TO FINANCIAL PERFORMANCE AND RISK-TAKING BEHAVIOR}

\author{
A dissertation submitted in partial fulfillment of \\ the requirements for the degree of \\ DOCTOR OF PHILOSOPHY \\ in \\ BUSINESS ADMINISTRATION \\ by \\ Fernando M. Patterson
}

2014 
To: Dean David R. Klock

College of Business Administration

This dissertation, written by Fernando M. Patterson, and entitled The Relation of Steroid Hormones and Personality Factors to Financial Performance and Risktaking Behavior, having been approved in respect to style and intellectual content, is referred to you for judgment.

We have read this dissertation and recommend that it be approved.

\begin{tabular}{rr}
\hline Anthony Dick \\
\hline John Nofsinger \\
\hline Brice Dupoyet
\end{tabular}

Chun-Hao Chang

Anthony De Caprio

Robert T. Daigler, Major Professor

Date of Defense: June 25, 2014

The dissertation of Fernando M. Patterson is approved.

Dean David R. Klock

College of Business Administration

Dean Lakshmi N. Reddi

University Graduate School

Florida International University, 2014 
(c) Copyright 2014 by Fernando M. Patterson

All rights reserved. 


\section{DEDICATION}

I dedicate this dissertation to my mother, who sacrificed much so her

children could get an education. Additionally, I dedicate this dissertation to my future progenies, to remind them to always persevere and to never give up. 


\section{ACKNOWLEDGMENTS}

First and foremost, I would like to thank my major professor, Dr. Robert T. Daigler, for his guidance and support. Without his remarkable skills as a mentor, this dissertation would not have been possible. Additionally, I would like to thank him for nurturing my skills as a researcher, and for introducing me to an area of financial research that matches my academic background and that $\mathrm{I}$ feel passionate about.

I am grateful to the members of my dissertation committee for their support, as well as to Dean Joyce Elam for her generous contribution that made the data collection possible. I would like to thank the Florida Education Fund for

their financial support. I would also like to thank Dr. Luis E. Arroyo-Mora of the Forensic \& Analytical Toxicology Facility and his staff for their contribution. Finally, I am grateful to my family and friends for their abiding support. 


\title{
ABSTRACT OF THE DISSERTATION \\ THE RELATION OF STEROID HORMONES AND PERSONALITY FACTORS \\ TO FINANCIAL PERFORMANCE AND RISK-TAKING BEHAVIOR
}

by

\author{
Fernando M. Patterson
}

Florida International University, 2014

Miami, Florida

\section{Professor Robert T. Daigler, Major Professor}

This doctoral dissertation addresses the biological and psychological components of financial decision-making for individuals. As such, it directly examines intrinsic human traits that are related to financial performance, rather than following the standard approach of inferring said traits from aggregate market data. Specifically, this dissertation examines the relation of personality traits, testosterone levels, and cortisol levels to financial choices and outcome under short-term (trading) and long-term (investing) investment horizons.

Subjects are recruited from advanced courses in finance at Florida International University. During the course of a semester (fourteen weeks) they complete a portfolio formation and rebalancing task, and answer a personality questionnaire. Additionally, subjects complete a series of trading simulations during the early morning of a preset date, and provide saliva samples. The saliva samples are analyzed for levels of testosterone and cortisol at a University lab facility. The relation of personality scores, testosterone levels, and cortisol levels 
to financial choices and outcomes is analyzed via linear regressions and Student's t-tests.

The results show that personality factors associated with detrimental life quality, such as paranoia, are related to long-term investment decisions associated with increased portfolio risk and return. Additionally, the levels of testosterone and cortisol play a significant role in initial portfolio formation decisions, but not in subsequent portfolio allocation decisions. As such, the results show that hormone levels contribute to initial long-term investment choices, but personality traits play a much greater role in portfolio maintenance. Alternatively, the results show that testosterone and cortisol levels play a significant role in many aspects of short-term investment, including the decision to buy or to sell, and timing preferences. Overall, the results show that hormone levels and personality traits play significant and distinctive roles in many aspects of financial decision-making. Therefore, this dissertation provides important implications for the practice and the study of finance, including information that could be used to make more rational financial choices, and to develop financial models with more realistic assumptions about investor behavior. 


\section{TABLE OF CONTENTS}

CHAPTER

PAGE

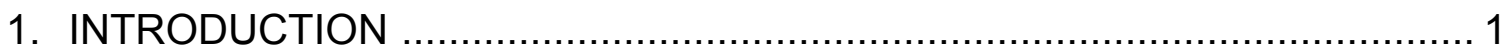

2. THE ABNORMAL PSYCHOLOGY OF INVESTMENT PERFORMANCE ......4 4

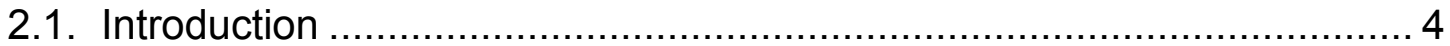

2.2. Portrayal of Investor Psychobiology in the Literature .......................... 7

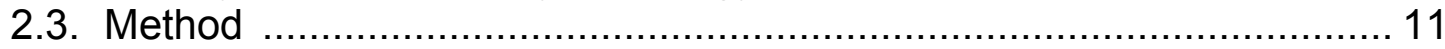

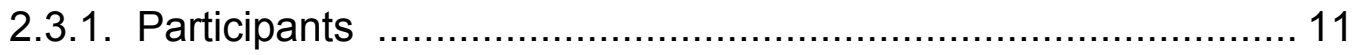

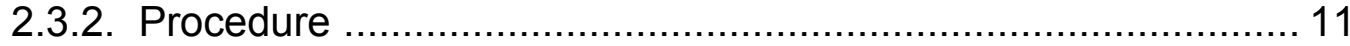

2.3.3. Investment Performance Measures ……............................... 12

2.3.4. Abnormal Personality Measures .......................................... 12

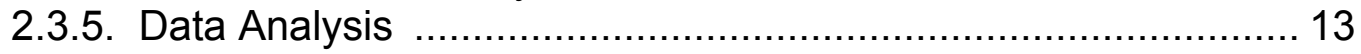

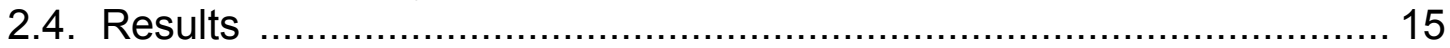

2.4.1. Investment Performance ............................................... 15

2.4.2. Investor Abnormal Personality ............................................. 16

2.4.3. Mental Pathology and Investment Performance ....................... 17

2.4.4. Abnormal Personality and Investment Performance ................ 20

2.4.5. Gender, Abnormal Personality, and Investment Performance .. 22

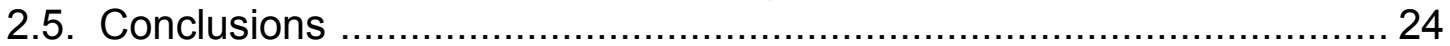

3. TESTOSTERONE AND FINANCIAL CHOICES ........................................ 36

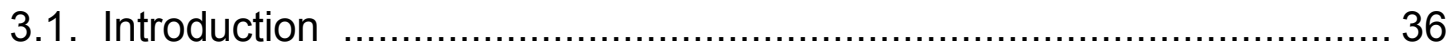

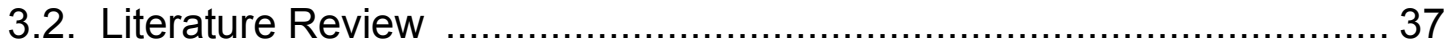

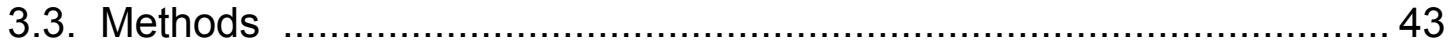

3.3.1. Subject Recruitment and Preparation ................................. 44

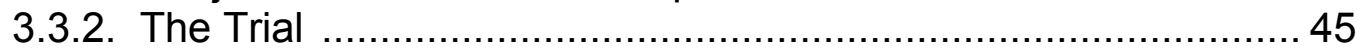

3.3.3. The Investment Simulations ............................................ 46

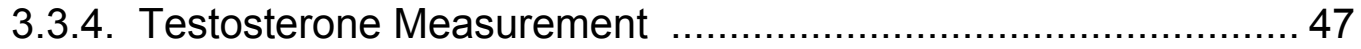

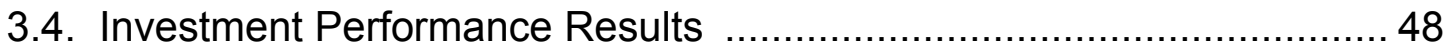

3.4.1. Asset Allocation Choices ............................................... 48

3.4.2. Investment Return and Volatility ......................................... 49

3.4.3. Investment Performance ................................................. 51

3.5. Testosterone and Investment Decisions and Outcome .......................5 53

3.5.1. Testosterone and Asset Allocation Decisions .......................... 53

3.5.2. Testosterone and Portfolio Investment Performance ................ 55

3.5.3. Testosterone and the Efficient Frontier ................................ 59

3.6. Testosterone and Options Trading Decisions and Outcome ................6 60

3.6.1. Options Trading Performance Overview ................................. 60

3.6.2. Testosterone and Options Contract Choice ............................. 61

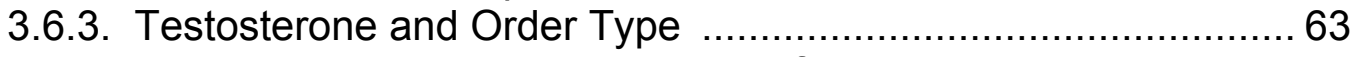

3.6.4. Testosterone and Trading Time Preferences ............................. 64

3.6.5. Testosterone and Options Trading Performance ....................... 66 


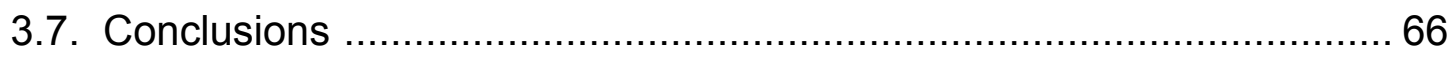

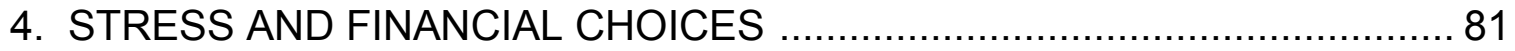

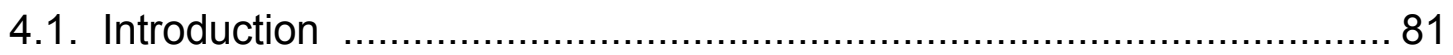

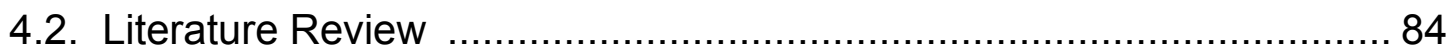

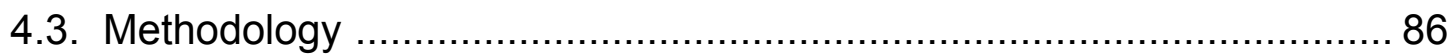

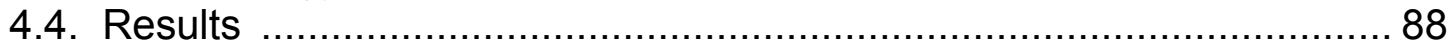

4.4.1. Stress and Investment Asset Allocation Decisions .................... 88

4.4.2. Stress and Expected Investment Performance ....................... 90

4.4.3. Stress and Options Trading Performance .............................. 94

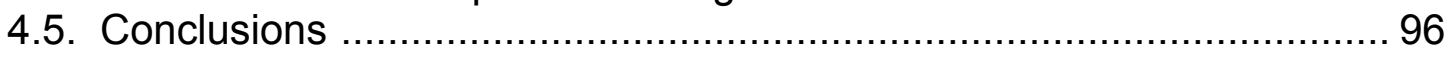

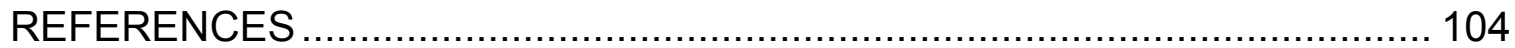

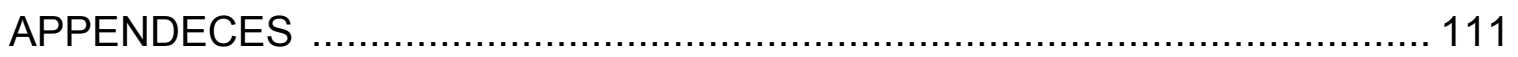

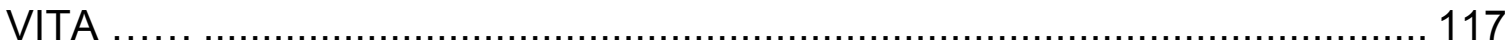




\section{LIST OF TABLES}

TABLE

PAGE

2.1. Abnormal Personality Factor Correlation Matrix …............................. 26

2.2. Investor Performance Summary Statistics ....................................... 27

2.3. Investor Abnormal Personality Summary Statistics ............................ 28

2.4. High, Average and Low Factor Scores and Investment Performance .... 29

2.5. Linear Relation between Factor Scores and Investment Performance ... 31

2.6. Male and Female Subject Abnormal Personality Summary Statistics ..... 32

2.7. Relation between Abnormal Personality Factors and Investment Performance in Women versus Men ................................................. 33

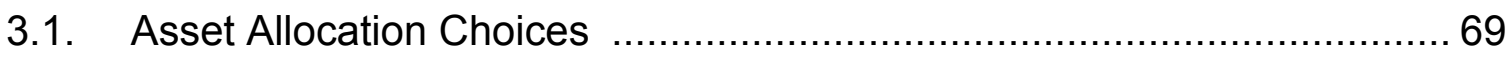

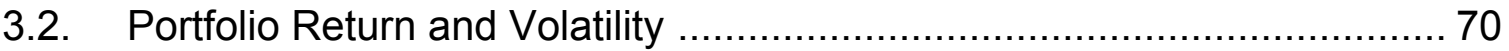

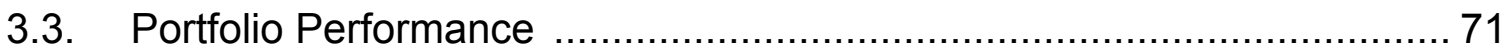

3.4. Testosterone Relation to Asset Allocation ....................................... 72

3.5. Relation of Testosterone to Expected Portfolio Performance ................ 73

3.6. Testosterone Relation to Portfolio Efficiency ................................... 74

3.7. Options Trading Summary Performance …..................................... 75

3.8. Testosterone, Number of Orders, and the Decision to Buy or Sell ......... 76

3.9. Testosterone and the Choice of Limit or Market Orders ….................. 77

3.10. Testosterone and Trading Time Preferences ........................................ 78

3.11. Testosterone and Options Trading Performance ................................ 79

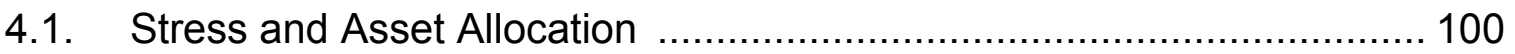

4.2. Relation of Stress to Expected Portfolio Performance ........................ 101 
4.3. Cortisol and Options Trading Preferences ........................................ 102

4.4. Cortisol and Trading Performance ................................................ 103 


\section{CHAPTER 1: INTRODUCTION}

The traditional approach to individual financial decision-making in the finance literature is to deduce investor behavior from asset returns (a top-down approach). However, much of the individual differences among investors are effectively lost in this approach, because asset returns are a consequence of mass behavior and not individual behavior. Using this general approach, researchers have identified various errors in judgment, also known as behavioral investment biases, which are related to the overall stock market behavior. For example, Barber and Odean (2000) report a link between excessive market trading and investor overconfidence, Coval and Shumway (2005) relate T-bond futures market price movements and CBOT trader risk-aversion, and Locke and Mann (2005) find that trader success can be predicted by the relative trading discipline of the trader. ${ }^{1}$ Alternatively, this doctoral dissertation studies how the psychobiological make-up of individuals determines their financial behavior (a bottom-up approach). That is, I examine the role of psychological (i.e., personality traits) and biological (i.e., testosterone and cortisol) factors on financial decision-making. The advantage of this approach is that it directly addresses the underpinnings of investor behavior, rather than deducing investor behavior from aggregate market data.

\footnotetext{
${ }^{1}$ Individuals who exhibit overconfidence have a confidence level in their abilities that is unjustified by their objective accuracy. Overconfidence generally leads to overestimating the probability of future success. Alternatively, risk-aversion is the tendency to prefer a certain outcome over a risky one when the expected payoff is the same. Risk-aversion leads to underestimating the probability of future success after realizing losses. Finally, trading discipline is defined as trading strategies that minimize behavioral biases.
} 
In order to truly understand how individual investor decision-making relates to portfolio (or market) behavior, we must start by identifying the biological and psychological traits related to financial decision-making. Every financial decision formulated by the brain has an underlying biological and psychological component. The decision to buy or sell, or to hedge or speculate, is the result of complex cerebral activity that is mediated by physiological factors, such as glucose (sugar) levels, hormone activity and memory, and by psychological factors, such as mood, stress and personality traits. Therefore, understanding the relation between the aforementioned factors and financial decision-making is necessary to understand the overall portfolio (market) behavior. This dissertation contributes to the developing literature by analyzing the relation of personality factors (Chapter 2), testosterone levels (Chapter 3) and cortisol levels (Chapter 4) to financial decision-making.

This dissertation has important practical implications for traders and investors. ${ }^{2}$ First, this dissertation shows that financial decisions and outcomes are related to intrinsic human factors outside of an individual's typical conscious control. This knowledge can be empowering to traders and investors, especially because it could help them to better understand their financial decision-making process and to cope with poor financial performance. Second, this dissertation provides information that could be used by traders and investors in order to make

\footnotetext{
2 In this dissertation the terms "trader" and "investor" are used in reference to financial activity type (i.e. trading versus investing), and not to define individuals exclusively as one or the other. That is, a trader is anyone holding positions for relatively short periods of time (e.g. minutes, hours, etc.), whereas an investor is anyone holding positions for relatively long periods of time (e.g. months, years, etc.).
} 
more rational financial decisions. Specifically, by understanding how personality factors and hormone levels are related to irrational choices leading to suboptimal investment performance, traders and investors can actively monitor their behavior in order to make more rational decisions. Finally, this project emphasizes the need for the traditional finance literature to be cognizant of the real factors that drive investor behavior. It is my belief that traditional models of finance will continue to fail until they incorporate real human behavior. 


\section{CHAPTER 2: THE ABNORMAL PSYCHOLOGY OF INVESTMENT PERFORMANCE}

\subsection{Introduction}

For decades popular investment folklore has linked personality traits to both investing decisions and the ability to choose winners and losers. However, issues such as the link between personality and investment performance are largely unexplored areas in academic literature. In this paper I examine how abnormal personality traits are associated with investment performance. I derive my motivation to study abnormal personality traits from anecdotal reports of extreme behavior with institutional traders, e.g. substance abuse and sleep deprivation, which raises the question of whether abnormal behavior in general can be related to successful (or unsuccessful) investors. Unlike normal personality traits (such as extroversion), abnormal traits (such as depression) better describe the mental health characteristics of an individual. Therefore, this study directly examines the question of whether and how mental health characteristics are related to investment financial outcomes. ${ }^{3}$

The association between underlying pathological developments in personality and harmful social behaviors is well documented, such as pathological gambling (Roy et al. 1989) and substance abuse (Tarter 1988). However, whether abnormal personality traits are associated with beneficial or harmful investment decisions has not been studied. As such, this study uses

3 When referring to personality characteristics, the terms "traits" and "factors" are used interchangeably. Similarly, the terms "abnormal personality" and "mental health" are commonly substituted for each other. 
Durand et al. (2008) and Durand et al. (2010) as foundations, in that they study the link between Norman's Big Five dimensions of personality (i.e., negative emotions, extroversion, openness to experience, agreeableness and conscientiousness) and investor financial choices and investment performance. Unlike those studies, I explore individual traits and not entire dimensions of personality, where the latter is composed of many traits. I also focus exclusively on the abnormal dimension of personality, which encompasses the disruptive patterns of behavior that can negatively affect investment decisions. My empirical investigation is also loosely related to the concepts elucidated by Gregory (2012), who descriptively examines the characteristics of "financial psychopaths" and how they can ruin lives by scamming individuals of their financial assets.

I first determine whether individuals who pursue a formal education in finance possess different mental health characteristics than the typical college student. Such an analysis can provide hints as to the personality and social behaviors of individuals who ultimately become professional investors or other finance oriented professionals. Second, I examine whether mental health characteristics are related to investment performance metrics, such as the degree of investment diversification, the investment return, the amount of realized risk, and the associated risk-adjusted return. As such, I examine both the importance of mental health and how mental pathology (or the lack thereof) relates to investment performance. Finally, I determine whether women and men differ significantly in terms of their respective mental health characteristics relative to their financial performance. 
I find that individuals who pursue a formal education in finance possess a different abnormal personality profile than the average college student. In particular, their levels of paranoia and psychopathic deviation are significantly above the college population mean levels. Additionally, I find that several abnormal personality factors are associated with the degree of portfolio diversification, as well as to the return, risk, and risk-adjusted return realized by these same individuals in their investment decisions. Consequently, the results show that mental health characteristics are related to both investment choices and financial performance.

The results also show that the relation between mental pathology and investment performance is not uniform across all abnormal personality factors. In other words, mental pathology in most factors does not typically hinder investment performance. In fact, investors who exhibit mental pathology in several abnormal personality factors (i.e., factor scores above 8 on the personality test taken) significantly outperform investors with low or average levels of mental pathology in the overall risk-adjusted performance. I also find that men and women who are in the finance sample differ significantly from each other on certain aspects of abnormal personality, including psychopathic deviation and brooding discontent - areas in which men score significantly higher than women. Furthermore, I find that men and women exhibit both differences and similarities in the manner in which their mental health is related to their investment performance. Such differences reflect gender specific mental strengths and weaknesses. In other words, certain mental pathologies that affect 
male investor performance do not affect female investor performance, and vice versa. As such, the results substantiate that benefits exist to diversifying investment professionals across gender.

I add to the developing behavioral finance literature by being the first to demonstrate that mental health characteristics (i.e., abnormal personality traits) possess a statistically significant association with investment performance. Overall, the findings encourage the use of mental health assessment for personal introspection regarding finance professionals' performance. Given the negative impact of irrational investment decisions on financial markets and institutions, such information can be of particular interest to regulators and employers looking to promote more rational decision-making.

\subsection{Portrayal of Investor Psychobiology in the Literature}

Investor decision-making and their ensuing financial performance is influenced by many psychological factors, including intelligence, the ability to make rational decisions, and personality traits. In particular, the ability to act rationally has received substantial coverage in the literature, mainly because rationality is a central assumption of even the most basic theoretical models in economics and finance. The extent such models fail to describe market behavior is attributed by behavioral finance to a failure of investors to act rationally due to the expression of psychological biases that affect financial decision-making. In particular, investment biases are "affect heuristics" that result from human emotions, which are often at odds with human rationality. Among the most commonly described biases are overconfidence (Odean 1999), self-attribution 
(Daniel et al. 1998), and the house-money effect (Thaler and Johnson 1990). Shefrin (2000) notes that such investment biases are highly pervasive and systematic. Furthermore, such biases typically result in detrimental financial outcomes because they promote irrational financial choices such as too much trading and taking unnecessary risks (see Baker and Nofsinger 2002 for a review of the literature on investment biases).

Alternatively, the errors in judgment associated with psychological biases should not be confused with personality traits, which are habitual patterns of behavior, thought and emotion. However, as with investment biases, personality traits are related to financial decision-making. Durand et al. (2008) show that several normal personality factors (such as extraversion, conscientiousness, and masculinity), are related to trading frequency and the proportion of shares invested in the market portfolio. ${ }^{4}$ Additionally, Durand et al. (2008) show that investor personality is related to investment outcomes, including return, realized risk, and risk-adjusted return. One explanation for their results is that personality factors help to shape financial preferences, and thereby influence the ensuing investment performance. In a related paper, Durand et al. (2010) show that personality factors are related to two investment biases, namely the availability heuristic and the disposition effect. Consequently, these results suggest that investment biases are related to personality characteristics. Therefore, it is

4 There are two major dimensions of personality: a normal dimension and an abnormal dimension. The normal dimension of personality describes human temperament and characteristics that are unrelated to mental health, such as extroversion, agreeableness, etc. The abnormal dimension of personality describes human traits that are related to mental disorders, such as paranoia, schizophrenia, etc. 
possible that personality factors influence investment performance by predisposing investors to committing financial judgment errors.

In addition to psychological factors, such as investment biases and personality traits, investor decision-making has biological underpinnings, including hormonal, genetic and neural correlates. For example, Coates and Herbert (2008) show that morning levels of the male sex hormone (testosterone) are predictive of daily profitability in male traders, whereas morning levels of the stress hormone (cortisol) are predictive of their afternoon return volatility. Similarly, Lo and Repin (2002) document significant changes in physiological variables, such as skin voltage and blood pressure, in traders during periods of heightened market volatility. Additional evidence of the role of investor biology in financial performance is provided by studies showing that medications and substance abuse alter financial risk-taking decisions. For example, Rogers et al. (2004) show that beta-blockers, which are commonly prescribed to treat high blood pressure, distort the perception of financial risk by decreasing the subjects' ability to discriminate between large and small financial losses during a gambling task. On the other hand, drugs of abuse, such as marijuana and alcohol, are associated with a persistent preference for risky financial choices (Lane et al. 2005).

The latest developments in brain imaging and genetic sequencing have further enhanced our understanding of the biological antecedents of financial decision-making. For example, Kuhnen and Knutson (2005) show that the brain's limbic system, which is responsible for the regulation of reward, punishment and 
emotions, is differentially activated prior to pursuing risk-seeking and risk-averse financial choices. Additionally, this brain region is activated during impending irrational choices. Their findings demonstrate that risk preferences and irrational financial decision-making have neural antecedents. Similarly, Kuhnen and Chiao (2009) show that individuals with a certain genetic marker take greater financial risk in an investment task and have a greater susceptibility to the "framing investment bias" than do individuals without this genetic marker. Thus, their results show that financial risk-taking and investment biases also possess a genetic antecedent.

Overall, investor decision-making and the ensuing investment performance is the result of the combined influence of psychological and biological factors. In fact, advances in behavioral neuroscience demonstrate that such factors are interrelated. For example, Cohen et al. (2005) show that the personality factor of extroversion has a genetic marker, and that extroversion scores are associated with activation of the brain's limbic system, which regulates emotions. Similarly, the personality factor of neuroticism, which is characterized by risk-aversion, is associated with a chronic activation of the lossavoidance component of the limbic system (Flory et al. 2004), and has a genetic marker (Arnold et al. 2004). On the other hand, acute activation of the lossavoidance system leads to experiencing anxiety (Bechara et al. 2000), fears of disappointment and regret (De Martino et al. 2009), and disgust, pain and loss (Wright et al. 2004). These findings are consistent with abnormal personality factors also possessing biological markers. As such, I expect that investor mental 
health plays a significant role in their financial decision-making as well as their ensuing financial performance in a similar fashion as their normal personality traits.

\subsection{Method}

\subsubsection{Participants}

A total of 221 finance students participated in an investment-personality study composed of 97 female (43.9\%) and 124 male participants (56.1\%). The study was restricted to graduate $(n=19)$ and undergraduate $(n=202)$ students enrolled in an investments course, with the majority of subjects ( $n=184 ; 83.3 \%)$ enrolled in an advanced security analysis course. Consequently, such subjects possessed a greater sophistication in finance and investments than the general population.

\subsubsection{Procedure}

Participants engaged in a thirteen-week investment task in which they controlled $\$ 50,000$ in paper money to invest freely in any kind of financial instrument, including cash. At the end of each week the participants determined their total portfolio value. The price for each trade was determined based on the close value on the day of trade submission. Trades and weekly portfolio values were checked for accuracy. During their trading activity the participants were encouraged to employ investment advice and news releases, as well as to research their investment vehicles. Their grade in the course was affected by up to one full grade by their overall risk-adjusted performance, using the S\&P500 
index as the benchmark. ${ }^{5}$ Therefore, allocating a large amount of money to poorly performing or highly volatile assets could result in poor performance.

In addition to the investment task, participants completed a personality test that measures both normal and abnormal aspects of personality. Only those who volunteered to complete the questionnaire are included in this study; over $95 \%$ of the total number of individuals completed the questionnaire. ${ }^{6}$

\subsubsection{Investment Performance Measures}

I employ the validated investment results to measure each individual's portfolio diversification, risk, return and risk-adjusted return. Since common stock is essentially the only investment in the portfolios (as stock represents $99 \%$ of all investments), I employ the Standard \& Poor's 500 index (S\&P 500) as a proxy for the market portfolio. The weekly portfolio values are converted into twelve weekly portfolio excess returns using the concurrent three-month T-bill risk-free rate. Appendix A describes the typical performance measures employed for the analysis.

\subsubsection{Abnormal Personality Measures}

I employ the Clinical Analysis Questionnaire (CAQ) developed by Raymond Cattell to assess the abnormal personality profile of participants. The $\mathrm{CAQ}$ is a 272 -item personality test that measures sixteen primary factors of normal personality (Part I), and twelve primary factors of abnormal personality

\footnotetext{
${ }^{5}$ The final grade was adjusted upward (downward) by $1 \%$ for each $1 \%$ the portfolio outperformed (underperformed) the S\&P500. The adjustment for graduate students was $0.5 \%$, since their grade distribution was more condensed.

${ }^{6}$ The participants knew all information would be analyzed anonymously. Furthermore, there were no consequences for declining to participate in the study.
} 
(Part II). Each personality factor is measured via twelve test items, and each item employs a 3-point Likert response scale of agree, disagree, and sometimes agree. Raw factor scores are converted into standard ten (sten) scores using standardization tables that reflect individual differences in age and gender. ${ }^{7}$ Sten scores rather than total scores are employed in the data analysis. Sten scores range from a minimum of 1 to a maximum of 10 in the majority of factors, and have a standardized mean of 5.5 and a standard deviation of 2 in the population. For all twelve abnormal factors measured in Part II, a sten score of 1 reflects an absence of mental pathology, whereas increasingly higher sten scores are associated with an increasingly greater degree of mental pathology. Appendix B provides summary descriptions of each abnormal factor. Table 2.1 shows the correlation matrix between the abnormal factors. These correlations show to what extent the factors are related. Since few correlations exceed 0.60 and none are 0.70 or above, there are no serious correlation issues among the factors. ${ }^{8}$

\subsubsection{Data Analysis}

Since the population mean (5.5) and its variance (2) for all abnormal factors is determined by the 16PF construction, I employ the Student's t-test to

\footnotetext{
7 Four standardization tables are provided in the CAQ Manual for converting raw scores to standard (sten) scores, namely, conversion tables for college male and female populations (based on age 20), and norms for general adult male and female populations (based on age 30). The tables were developed via a non-linear transformation that normalizes the sten scores so that the resulting mean and standard deviation are 5.5 and 2 , respectively.

${ }^{8}$ Mental health characteristics seldom exhibit high comorbidity (comorbidity is the simultaneous presence of two or more medical conditions, whether or not they typically coexist for an individual). The $16 \mathrm{PF}$ is constructed using a factor analysis approach to find (relatively) independent psychological factors. Therefore, I consider the correlation between the abnormal personality factors to be indicative of comorbidity but not necessarily associated with true multicollinearity of related factors. The correlations in Table 2.1 do not approach the 0.9 correlations typically associated with troublesome multicollinarity.
} 
compare participants' factor scores to their population averages. On the other hand, male and female factor scores are compared via the Welch-Satterthwaite ttest, which does not assume equal variances. ${ }^{9}$ Furthermore, I crosscheck the results for all t-tests with their nonparametric equivalent Wilcoxon signed-rank test, which does not make assumptions concerning the distribution of the factor scores.

I analyze the relation between investor mental health and his/her investment performance by employing stepwise regressions using the backward elimination procedure, where each performance measure is originally regressed on all twelve abnormal personality factors. ${ }^{10}$ In order to capture any gender differences, I perform the analysis for the entire sample as well as for the female and male subsamples separately. Since the objective is to determine whether a relation exists between investor mental health and his/her investment performance as well as the form of such a relation, I do not make any assumptions concerning the components or exact nature of this relation. ${ }^{11}$

\footnotetext{
${ }^{9}$ An appropriate personality factor comparison between males and females is made possible by the use of sten scores. Unlike total scores, in which men and women exhibit natural differences, sten scores are derived from total scores after accounting for the gender differences. For example, a total score of 13 on psychopathic deviation (factor Pp) translates into a sten score of 5 in a female college student and a sten score of 4 in a male college student, since male college students naturally possess higher total scores in factor Pp than female college students.

10 The objective of the backward elimination procedure is to find a linear model that best explains the investment performance metric using the abnormal personality factors. Initially, F-statistics are computed for all of the abnormal personality factors. The factor with the p-value that most exceeds the specified critical $p$-value $(10 \%)$ is then removed from the model. The procedure is repeated until no $p$-values exceeding the critical $p$-value remain in the model.

11 The lack of literature on this subject also limits us from formulating specific hypotheses about the relation between abnormal personality factors and investment performance. In the results section I discuss the intuition behind the observed results.
} 
Regression analysis helps us to understand the general linear relation between investor abnormal psychology factor scores and his/her investment performance. However, it does not tell us how extreme personality abnormalities are related to investment performance. Therefore, I also analyze the relation between abnormal personality factors and investor performance without the restrictive assumptions of linear regression analysis. Specifically, I compare the investment performance of investors with low factor scores (scores of 1-3), average factor scores (scores of 4-7), and high factor scores (scores of 8-10) using the Welch-Satterthwaite t-tests and Wilcoxon signed-rank tests. These demarcations are the same ones employed by healthcare professionals. Therefore, they allow us to meaningfully compare the investment performance of healthy, normal, and psychologically abnormal investors.

\subsection{Results}

\subsubsection{Investment Performance}

Investor performance is summarized in Table 2.2. The mean and median R-squared values show that investors' portfolios are $59 \%$ to $67 \%$ as diversified as the market portfolio. However, there is substantial variation in portfolio diversification within the sample, which shows that investors have heterogeneous diversification preferences. Similarly, the variation in portfolio beta and return volatility shows that the sample of investors has heterogeneous risk preferences. On average, investors realized economically significant excess returns (average excess returns, alpha), regardless of the degree to which they diversified their portfolios. However, the measures of risk-adjusted return have a substantial 
variation within the sample, showing that some investors realized losses when greater risk was undertaken. Specifically, $31.7 \%$ of investors realized negative Sharpe ratios during a down-market, whereas $5.88 \%$ of investors realized negative Sharpe ratios during an up-market.

\subsubsection{Investor Abnormal Personality}

Table 2.3 displays the abnormal personality results of the CAQ test for the sample of college students. Figure 2.1 provides a visual representation of the average abnormal personality profile, as well as the associated $25^{\text {th }}$ and $75^{\text {th }}$ percentiles of the profile across the sample. Compared to the population average factor score of 5.5, the sample exhibits significantly different scores for all but the brooding discontent factor (D3). In particular, the sample exhibits the largest positive differences for the paranoia factor $(\mathrm{Pa})$ and the psychopathic deviation factor $(P p)$. This means that individuals pursuing a finance education possess a lower tendency to trust others and a higher tendency to break the rules than the average college student. The high incidence of psychopathic deviations in finance students is consistent with the discussion of financial psychopaths on Wall Street by Gregory (2012). In particular, the results showing that many of those in the finance field have some aspects of psychopathic tendencies is consistent with individuals possessing such traits before entering the field, rather than developing such traits as a result of the profession's "culture."

The sample used here also exhibits lower than average levels of mental pathology for many factors, including the majority of depression variants (the $D$ factors), schizophrenia (Sc), compulsivity (As) and psychosis (Ps). These factors 
have a less intuitive relation to financial decision-making, and have more to do with overall wellbeing. In fact, high scores on these factors typically have crippling life-style effects on individuals. Therefore, it is not surprising that the sample exhibits relatively "healthy" scores for such factors. Most importantly, the results show that individuals who pursue a career in finance exhibit a mental health profile that is different on a statistically significant basis relative to the general population of college students. In particular, such individuals display mental stability across many factors that are necessary for proper daily functioning, as well as characteristics typically associated with risk-taking, such as low levels of trust and a greater tendency toward engaging in illegal acts or breaking of the rules.

\subsubsection{Mental Pathology and Investment Performance}

Table 2.4 displays the average performance for investors with "low", "average," and "high" scores on abnormal personality factors. These demarcations are used to identify an individuals' mental pathology level (such as low, average and high mental pathology, respectively). Overall, the results show that investors in the different abnormal personality groups exhibit significant differences in every measure of investment performance. For example, investors who are enthusiastic and energetic (i.e., low D5), as well as relaxed, considerable and cheerful with people (i.e., low D7) diversify their portfolios to a lesser degree than investors with average scores on such factors. On the other hand, investors who realistically appraise themselves and others, and show an absence of regressive behavior (i.e., low Sc) diversify their portfolios to a greater 
degree than investors who retreat from reality and have uncontrolled and sudden impulses (i.e., high Sc). These results provide the first line of evidence that mental illness hinders the desire, ability or will to diversify an investment portfolio. $^{12}$

The measures of return (i.e., AVE, HPR and Alpha) show that either low, average or high levels of specific mental pathologies can be associated with the highest and lowest levels of profitability, depending on the factor in question. For example, investors with average levels of anxious depression (D4) achieve a larger holding period return than investors with low levels of anxious depression, as well as achieving a larger average return than investors with either low or high levels of anxious depression. On the other hand, investors with low levels of bored withdrawal (D7) and hypochondriasis (D1), achieve larger returns than investors with average pathology levels on such factors. Finally, investors with high levels of psychopathic deviation (Pp) achieve a larger holding period return than investors with average levels of psychopathic deviation.

The relation between investor mental health and financial risk-taking is also not straightforward. For example, investors with high levels of both hypochondriasis (D1) and guilt and resentment (D6), experience significantly lower volatility in their returns than investors with average and low levels of pathology on these factors. Similarly, investors with high levels of schizophrenia (Sc) have lower betas compared to investors with low levels of schizophrenia. On the other hand, investors with low levels of compulsivity (As) and suicidal disgust

\footnotetext{
${ }^{12}$ Regressive behavior means to revert to an old, usually immature behavior.
} 
(D2) experience higher return volatility and portfolio betas, respectively, compared to investors with average and high levels of pathology on such factors. Finally, investors with high levels of paranoia $(\mathrm{Pa})$ and psychopathic deviation $(\mathrm{Pp})$ experience greater return volatility than investors with low pathology on these factors. ${ }^{13}$

In terms of risk-adjusted investment performance, the results show that some dimensions of mental pathology are detrimental to investment performance, whereas others appear to enhance performance. For example, investors with low levels of pathology on bored withdrawal (D7) and schizophrenia (Sc) exhibit greater Sharpe ratios than individuals with average scores on such factors. Alternatively, investors with average scores on anxious depression (D4) outperform investors with low levels of anxious depression on a risk-adjusted basis (i.e., using the Sharpe ratio). Interestingly, psychopathic deviation is the one factor where both low and high scoring investors outperform their average scoring investors. Therefore, the overall conclusion from the results is that high levels of mental pathology are not necessarily related to inferior riskadjusted performance. In fact, in certain cases it might lead to better return for the risk undertaken.

\footnotetext{
13 Paranoia and schizophrenia are likely to be linked to greater financial risk-taking via their association with sensation seeking (Blackburn 1969). Zuckerman (1979 and 1994) finds that sensation seeking is associated with participation in a number of risky activities, reckless driving and drug abuse. Furthermore, Horvath and Zuckerman (1993) find that high sensation seekers tend to appraise risk lower than do low sensation seekers.
} 


\subsubsection{Abnormal Personality and Investment Performance}

In this section I examine the overall relation between abnormal personality factor scores and investment performance measures in a fashion similar to Durand et al. (2010). The analysis employs the entire range of factor scores (i.e., 1 to 10) in a linear regression model by using the backward elimination procedure for regression. ${ }^{14}$ The regression results displayed in Table 2.5 show that investment performance and the degree of portfolio diversification is related to an individual's mental health. In particular, investor scores on hypochondriasis (D1) and low energy depression (D5) relate to the diversification measure of the portfolio R-squared. In this regard, the less the concern for bodily functions, illness and disability and the more they feel worried and weary, the more likely they are to diversify their portfolios. These results provide a partial explanation for why many studies, such as Barber and Odean (2000), find that retail investors hold portfolios concentrated in only a few stocks. In other words, in addition to cognitive abilities (Korniotis and Kumar 2008), financial sophistication and behavioral biases (Goetzmann and Kumar 2008), and investor resourcefulness (Ivkovich et al. 2008), I show that mental health is another explanatory variable for portfolio diversification preferences. Moreover, I do not find that investor trust levels (i.e., paranoia) are associated with the degree of portfolio diversification, which seems to contradict Guiso et al. (2008) who find that individuals with a general lack of trust have a limited participation in the stock market. The data are

\footnotetext{
${ }^{14} \mathrm{I}$ opt not to run regressions based on personality factor groupings (such as low, normal and high scores) since such comparisons are already addressed by the univariate analysis presented in the previous section.
} 
examined via the White test, showing no violation of homoscedasticity for this table, or other relevant tables.

Regarding portfolio risk, the results show that greater levels of paranoia $(\mathrm{Pa})$ are related to greater return volatility and portfolio beta, which means that investors who are less trusting of others take greater financial risks. These results are consistent with studies that find paranoia to be related to risky social behaviors, including pathological gambling (Graham and Lowenfeld 1986), risky sexual behaviors, and drug use (Elifson et al. 2006). The results add to the literature by showing that paranoia is also related to financial risk-taking. Similarly, I find that investors who are zestful (i.e., a lower score on factor D2), experience greater worrying (i.e., a higher score on factor D5), and realistically appraise themselves (i.e., a lower score on factor Sc), create portfolios with higher betas. In fact, the scores on factors $\mathrm{Pa}, \mathrm{D} 2$, D5, and Sc together explain about $5 \%$ of the total variation in portfolio beta.

Lastly, the results show that paranoia and psychopathic deviation are related to the Treynor index of beta-adjusted returns. In general, investors who are more paranoid and less psychopathically deviant exhibit greater risk-adjusted performance, as measured via the Treynor index. Interestingly, these are the same two factors in which the sample of college students score significantly above the population mean. As such, paranoia and psychopathic deviation seem to play a role in selecting a career in finance as well as during financial decisionmaking. 
The results shown in this section offer a different perspective than those by Durand et al. (2010). In particular, I identify the particular personality factors associated with the Big Five personality dimensions as I relate them to investment performance, as well as identify other traits not covered by the Five Factor Model. Widiger and Mullins-Sweatt (2009) provide a table where they relate several abnormal personality traits to the Big Five personality dimensions. Using this table it is possible to compare some of my results to Durand et al. (2010). In particular, I show that energy depression (D5) is positively related to portfolio diversification and beta risk, which is consistent with Durand et al. (2010) who show that negative emotions, which includes depression as one of its traits, is positively related to portfolio diversification and beta. I also find that traits not covered by the "Big Five" are related to measures of investment performance that are similar to those in Durand et al. (2010), as well as vice-versa; such results show that that neither the personality inventory examined here or the Big Five used in Durand et al. (2010) fully captures the link between investor personality and his/her financial performance.

\subsubsection{Gender, Abnormal Personality, and Investment Performance}

The use of abnormal personality factor sten scores instead of total scores allows us to compare male and female subjects, with the sten scores accounting for the natural gender differences inherent in abnormal personality. In terms of investment performance, I find that that men exhibit significantly greater portfolio return volatility than women (the results are available upon request). Otherwise, men and women diversify their portfolios to a similar extent, as well as achieve 
similar gross and risk-adjusted returns. These results negate the common misperception than men are better investors than women. On the other hand, the results do show that men experience greater return volatility than women, which is consistent with other studies on gender differences and risk-taking preferences (e.g., Eckel and Grossman 2002). Furthermore, as the results in Table 2.6 show, men have higher brooding discontent (D3) and psychopathic deviation (Pp) scores than women, which is consistent with their differences in risk-taking. Moreover, men possess a higher degree of uncontrolled and sudden impulses (Sc). In other words, men seeking careers in finance seek excitement, are restless, take risks, try new things, engage in illegal acts or breaking rules, possess less impulse control, and exhibit anti-social behavior to a greater extent than their female counterparts.

A visual representation of the average male and female personality profile is shown in Figure 2. Even though noticeable differences exist, the figure shows that men and women seeking careers in finance still share more similarities than differences in their mental health profile. However, this does not mean that the manner in which mental health and financial performance are related is the same for men and for women. In fact, the results displayed in Table 2.7 show that the factors associated with a particular investment performance measure in men are not necessarily the same factors for women. For example, greater levels of hypochondriasis (D1) are associated with lower portfolio diversification for men. Conversely, whereas women score significantly higher in the hypochondriasis factor than men, their hypochondriasis scores are unrelated to financial 
performance. Similarly, a greater level of paranoia $(\mathrm{Pa})$ in women is associated with greater portfolio volatility (SD), whereas men's levels of paranoia are unrelated to their investment performance.

\subsection{Conclusions}

In this study I analyze the relation between investor mental health and his/her investment performance. As such, the results provide clues concerning the mental health characteristics of individuals who are likely to seek a career in the investment area of finance, as well as the link between their investment success and personality factors. I find that these individuals exhibit significantly higher levels of paranoia and psychopathic deviation than the average person. This supports the ad hoc supposition that such abnormal personality factors are higher in the finance profession than in the general population. Furthermore, I show that abnormal personality factors are related to portfolio diversification, realized risk, return, and risk-adjusted return.

The results have implications for finance practitioners. Investors interested in understanding and improving their financial performance should not neglect the effects of their abnormal personality traits to their financial performance. In fact, research shows that investors who are highly self-monitoring perform better than their peers (Biais et al. 2002). As such, self-monitoring of our own abnormal psychology can lead to improved financial performance.

Future studies could compare different kinds of finance professionals, such as traders, managers and analysts, to determine differences in their mental health characteristics. Those results could then be compared to mines to 
determine the personality characteristics of those who are ultimately successful in the finance industry. In addition to career choice, mental health characteristics could also be related to investment preferences, styles, and the social behaviors of finance professionals. As such, future studies could address whether the social behaviors of investment professionals are related to their financial decision-making.

Finally, I leave it to future studies to address the precise mechanism by which mental health is related to financial outcome. For example, studies could address whether the perception of financial risk and the propensity to commit investment biases are related to mental health characteristics. Durand et al. (2010) find an association between normal personality traits and investment biases. Therefore, it is worth exploring whether a similar relation exists between investment biases and abnormal personality traits. This line of research has clear implications for practitioners. Additionally, it can serve to enhance our current understanding of investor financial decisions and the behavioral models that rely on them. 
Table 2.1

Abnormal Personality Factor Correlation Matrix

This table shows the correlation coefficients between the twelve abnormal personality factors in the sample $(n=221)$.

\begin{tabular}{|c|c|c|c|c|c|c|c|c|c|c|c|c|}
\hline & D1 & D2 & D3 & D4 & D5 & D6 & D7 & $\mathrm{Pa}$ & Pp & Sc & As & Ps \\
\hline D1 & 1.00 & 0.52 & -0.14 & 0.51 & 0.68 & 0.57 & 0.48 & 0.37 & -0.39 & 0.43 & 0.39 & 0.54 \\
\hline D2 & 0.52 & 1.00 & -0.02 & 0.34 & 0.58 & 0.56 & 0.48 & 0.43 & -0.30 & 0.54 & 0.35 & 0.47 \\
\hline D3 & -0.14 & -0.02 & 1.00 & -0.26 & -0.12 & -0.23 & -0.11 & 0.05 & 0.50 & 0.03 & -0.13 & -0.20 \\
\hline D4 & 0.51 & 0.34 & -0.26 & 1.00 & 0.47 & 0.46 & 0.33 & 0.20 & -0.46 & 0.32 & 0.46 & 0.53 \\
\hline D5 & 0.68 & 0.58 & -0.12 & 0.47 & 1.00 & 0.54 & 0.51 & 0.35 & -0.36 & 0.49 & 0.38 & 0.54 \\
\hline D6 & 0.57 & 0.56 & -0.23 & 0.46 & 0.54 & 1.00 & 0.48 & 0.36 & -0.42 & 0.43 & 0.56 & 0.47 \\
\hline D7 & 0.48 & 0.48 & -0.11 & 0.33 & 0.51 & 0.48 & 1.00 & 0.39 & -0.22 & 0.45 & 0.33 & 0.50 \\
\hline $\mathbf{P a}$ & 0.37 & 0.43 & 0.05 & 0.20 & 0.35 & 0.36 & 0.39 & 1.00 & -0.08 & 0.65 & 0.41 & 0.41 \\
\hline $\mathrm{Pp}$ & -0.39 & -0.30 & 0.50 & -0.46 & -0.36 & -0.42 & -0.22 & -0.08 & 1.00 & -0.20 & -0.33 & -0.41 \\
\hline Sc & 0.43 & 0.54 & 0.03 & 0.32 & 0.49 & 0.43 & 0.45 & 0.65 & -0.20 & 1.00 & 0.46 & 0.50 \\
\hline As & 0.39 & 0.35 & -0.13 & 0.46 & 0.38 & 0.56 & 0.33 & 0.41 & -0.33 & 0.46 & 1.00 & 0.37 \\
\hline Ps & 0.54 & 0.47 & -0.20 & 0.53 & 0.54 & 0.47 & 0.50 & 0.41 & -0.41 & 0.50 & 0.37 & 1.00 \\
\hline
\end{tabular}

Notes: Appendix $B$ provides descriptions of the personality factors. For this sample size, a correlation coefficient greater than 0.11 or less than -0.11 is regarded as statistically significant. 
Table 2.2

\section{Investor Performance Summary Statistics}

This table displays the summary statistics for portfolio performance for the entire sample $(n=221)$. The table shows the abbreviation (Label) used for each performance measure, the sample mean, median, minimum (Min), maximum (Max) and standard deviation (St. Dev) of the scores for each performance measure.

\begin{tabular}{|llrrrrr|}
\hline Performance measure & Label & Mean & Median & Min & Max & St. Dev \\
\hline Portfolio diversification & PDIV & 0.5912 & 0.6675 & 0.0000 & 0.9766 & 0.2664 \\
\hline Average excess return & AVE & 0.1279 & 0.0955 & -0.8388 & 2.5594 & 0.4866 \\
\hline Holding period return & HPR & 0.1017 & 0.0809 & -0.8562 & 2.4896 & 0.4701 \\
\hline St. Dev of returns & SD & 0.2099 & 0.1744 & 0.0040 & 0.7844 & 0.1243 \\
\hline Sharpe ratio & Sharpe & 1.2919 & 0.5700 & -0.6104 & 12.0320 & 1.8246 \\
\hline Portfolio alpha & Alpha & 0.0473 & 0.0210 & -0.7460 & 1.8877 & 0.2939 \\
\hline Portfolio beta & Beta & 0.8184 & 0.7954 & -2.7596 & 3.2306 & 0.4945 \\
\hline Treynor ratio & Treynor & 0.6844 & 0.1148 & -6.4140 & 101.3602 & 6.8644 \\
\hline
\end{tabular}

Notes: Appendix A describes how each performance measure is computed. 
Table 2.3

\section{Investor Abnormal Personality Summary Statistics}

This table displays the mean and standard deviation (St. Dev) of personality factor scores for the entire sample $(n=221)$. The twelve abnormal personality factors are measured via Part II of Cattell's Clinical Analysis Questionnaire. The factors are described in Appendix B. The sample mean scores are compared to the college student population mean scores of 5.5 via the Student's t-test. The resultant one-tail p-value is shown in the last column.

\begin{tabular}{|c|c|c|c|}
\hline Personality factor & Mean & St. Dev & p-value ( 1 tail) \\
\hline $\mathrm{D} 1$ *** & 4.66 & 2.13 & $<0.0001$ \\
\hline D2*** & 4.47 & 1.64 & $<0.0001$ \\
\hline D3 & 5.63 & 2.27 & 0.2000 \\
\hline D4*** & 4.91 & 1.86 & $<0.0001$ \\
\hline D5 ${ }^{\star \star \star}$ & 4.52 & 1.92 & $<0.0001$ \\
\hline D6*** & 4.84 & 1.94 & $<0.0001$ \\
\hline D7*** & 5.00 & 1.91 & 0.0001 \\
\hline $\mathrm{Pa}^{\star \star \star}$ & 5.81 & 1.94 & 0.0085 \\
\hline$P p^{\star \star *}$ & 6.30 & 2.10 & $<0.0001$ \\
\hline$S c^{* \star \star}$ & 4.72 & 1.90 & $<0.0001$ \\
\hline$A S^{* \star *}$ & 5.17 & 2.07 & 0.0089 \\
\hline$P S^{* * *}$ & 4.78 & 1.51 & $<0.0001$ \\
\hline
\end{tabular}

Notes: Significant differences are given next to the factor label in terms of $10 \%$ $\left.{ }^{(}\right), 5 \%\left(^{* *}\right)$ and $1 \%\left(^{* \star *}\right)$ levels. All t-test results for mean differences were consistent with the results obtained from the non-parametric Wilcoxon signedranked tests for median differences. 
Table 2.4

\section{High, Average and Low Factor Scores and Investment Performance}

This table shows the average performance of investors with low (1-3), average (4-7) and high (8-10) abnormal personality factor sten scores in the columns under "Mean performance." The sample size is displayed in parenthesis under the average performance values. P-values for significant differences between low $(\mathrm{L})$, average $(\mathrm{A})$ and high $(\mathrm{H})$ scoring investors are displayed in the next three columns, under " $p$-value ( 1 tail)." Only $p$-values with a significance level below $10 \%$ are displayed. First, the groups were tested for equality of variance using the F-test with a $5 \%$ significance level. Then, groups with statistically equal variances were tested for mean differences using the pooled two-sample t-test. Alternatively, groups with statistically different variances were tested for mean differences using the Welch-Satterthwaite two-sample t-test. The WelchSatterthwaite $p$-values are displayed in italics, whereas the pooled p-values are displayed in normal type.

\begin{tabular}{|llllllll|}
\hline & & \multicolumn{3}{c}{ Mean Performance } & \multicolumn{3}{c|}{ p-value (1 tail) } \\
\hline Factor & Measure & Low sten & Ave sten & High sten & L vs A & A vs H & L vs H \\
\hline D1 & SD & 0.2192 & 0.2101 & 0.1750 & & 0.0629 & 0.0717 \\
& & $(72)$ & $(129)$ & $(20)$ & & & 0.0174 \\
\hline D2 & Beta & 0.8734 & 0.7966 & 0.5989 & & & 0.0167 \\
& & $(86)$ & $(126)$ & $(9)$ & & & \\
\hline D3 & Alpha & -0.0428 & 0.0571 & 0.0895 & 0.0134 & & \\
& & $(37)$ & $(137)$ & $(47)$ & & & \\
\hline D4 & AVE & 0.0339 & 0.1749 & 0.0362 & 0.0399 & 0.0584 & \\
& & $(52)$ & $(147)$ & $(22)$ & & & \\
\hline D4 & HPR & 0.0203 & 0.1428 & 0.0199 & 0.0574 & & \\
& & $(52)$ & $(147)$ & $(22)$ & & & \\
\hline D4 & Sharpe & 1.0275 & 1.3966 & 1.2170 & 0.0709 & & \\
& & $(52)$ & $(147)$ & $(22)$ & & & \\
\hline D4 & Alpha & -0.0136 & 0.0696 & 0.0424 & 0.0431 & & \\
& & $(52)$ & $(147)$ & $(22)$ & & & \\
\hline D5 & PDIV & 0.5318 & 0.6187 & 0.6096 & 0.0153 & & \\
& & $(68)$ & $(135)$ & $(18)$ & & & \\
\hline D5 & SD & 0.1973 & 0.2221 & 0.1661 & 0.0940 & 0.0336 & \\
& & $(68)$ & $(135)$ & $(18)$ & & & \\
\hline D5 & Beta & 0.7531 & 0.8615 & 0.7418 & 0.0948 & 0.0729 & \\
& & $(68)$ & $(135)$ & $(18)$ & & & \\
\hline
\end{tabular}


Table 2.4 - Continuation

\begin{tabular}{|c|c|c|c|c|c|c|c|}
\hline & & \multicolumn{3}{|c|}{ Mean Performance } & \multicolumn{3}{|c|}{ p-value (1 tail) } \\
\hline Factor & Measure & Low sten & Ave sten & High sten & L vs A & A vs $\mathrm{H}$ & L vs H \\
\hline D6 & SD & $\begin{array}{l}0.2256 \\
(59)\end{array}$ & $\begin{array}{l}0.2102 \\
(141)\end{array}$ & $\begin{array}{l}0.1641 \\
(21)\end{array}$ & & 0.0106 & 0.0062 \\
\hline D7 & PDIV & $\begin{array}{l}0.5509 \\
(52)\end{array}$ & $\begin{array}{l}0.6122 \\
(149)\end{array}$ & $\begin{array}{l}0.5394 \\
(20)\end{array}$ & 0.0764 & & \\
\hline D7 & AVE & $\begin{array}{l}0.2398 \\
(52)\end{array}$ & $\begin{array}{l}0.0909 \\
(149)\end{array}$ & $\begin{array}{l}0.1122 \\
(20)\end{array}$ & 0.0321 & & \\
\hline D7 & HPR & $\begin{array}{l}0.2124 \\
(52)\end{array}$ & $\begin{array}{l}0.0605 \\
(149)\end{array}$ & $\begin{array}{l}0.1208 \\
(20)\end{array}$ & 0.0248 & & \\
\hline D7 & Sharpe & $\begin{array}{l}1.6718 \\
(52)\end{array}$ & $\begin{array}{l}1.1748 \\
(149)\end{array}$ & $\begin{array}{l}0.1870 \\
(20)\end{array}$ & 0.0783 & & \\
\hline $\mathbf{P a}$ & SD & $\begin{array}{l}0.1471 \\
(27)\end{array}$ & $\begin{array}{l}0.2181 \\
(151)\end{array}$ & $\begin{array}{l}0.2207 \\
(43)\end{array}$ & 0.0001 & & 0.0005 \\
\hline $\mathbf{P a}$ & Beta & $\begin{array}{l}0.6795 \\
(27)\end{array}$ & $\begin{array}{l}0.8231 \\
(151)\end{array}$ & $\begin{array}{l}0.8890 \\
(43)\end{array}$ & 0.0432 & & 0.0320 \\
\hline $\mathrm{Pp}$ & HPR & $\begin{array}{l}0.1664 \\
(22)\end{array}$ & $\begin{array}{l}0.0596 \\
(129)\end{array}$ & $\begin{array}{l}0.1591 \\
(70)\end{array}$ & & 0.0981 & \\
\hline $\mathrm{Pp}$ & SD & $\begin{array}{l}0.1842 \\
(22)\end{array}$ & $\begin{array}{l}0.2081 \\
(129)\end{array}$ & $\begin{array}{l}0.2212 \\
(70)\end{array}$ & & & 0.0536 \\
\hline $\mathrm{Pp}$ & Sharpe & $\begin{array}{l}1.6482 \\
(22)\end{array}$ & $\begin{array}{l}1.1062 \\
(129) \\
\end{array}$ & $\begin{array}{l}1.5220 \\
(70)\end{array}$ & 0.0784 & 0.0793 & \\
\hline $\mathrm{Pp}$ & Alpha & $\begin{array}{l}0.0703 \\
(22)\end{array}$ & $\begin{array}{l}0.0204 \\
(129)\end{array}$ & $\begin{array}{l}0.0895 \\
(70)\end{array}$ & & 0.0745 & \\
\hline $\mathrm{Pp}$ & Treynor & $\begin{array}{l}4.9112 \\
(22)\end{array}$ & $\begin{array}{l}0.1310 \\
(129) \\
\end{array}$ & $\begin{array}{l}0.3758 \\
(70)\end{array}$ & & 0.0408 & \\
\hline Sc & PDIV & $\begin{array}{l}0.6243 \\
(59)\end{array}$ & $\begin{array}{l}0.5869 \\
(150)\end{array}$ & $\begin{array}{l}0.4821 \\
(12)\end{array}$ & & & 0.0327 \\
\hline Sc & SD & $\begin{array}{l}0.1839 \\
(59)\end{array}$ & $\begin{array}{l}0.2215 \\
(150)\end{array}$ & $\begin{array}{l}0.1924 \\
(12)\end{array}$ & 0.0257 & & \\
\hline Sc & Sharpe & $\begin{array}{l}1.6587 \\
(59)\end{array}$ & $\begin{array}{l}1.1606 \\
(150)\end{array}$ & $\begin{array}{l}1.1290 \\
(12)\end{array}$ & 0.0391 & & \\
\hline Sc & Beta & $\begin{array}{l}0.8548 \\
(59)\end{array}$ & $\begin{array}{l}0.8164 \\
(150)\end{array}$ & $\begin{array}{l}0.6648 \\
(12)\end{array}$ & & & 0.0541 \\
\hline As & SD & $\begin{array}{l}0.2295 \\
(50)\end{array}$ & $\begin{array}{l}0.1989 \\
(130)\end{array}$ & $\begin{array}{l}0.2208 \\
(41)\end{array}$ & 0.0959 & & \\
\hline
\end{tabular}

Notes: Appendix A provides descriptions of the performance measures and Appendix $B$ provides descriptions of the abnormal personality factors. 
Table 2.5

\section{Linear Relation between Factor Scores and Investment Performance}

This table shows the regression results using the stepwise backward elimination procedure, where the dependent variable is one of the portfolio performance measures (columns) and the independent variables are the twelve abnormal personality factors (rows). Only the measures with a significant relation to abnormal personality factors after the stepwise backward elimination regression results are displayed. Homoskedasticity of the error terms is verified using the White test, which tests the null hypothesis that the variance of the residuals is homogeneous.

\begin{tabular}{|c|c|c|c|c|}
\hline $\begin{array}{l}\text { Independent } \\
\text { variable }\end{array}$ & PDIV & SD & Beta & Treynor \\
\hline \multicolumn{5}{|c|}{ 草-0.0254 } \\
\hline D2 & & & ${ }^{*}-0.0503$ & \\
\hline \multicolumn{5}{|l|}{ D3 } \\
\hline \multicolumn{5}{|l|}{ D4 } \\
\hline D5 & ${ }^{* *} 0.0274$ & & ${ }^{*} 0.0412$ & \\
\hline D6 & & ${ }^{* *}-0.0098$ & & \\
\hline \multicolumn{5}{|l|}{ D7 } \\
\hline $\mathbf{P a}$ & & ${ }^{\star *} 0.0106$ & ${ }^{\star *} 0.0566$ & ${ }^{*} 0.4586$ \\
\hline Pp & & & & ${ }^{* *}-0.5087$ \\
\hline Sc & & & ${ }^{* *}-0.0520$ & \\
\hline \multicolumn{5}{|l|}{ As } \\
\hline \multicolumn{5}{|l|}{ Ps } \\
\hline \multicolumn{5}{|l|}{ Summary stats } \\
\hline$R^{2}$ & $2.57 \%$ & $3.28 \%$ & $5.13 \%$ & $4.40 \%$ \\
\hline
\end{tabular}

Notes: The significance of the regression coefficients is displayed next to the coefficients by employing the following asterisks: significant at the 10\% $\left({ }^{\star}\right), 5 \%$ ${ }^{(* *)}$, and $1 \%{ }^{(* *)}$ levels. Also shown is the regression $R$-squared value under the "Summary stats" label. Appendices $A$ and B provide descriptions of the performance measures and the abnormal personality factors, respectively. 
Table 2.6

\section{Male and Female Subject Abnormal Personality Summary Statistics}

This table displays the mean and standard deviation (St. Dev) of the abnormal personality factor scores of the male $(n=124)$ and female $(n=97)$ subjects in the sample. Mean differences in the male and female scores are tested using the two-sample Student t-test. The one tail p-value is shown in the last column.

\begin{tabular}{|c|c|c|c|c|c|}
\hline & \multicolumn{2}{|c|}{ Males } & \multicolumn{2}{|c|}{ Females } & \\
\hline Personality factor & Mean & St. Dev & Mean & St. Dev & p-value (1 tail) \\
\hline D1** & 4.42 & 2.04 & 4.96 & 2.21 & 0.0307 \\
\hline D2 & 4.59 & 1.58 & 4.32 & 1.72 & 0.1141 \\
\hline $\mathrm{D3}^{\star \star \star}$ & 6.05 & 2.26 & 5.09 & 2.18 & 0.0009 \\
\hline D4 & 4.92 & 1.81 & 4.91 & 1.93 & 0.4809 \\
\hline D5 & 4.56 & 1.89 & 4.46 & 1.97 & 0.3619 \\
\hline D6 & 4.76 & 2.00 & 4.94 & 1.88 & 0.2479 \\
\hline D7 & 5.00 & 1.94 & 5.01 & 1.87 & 0.4842 \\
\hline $\mathbf{P a}$ & 5.88 & 1.87 & 5.73 & 2.04 & 0.2888 \\
\hline $\mathrm{Pp}^{\star \star}$ & 6.57 & 2.00 & 5.95 & 2.18 & 0.0140 \\
\hline Sc* & 4.87 & 1.77 & 4.53 & 2.05 & 0.0907 \\
\hline As & 5.08 & 2.10 & 5.28 & 2.04 & 0.2412 \\
\hline Ps & 4.80 & 1.51 & 4.75 & 1.53 & 0.4120 \\
\hline
\end{tabular}

Notes: Significant differences in the mean scores are given next to the factor label in terms of the $10 \%\left(^{*}\right), 5 \%\left(^{* *}\right)$ and $1 \%\left(^{* * *}\right)$ levels. See Appendix B for a description of the factors. All t-test results for the mean differences are consistent with the results obtained from the non-parametric Wilcoxon signed-ranked tests for median differences. 


\section{Table 2.7}

\section{Relation between Abnormal Personality Factors and Investment Performance in Women versus Men}

This table shows the regression results using the stepwise backward elimination procedure for significant variables only. The dependent variable is one of the portfolio performance metrics and the independent variables are the twelve abnormal personality factors for the sample of female $(n=97)$ and male $(n=124)$ participants.

\begin{tabular}{|c|c|c|c|c|c|c|c|c|c|}
\hline & & & Wo & & & & & Men & \\
\hline $\begin{array}{l}\text { Independent } \\
\text { variables }\end{array}$ & PDIV & AVE & SD & Sharpe & Alpha & Treynor & PDIV & Sharpe & Beta \\
\hline D1 & & & & & & & $* *-0.0325$ & & \\
\hline D2 & & ${ }^{*}-0.0610$ & & & & & & ${ }^{* \star} 0.2517$ & ${ }^{* * *}-0.0964$ \\
\hline D3 & ${ }^{*} 0.0227$ & & & & & & & & \\
\hline D4 & & & & & & & & & \\
\hline D5 & & & & & & & $* * \star 0.0522$ & & ${ }^{* *} 0.0755$ \\
\hline D6 & & ${ }^{* *} 0.0710$ & ${ }^{* \star}-0.0148$ & & & & & & \\
\hline D7 & & & & & & & & & \\
\hline $\mathbf{P a}$ & & & ${ }^{* \star *} 0.0140$ & & & ${ }^{*} 0.8774$ & & & \\
\hline $\mathbf{P p}$ & & & & & & ${ }^{*}-0.9259$ & & & \\
\hline Sc & ${ }^{* *}-0.0295$ & & & & & & & ${ }^{*}-0.2042$ & \\
\hline As & ${ }^{*} 0.0274$ & $* *-0.0598$ & & *-0.1782 & ${ }^{* *}-0.0327$ & & & & \\
\hline Ps & & & & & & & & & \\
\hline $\begin{array}{l}\text { Summary } \\
\text { stats }\end{array}$ & & & & & & & & & \\
\hline$R^{2}$ & $7.61 \%$ & $8.30 \%$ & $9.43 \%$ & $3.55 \%$ & $3.08 \%$ & $8.03 \%$ & $8.01 \%$ & $4.28 \%$ & $6.64 \%$ \\
\hline
\end{tabular}

Notes: Appendices $A$ and $B$ provide descriptions of the performance measures and the abnormal personality factors, respectively. The homoskedasticity of the error terms was verified using the White test, which tests the null hypothesis that the variance of the residuals is homogenous. The significance of the regression coefficients is displayed at the $10 \%$ $\left.{ }^{(}\right), 5 \%\left(^{\star \star}\right)$, and $\left.1 \%{ }^{(\star \star}\right)$ levels next to the coefficient. Also shown is the regression $R$-squared value under the "Summary stats." 


\section{Figure 2.1}

\section{Plot of Abnormal Factor Scores Percentiles of the Sample}

This figure displays the 25 th, $50^{\text {th }}$ (i.e. the mean), and $75^{\text {th }}$ percentile of the sten scores for the twelve abnormal personality factors. The sample size is 221 . The gradient (non-jagged) line represents the college student population mean scores of 5.5. Table 2.3 provides the numerical values for the sample mean scores and standard deviations of the $50^{\text {th }}$ percentile results. Appendix B describes the personality factors.

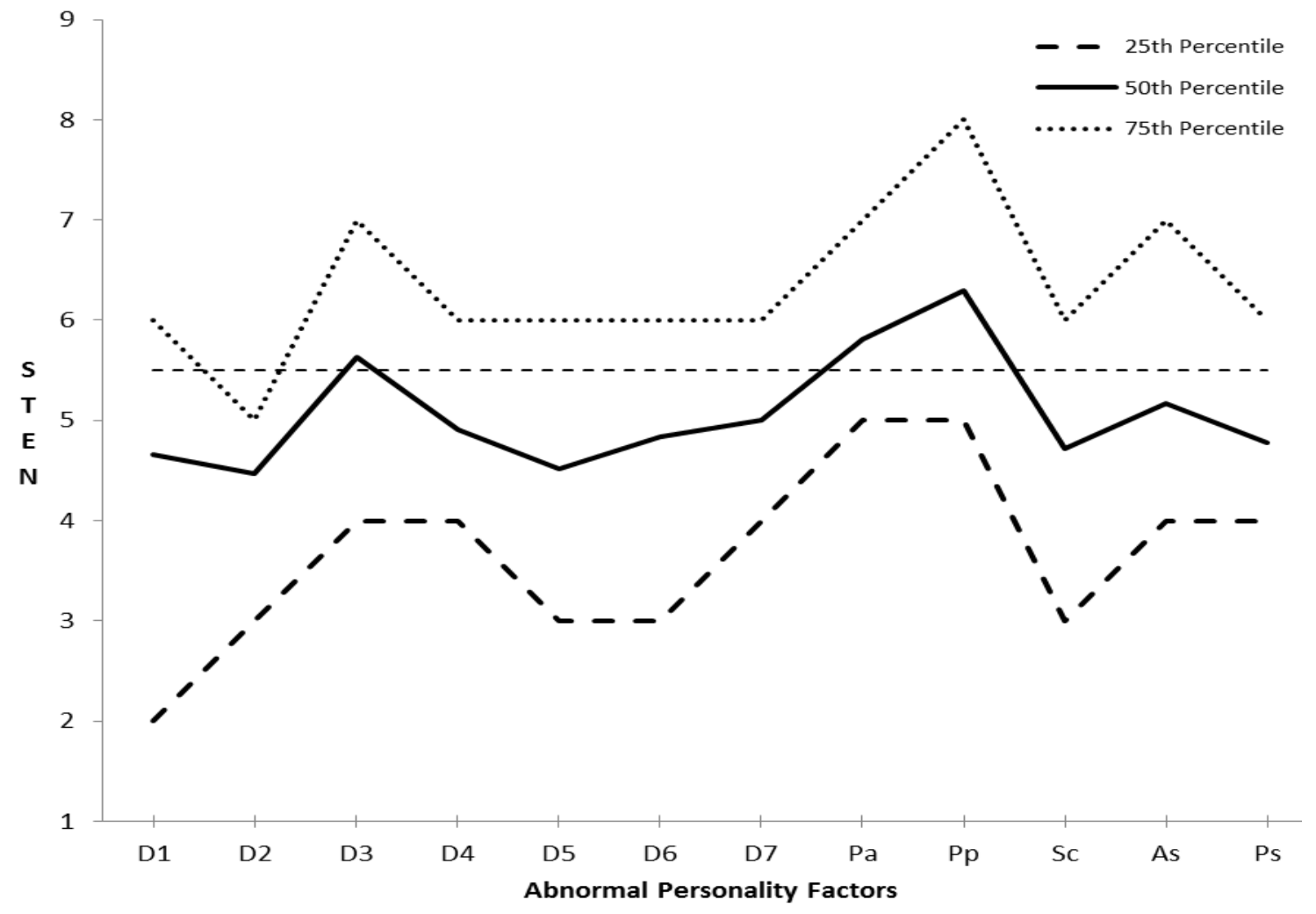




\section{Figure 2.2}

Plot of Male and Female Mean Abnormal Personality Factor Scores

This figure displays the average male $(n=124)$ and female $(n=97)$ abnormal personality factor scores. The gradient (non-jagged) line represents the college student population mean scores of 5.5. Table 2.6 provides the male and female mean and standard deviation scores. Appendix B provides descriptions of the personality factors.

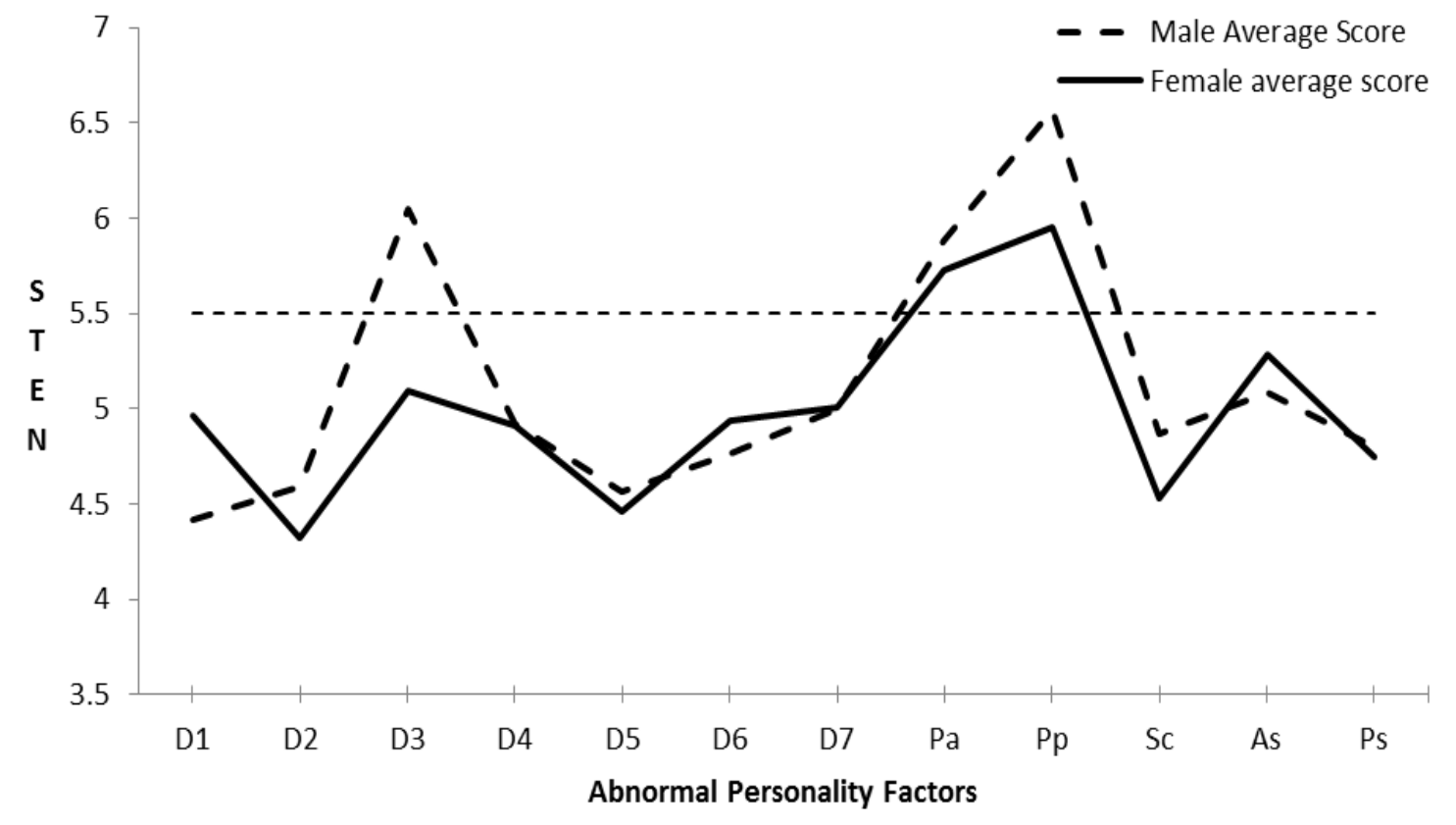




\section{CHAPTER 3: TESTOSTERONE AND FINANCIAL CHOICES}

\subsection{Introduction}

This essay deals with the effect of the sex hormone testosterone on financial decision making. A large body of research (summarized below) demonstrates that testosterone plays a key role in decisions involving economic risk and reward. In particular, testosterone is thought to exert a significant influence on the cognitive processes that deal with the interpretation of financial information, risk preferences, and investor confidence (Coates et al. 2010). Therefore, the testosterone level can have important repercussions on our financial decisions and the resulting investment outcomes. However, the nature of this role is not well understood. For example, it is not known whether testosterone influences every kind of financial choice (such as long-term investing versus high-frequency trading), or if its effect is limited to a particular subset of financial tasks. Additionally, the behavioral mechanism of testosterone affecting financial decision making, including its effect on risk perception and cognitive biases leading to irrational choices, is poorly understood.

Understanding the role of testosterone in financial decision making is important for several reasons. First, individual investors could benefit from being aware of the role of testosterone on their financial choices. By actively monitoring their testosterone levels, individual investors could maintain testosterone levels within a range that is considered optimal for decision making — such as a range associated with a greater number of rational decisions, a lower exposure to unnecessary risk, and higher profitability. Second, institutional investors, such as 
large corporations and investment funds, could benefit from having their traders consider the role of testosterone in financial decision making and its effect on ensuing outcomes. Third, financial markets and market regulators would benefit from an increased number of responsible investors who actively manage the influence of testosterone on their financial choices.

In this essay, I investigate the role of testosterone on financial choices and outcomes during a portfolio formation (asset allocation) task and an options trading task. The tasks involve financial decision making for long term investment and high frequency trading. Thus, this essay examines whether decision "frequency," which is high during the options trading task, and low during the portfolio formation task, determines whether testosterone is related to financial decision making. Given that males have approximately 20 times more circulating testosterone than females do; this study also investigates the important issue of gender differences in the relation of testosterone with financial decision making. Finally, this essay analyzes the behavioral influence of testosterone on financial decision making by examining whether levels of testosterone affect asset allocation choices or are associated with costly financial behavior, such as excessive trading.

\subsection{Literature Review}

Only a few studies have addressed the effect of testosterone on financial decision making, leaving much to be explored. Three important issues that remain poorly understood are: 1) how does testosterone affect financial outcomes (such as investment risk and return)? 2) Is testosterone related to 
different types of financial decisions (such as decisions concerning trading versus decisions involving investing)? And 3) what is the behavioral mechanism by which testosterone influences financial decisions? The reminder of this section describes the extent to which these three questions are addressed in the literature to date.

Literature on the relation of testosterone to financial decision making is concentrated in a few recent studies. Coates and Herbert (2008) and Coates et al. (2009) find evidence for a correlation of testosterone levels with financial decision making. Coates and Herbert measured morning (11:00 a.m.) and afternoon (4:00 p.m.) testosterone levels in a small group $(n=17)$ of male traders for eight consecutive business days under real working conditions. The authors find that traders achieve a significantly greater daily profitability (profit and loss level, or $\mathrm{P} \& \mathrm{~L}$ ) on days when their morning testosterone level is above their overall median level over the course of the study. These results indicate that morning testosterone levels can partially predict the direction of daily profitability in traders. Similarly, Coates, et al. (2009) measure the second digit to fourth digit finger ratio (2D:4D) of 44 high frequency male traders and find it to be predictive of the traders' $\mathrm{P} \& \mathrm{~L}$ levels over a 20 -month period. The $2 \mathrm{D}: 4 \mathrm{D}$ ratio is directly related to the amount of in-utero testosterone exposure. Therefore, the results suggest that prenatal testosterone level is associated to the long-term profitability of high-frequency traders.

The Coates and Herbert (2008) and Coates et al. (2009) studies show evidence that testosterone is related to financial profitability, providing a partial 
answer to the question of how testosterone affects financial outcomes. However, they do not find that a relation exists between testosterone and financial risk taking. This finding (or rather lack thereof) is curious, given the empirical evidence linking testosterone to a variety of social behaviors involving risk, such as a higher likelihood of committing a violent crime among male prison inmates (Dabbs et al. 1987), drug use, aggressive violence and high-risk sexual behavior among anabolic steroid users (Middleman and DuRant 1996), and antisocial and deviant behavior among male U.S. Army veterans (Mazur 1995). Nevertheless, the medical literature shows that monetary incentives are processed by different brain areas than other kinds of rewards (Knutson et al. 2001). Therefore, the results in Coates and Herbert (2008) and in Coates et al. (2009) support the view that financial risk taking is not related to testosterone levels due to the unique way in which the brain perceives and responds to financial risk.

Apicella et al. (2008) investigate the link between testosterone and financial risk preferences in men. Participants are asked to bet any desired amount of money from an original $\$ 250$ endowment in a coin-toss gamble. A winning toss returns 2.5 times the amount wagered, whereas a losing toss forfeits the amount of the bet. The authors show that salivary testosterone level (Sal-T) is positively correlated with the amount bet in the gamble. As such, the results show that endogenous testosterone levels are related to financial risk preferences in men. In contrast, Sapienza et al. (2009) measure risk aversion using the algorithm from Holt and Laury (2002), in a task where subjects make choices between a risky lottery and varying certainty equivalents that provides a 
guaranteed return. ${ }^{15}$ They find that salivary testosterone is associated with lower risk aversion among women, but not among men. As such, Apicella et al. (2008) and Sapienza et al. (2009) provide conflicting results as to whether a relation between testosterone levels and risk aversion actually exists. However, their conflicting results could be due to the way that each study measured risk aversion, which is notoriously difficult to do.

Studies in which participants are administered testosterone exogenously (i.e. orally or intravenously) also have yielded inconsistent results. Van Honk et al. (2004) show that women who are given exogenous testosterone exhibit decreased risk aversion during the lowa Gambling Task (IGT). These results are consistent with Stanton et al. (2011), who show that endogenous testosterone levels are positively associated with risk taking in the IGT among men and women. Alternatively, Goudriaan et al. (2010) fail to show that men with supraphysiological levels of testosterone perform differently in the IGT. Similarly, Zethraeus et al. (2009), using a version of Holt and Laury's (2002) algorithm, fail to show that testosterone administration in women is associated with financial risk preferences. Therefore, similar to the studies analyzing the relation between endogenous levels of testosterone and financial risk taking (discussed in the previous paragraph), studies using exogenous measures of testosterone fail to provide consistent results.

\footnotetext{
${ }^{15}$ Holt and Laury (2002)'s algorithm is a method to measure the degree of risk aversion. Subjects are presented with a menu of paired lottery choices which are structured so that the crossover point to the high-risk lottery can be employed to infer the level of risk aversion.
} 
Stanton et al. (2011) propose that the inconsistent results from studies examining the relation between testosterone and economic risk are due to the nonlinear effect of testosterone on economic risk. In particular, they show that endogenous testosterone levels have a U-shaped association with financial risk preference and ambiguity preference, but not with loss aversion. ${ }^{16}$ Thus, both men and women with intermediate levels of testosterone were found to be risk and ambiguity averse, whereas those with low and high testosterone were found to be risk and ambiguity neutral. However, the inconsistent results found throughout the literature could also be due to the fact that studies use a variety of different tasks to measure economic risk, use either laboratory or real-life settings, measure either endogenous or exogenously manipulated levels of testosterone, and include either one or both genders. Consequently, the Ushaped financial risk versus ambiguity relation is as yet unproven.

Because of the difficulties associated with replicating real-life economic incentives in the laboratory, several studies prefer to examine investor behavior in their natural environment. However, the nature of the financial task itself can be the explanation of why studies of this kind (e.g., Coates and Herbert 2008; Coates et al. 2009), do not find that testosterone level is related to financial risk taking in professional traders. Which brings us to the next question: Is testosterone related to all types of financial tasks (i.e., both trading and investing

\footnotetext{
${ }^{16}$ Ambiguity preference describes the preference towards known risks and unknown risks. As such, an ambiguity averse individual prefers known risk situations over unknown risks situations. Importantly, ambiguity describes situations where outcome probabilities are unknown. Alternatively, risk aversion describes situations where outcome probabilities are known (see Epstein 1999).
} 
or short-term and long-term)? Coates and Herbert (2008) and Coates et al. (2009) use a sample of traders, whom by definition engage in very short-term financial decisions. At this level of decision making, factors other than testosterone can play a larger role in the risk undertaken by individuals. In fact, Coates and Herbert (2008) find that the stress hormone cortisol is linked to the volatility of the traders' P\&L levels and the volatility of the market, which shows that stress level plays a larger role than testosterone in the risk-taking behavior of traders. Alternatively, the time pressure that pervades high-frequency trading is present to a much lesser degree in other kinds of financial tasks, such as longterm investment planning and decision-making games like the IGT. Thus, we can intuitively link the pressure to quickly produce results during high-frequency trading to high stress, which could outweigh the influence of testosterone on risk taking during trading.

Finally, only a few studies examine the question of how testosterone levels influence financial decision making. This is perhaps the most difficult question to answer, because it involves understanding the biochemical mechanism of testosterone action in the brain. In general, testosterone is thought to influence financial decision making by shifting economic utility functions, confidence levels, and/or risk preferences, through its effect on the brain's nucleus accumbens. As a part of the dopamine system, the nucleus accumbens is associated with pleasure as well as irrational, risk-seeking behavior (Kuhnen 
and Knutson 2005). ${ }^{17}$ Evidence of the "rewarding" property of testosterone is also found in addiction studies of humans taking anabolic steroids (Kashkin and Kleber 1989).$^{18}$ Biologists have also found that male primates (including humans) experience elevated levels of testosterone during situations of physical challenge. For example, athletes show increased testosterone levels during competition, and testosterone levels increase further after winning an event (Gladue et al. 1989). Therefore, testosterone appears to play a major role in winning and losing contests.

\subsection{Methods ${ }^{19}$}

This study follows a similar methodology as other studies on the relation of endogenous testosterone levels to economic behavior. That is, subjects provide demographic information as well as a saliva sample that is used to measure their level of testosterone. After subjects provide the saliva sample, they engage in three financial tasks using a trading and investment simulation software. Finally, their level of testosterone is related to their financial performance and risk-taking behavior via statistical analysis.

\footnotetext{
17 Dopamine is the major neurotransmitter of the reward system of the brain, which includes the ventral tegmental area, the nucleus accumbens, the amygdala, the hippocampus, and the medial prefrontal cortex. Rewarding experiences such as food, sex, and drugs lead to the release of dopamine, providing feelings of enjoyment and motivating the reinforcement of these activities. Bressan and Crippa (2005) provide a basic review of the dopamine system and its role in reward and pleasure.

${ }^{18}$ This rewarding property is thought to be due to the effects of testosterone and its two metabolic byproducts (dihydrotestosterone (DHT) and estradiol) on the nucleus accumbens, causing an increase in dopamine release (Frye et al. 2002).

19 Prior to conducting the study, Institutional Review Board (IRB) approval was obtained from Florida International University's Office of Research (Protocol Approval \#IRB-13-003).
} 


\subsubsection{Subject Recruitment and Preparation}

In order to employ participants who possess a superior knowledge base in finance (as compared to the average person) subjects were recruited from graduate students in Florida International University's financial software course, in which they learn to use the financial trading simulation application Rotman Interactive Trader 2.0 (RIT 2.0). ${ }^{20}$ Forty-eight students agreed to participate in the study and signed consent forms. ${ }^{21}$ The sample is composed of 14 women $(31 \%)$ and 31 men $(69 \%) .{ }^{22}$

In order to ensure that participants were proficient users of RIT 2.0, the trial was scheduled at the end of the course, when participants had had sufficient experience with RIT 2.0. (After the trial, participants were asked to rate their level of comfort using RIT 2.0, on a scale of 1 (lowest comfort) to 5 (highest comfort). The median response score is 4 , showing that most participants had a high degree of comfort).

Participants were given access to the simulation case descriptions employed in the study on the course website several weeks prior to the trial. Therefore, participants who were interested in performing well in the trial

20 The simulation software was developed at the BMO Financial Group Finance Research and Trading Lab (the Rotman Finance Lab) at the University of Toronto's Joseph L. Rotman School of Management). With the permission of the instructor, study participants were recruited during the second week of the course. Potential participants were then provided a general description of the study and told what was expected of them, including that they would be expected to provide saliva samples. However, participants did not know what was being tested for in the saliva.

${ }^{21}$ Subjects were asked to provide data regarding their age, gender, and ethnicity (one subject withheld the age data.) Three subjects subsequently dropped out, leaving a final trial sample comprised of 45 subjects (a participation rate of $94 \%$ ).

22 Participants were from several ethnic backgrounds, including Asian (33\%), Black $(7 \%)$, Hispanic (44\%) and White (16\%), and they ranged in age from 22 to 50, with a median age of 25 at the time of the study. 
prepared by reading the cases and using the accompanying Excel spreadsheet to understand the cases in advance. In a post-trial questionnaire participants were asked to rate their preparation for the trial on a scale of 1 (lowest) to 5 (highest). The median score is 4 , showing that most participants believed they achieved a high degree of preparation for the trial. Additionally, 34 (76\%) participants reported using the Excel spreadsheet to prepare for the portfolio formation task. ${ }^{23}$

\subsubsection{The Trial}

One week before the trial, participants were given a printout with detailed preparation instructions. This same handout was posted to the Blackboard Learn online course interface. Since testosterone follows a circadian rhythm, with the highest levels exhibited during the morning hours, the trial was conducted in the morning.

Participants were instructed to arrive at the computer lab facility by $8: 15$ a.m. on the day of the trial, and to refrain from eating or drinking anything after 8:00 a.m. on that day, in order to provide a clean saliva sample. The trial began at 8:20 a.m. and lasted for one hour. Saliva samples were collected immediately before the trial, using a standard procedure. ${ }^{24}$ After the trial, the saliva samples

\footnotetext{
${ }^{23}$ During the week before the trial, participants were reminded via an online announcement to review the study instructions and simulation cases, and they were asked to take a short online questionnaire to test their knowledge about the instructions and the simulation cases. Thus, every measure was taken to ensure that participants knew in advance what to expect during the trial. By the day of the trial, 37 (77\%) participants had completed the online questionnaire. The median score is 5 (out of 6 questions), showing that the majority of participants were very familiar with the trial instructions and the simulation cases

${ }^{24}$ The procedure can be summarized as follows: Each subject was provided with a Salivette ${ }^{\circledR}$ test tube at the time of collection. All subjects were given sugar-free gum in order to stimulate saliva
} 
were transported to a Florida International University lab facility, were the salivary testosterone (Sal-T) levels were measured via mass spectrometric analysis. ${ }^{25}$

\subsubsection{The Investment Simulations}

Immediately following the collection of the saliva sample, participants engaged in three financial tasks using RIT 2.0. ${ }^{26}$ The first two tasks involve investment decision-making (i.e., long-term financial choices), whereas the third task involves trading decision-making (i.e., short-term financial choices). The investment tasks are identical to each other, and they are identified as "Diversification" by Rotman. Henceforth these tasks are referred to as the Diversification 1 (DIV1) and Diversification 2 (DIV2) tasks, whereby the number provides the order in which the tasks were performed - that is, DIV1 is the first task of the trial, whereas DIV2 is the second task of the trial.

production. Subjects produced a minimum sample of $3 \mathrm{ml}$ of saliva, which they inserted into the test tube. The test tubes were sealed and refrigerated within $48-72$ hours of collection at $-20^{\circ} \mathrm{C}$ until analysis. The timespan between saliva collection and refrigeration does not influence hormonal concentration, as saliva can last up to five days on average before it degrades.

${ }^{25}$ The procedure for mass spectrometric analysis can be summarized as follows: To $1000 \mu \mathrm{L}$ of saliva add both methanol Internal standard (Testosterone $\left.D_{3}\right) 1 \mathrm{ng}$; Cortisol-D $42 \mathrm{ng} / 100 \mu \mathrm{L}$. The samples are mixed with $4 \mathrm{ml}$ of ethyl acetate, agitated for 15 minutes, and then centrifuged at $3000 \mathrm{rpm}$ for 10 minutes. After the aqueous layer is frozen, the ethyl acetate layer is isolated. The solution is evaporated using a centrifugation evaporator. The extract is dissolved in $100 \mu \mathrm{L}$ of 70 $\%$ acetonitrile, and $10 \mu \mathrm{L}$ of this solution is injected into the LC/MS/MS system. A parallel solid phase extraction (SPE) process using $1 \mathrm{ml} 30 \mathrm{mg} \mathrm{HLB}$ cartridges is used instead of organic extraction. Here $1000 \mu \mathrm{L}$ of the saliva sample is used, fortified with the corresponding internal standard and centrifuged at $3000 \mathrm{rpm}$. The supernatant is subject to SPE analysis using a mix of water and methanol, and the final methanolic extract is evaporated and reconstituted in the mobile phase for further mass spectrometric analysis. Simultaneous Testosterone, Testosterone$\mathrm{D}_{3}$, Cortisol and Cortisol $\mathrm{Dd}_{4}$ are determined using selective reaction monitoring (SRM) of the following transitions $(\mathrm{m} / \mathrm{z}): 289.3 \rightarrow 97.3,292.3 \rightarrow 97.3,363.3 \rightarrow 327.1$, and $367.3 \rightarrow 331.3$, respectively. For quantification purposes, at least five levels of calibration are use in the $\mathrm{pg} / \mu \mathrm{L}$ range, using an internal standard.

26 The cases were developed by the Rotman Finance Lab to be used with the RIT simulation software. Case descriptions are available for download from at the Lab's website for subscribers. Additionally, instructors have access to the case solutions and to the master Excel spreadsheets that allow each case to be tailored as needed. 
During the investment tasks subjects have an endowment of $\$ 500,000$ to invest in a portfolio of assets that must grow to $\$ 1.5$ million by the end of the simulated time horizon (i.e., 20 years). The subjects can choose from five Electronic Trading Funds (ETFs) of different historical returns and volatilities (shown in Table 3.1). After making their allocation choices in the ETFs (or in CASH for funds not invested), each of the ETF prices evolve as a random walk with positive drift and standard deviation, as given by their historical return and volatility. As such, the price paths can be significantly different between DIV1 and DIV2. The investigator did not manipulate the price path of any security. Although DIV1 and DIV2 are identical, they are not considered so from a financial decision-making perspective. This is because naïve investors typically allow their recent past performance to influence their subsequent investment choices. Since DIV1 is immediately followed by DIV2, DIV1 is regarded as an initial portfolio creation task, whereas DIV2 is regarded as a portfolio rebalancing task.

The third task of the trial is an options trading simulation, involving four options contracts on the same non-dividend paying stock. The stock is not tradable, but its price is observable. The price of the stock follows a stochastic pre-generated path over the duration of the case. The options can be purchased or sold via limit or market orders.

\subsubsection{Testosterone Measurement}

Free (unbound) saliva testosterone (Sal-T) measurement is the preferred method to study circulating levels of testosterone in the body because of to the noninvasiveness of the procedure used to collect the saliva. However, unlike 
blood analysis, there is no standard way to measure the Sal-T concentration. Therefore, benchmarking is constrained by the particular procedure used to determine the concentration of Sal-T. In other words, it is difficult to compare absolute levels of Sal-T across studies because of the different methodologies used to test for concentration. Therefore, I let the sample statistics dictate what constitutes high, intermediate, and low levels of Sal-T in subjects.

Another aspect of testosterone measurement to consider is the fact that testosterone, being the primary male sex hormone, is many times higher in males than in females. In this sample, the mean Sal-T concentration was 30.0 $\mathrm{pg} / \mathrm{mL}(\mathrm{SD}=17.0)$ in men and $7.4 \mathrm{pg} / \mathrm{mL}(\mathrm{SD}=9.1)$ in women. ${ }^{27}$ Due to the natural gender difference in testosterone level, I converted individual raw Sal-T levels to z-scores relative to the Sal-T distribution for the gender of the individual. This technique is employed by other studies that use a sample of mixed genders (e.g., Mehta et al. 2008). The z-scores are used for all the analyses.

\subsection{Investment Performance Results}

\subsubsection{Asset Allocation Choices}

Table 3.1 shows the average asset allocation choices of subjects during each task. The results show that subjects give HOME and GROW, which are the two most volatile assets, approximately equal average weighs during both tasks. In fact, there is no significant difference between HOME and GROW investment proportions within each task. This shows that subjects regard HOME and GROW

27 Stanton et al. (2011) obtains mean salivary testosterone levels of $86.5 \mathrm{pg} / \mathrm{mL}(\mathrm{SD}=26.0)$ for men and $14.2 \mathrm{pg} / \mathrm{mL}(\mathrm{SD}=7.0)$ for women. These levels are very different from the ones in this study, illustrating the difficulties in benchmarking Sal-T using different protocols and results from other studies. 
as equivalent securities, despite GROW having almost twice the volatility as HOME. Combined, the proportions invested in HOME and GROW account for almost half the total allowance, showing that subjects value "risker" assets more than they value safer ones. A similar phenomenon is apparent between BOND and MINE. Despite having twice the volatility, the proportion of funds allocated to MINE is not significantly different from that allocated to BOND during both tasks. This result shows that subjects likely consider BOND and MINE to be relatively "similar" securities.

The smallest proportion of funds was allocated to MMKT during DIV1 and DIV2. Surprisingly, a considerable proportion of funds was left uninvested (kept as $\mathrm{CASH}$ ), especially during DIV1. The redistribution of $\mathrm{CASH}$ into the four riskier assets during DIV2 demonstrates that investors learned from their prior task performance. The fact that subjects still prefer to keep some funds as CASH during DIV2 instead of investing it in MMKT demonstrates a certain level of irrational risk aversion. The reason that allocating to CASH instead of MMKT is irrational is because their historical volatility is essentially equivalent whereas CASH provides no return and MMKT provides a $2 \%$ return.

\subsubsection{Investment Return and Volatility}

After subjects allocate their allowance (partially or fully) across the five ETFs, the price of each instrument evolves over a simulated period of 20 years. The price path is randomly selected for each ETF based on a normal meandistribution equal to the ETF's historical return and a standard deviation equal to the ETF's historical volatility. Monte Carlo simulations of 2,000 iterations were 
performed for each subject in order to calculate the expected portfolio return, volatility and shortfall. ${ }^{28}$ Table 3.2 shows the portfolios' expected and realized return and volatility during DIV1 and DIV2.

Table 3.2 shows that expected portfolio return is significantly larger for DIV2, but the realized return underwent a significant drop. These results are similar to what transpires in real life investments - investments do not always live up to their expectations. The table also shows a significant increase in portfolio volatility (both expected and realized) during DIV2, which is consistent with an allocation into riskier securities, as seen in Table 3.1

Subjects had an investment goal of (at least) $\$ 1.5$ million by the end of 20 years. Since their initial allowance was $\$ 500,000$, their goal was to achieve a return of $200 \%$ over the 20 years, or an annual return of $5.65 \%$. Given that the average annual return during DIV1 far exceeded the required annual return, the combined results of Table 3.1 and Table 3.2 show that subjects in the sample take greater risks than needed to meet their investment goal. These results also illustrate that investors are return-oriented rather than goal-oriented. In other words, after outperforming their objectives in DIV1, subjects choose to increase

\footnotetext{
${ }^{28}$ Subjects were able to run the Monte Carlo simulations on their own before the trial if they desired. The Monte Carlo simulations were based on 2,000 iterations, meaning that the resulting return and volatility were the average of 2,000 different possibilities for the combined portfolio of assets. Therefore, the results of the Monte Carlo simulation very closely approximate the expected return that could be computed using the weights and the historical returns of the securities. Aside from the Monte Carlo simulations, subjects had no other way to compute a numerical value for the expected portfolio volatility, because the numerical correlations between the securities were only known to the researcher.
} 
their risk further in DIV2, even though with greater risk comes a greater chance of falling short of achieving the minimum required $\$ 1.5$ million portfolio value. ${ }^{29}$

\subsubsection{Investment Performance}

The chance of not achieving the required investment goal (e.g., the percentage shortfall) can be computed via Monte Carlo simulation. The average percentage shortfall for DIV1 and DIV2 is shown in Table 3.3. The table also shows additional measures of risk and return associated with the allocation choices of subjects, including the Sharpe ratio (the ratio of excess return to volatility), the final portfolio value, the total return (over 20 years), the abnormal return (the realized return in excess of the expected return), and the value at risk (VaR, the maximum expected loss in one year for a 95\% confidence level).

The results in Table 3.3 are consistent with the increased risk undertaken during DIV2, as shown in Table 3.2. In particular, the maximum size of yearly losses $(\mathrm{VaR})$ is higher for DIV2. Additionally, although the chance of not meeting the investment objective of $\$ 1.5$ million in 20 years (shortfall) is lower during DIV2, this is due to a much lower proportion of funds left uninvested in Cash during DIV2. Funds not invested achieve a zero return, whereas funds invested in the MMKT security achieve $2 \%$ return on average - neither choice comes close to the $5.65 \%$ annual return necessary to meet the investment goal.

\footnotetext{
29 It is possible that some subjects had goals surpassing the $5.65 \%$ benchmark. This is not unlike what transpires in real life. Investment managers have been known to take much larger risks than instructed by their clients. However, this does not take away from the fact that by taking more risk, they could also realize greater losses, and therefore fail to meet their client's demands. Additionally, subjects were told that risk-adjusted performance, and not gross performance, was the measure of success.
} 
Therefore, as the proportion of funds either not invested or invested in MMKT decreases during DIV2, so does the shortfall.

Consistent with the greater risk undertaken during DIV2, Table 3.3 shows that the average DIV2 portfolio is expected to generate greater final wealth, total return, and abnormal return than the average DIV1 portfolio. However, the significant differences between DIV1 and DIV2 portfolio composition and expected performance show that investor choices during DIV2 are partly influenced by the allocation choices and the portfolio performance during DIV1. However, as asset managers frequently caution, recent past performance is not a predictor of future performance, and ultimately, the realized performance during DIV2 is significantly lower than the realized performance during DIV1. Thus, subjects should not have let the realized performance from DIV1 influence their portfolio formation decisions for DIV2, because the return process for each security is independently identically distributed (i.i.d.).

Table 3.3 also shows that predicted Sharpe ratios for DIV2 are statistically lower than those of DIV1. Therefore, the additional risk undertaken during DIV2 does not result in superior risk-adjusted returns relative to DIV1. The difference in Shape ratios demonstrates that differences in portfolio efficiency could exist between DIV1 and DIV2. In other words, on average the portfolios formed during one of the tasks could lay further away from the efficient frontier than portfolios formed during the other task.

Appendix C provides a detailed discussion of portfolio efficiency in relation to DIV1 and DIV2. Overall, the results show that there is no difference in portfolio 
efficiency between DIV1 and DIV2. As such, the results show that investors do not actually learn to allocate funds more efficiently during DIV2 after observing their performance for DIV1. Rather, the obvious link between DIV1 performance and DIV2 allocation choices appears to have more to do with being returnoriented rather than goal-oriented — which could be related to the "rewarding" properties of testosterone, as shown in the literature.

\subsection{Testosterone and Investment Decisions and Outcome}

\subsubsection{Testosterone and Asset Allocation Decisions}

The literature reviewed in Section 3.2 shows that some research finds the relation between testosterone and economic decision to be linear and other research finds it to be quadratic. Consequently, in this research two regression models are used in order to capture the potential appropriate relation, namely linear (Model 1) and/or quadratic (Model 2). A third model (Model 3) adds the gender of investors as a dummy variable (Females=0, Males=1) to capture gender differences not accounted for by the role of testosterone. Lastly, a fourth model (Model 4) is performed on DIV2 variables in order to capture the influence of the performance during DIV1.

Table 3.4 displays the significant relation between salivary testosterone (Sal-T) and asset allocation during DIV1 (Panel A) and DIV2 (Panel B). Since the results in Table 3.1 show that subjects view certain securities as being "similar," the relation of testosterone to fund allocation is also examined for the combined high-risk securities (HOME and GROW), medium-risk securities (BOND and 
MINE), and low-risk securities (MMKT and CASH) - although CASH is technically not a security and is also risk-free.

Table 3.4, Panel A shows that the predominant relation between Sal-T and the initial asset allocation decisions (DIV1) is linear in nature. Specifically, a negative relation exists between Sal-T and the proportion of funds allocated to High Risk securities, including GROW, whereas a positive relation exists between Sal-T and the proportion of funds allocated to the Low Risk securities. Thus, the results show that testosterone possesses a negative linear relation to risk taking during the initial allocation decisions in investment tasks. These results are incongruent with studies that report a positive relation between testosterone levels and risk-taking (e.g., Apicella et al. 2008), studies that report a negative relation between testosterone levels and risk-aversion (e.g., Sapienze et al. 2009), and studies that report a quadratic relation between testosterone levels and economic risk-aversion (e.g., Stanton et al. 2011). However, these studies rely on economic games, such as the IGT, to evaluate investor risk preferences. In contrast, the investment scenario in this study is very realistic, as individuals are often required to allocate funds to their own retirement portfolios using similar investment instruments and information (such as the historical return and volatility of the securities). Furthermore, it is unlikely that individuals have similar risk preferences for gambles as they do for their retirement choices. Thus, individuals are unlikely to make financial decisions about how to balance their investment portfolios the same way they make gambling choices in Las Vegas during a weekend getaway. 
Table 3.4 also shows that during portfolio rebalancing the Panel B testosterone levels are related to the allocation of funds into securities with intermediate risk levels (i.e., MINE and BOND), showing a shift from DIV1 risk preferences. Additionally, the results show that nonspecific gender differences (i.e., gender differences not related to levels of testosterone), and the memory of recent past performance, shape the nature of the relation between testosterone and reallocation choices. Specifically, high and low testosterone subjects exhibit lower $\mathrm{CASH}$ allocation and higher BOND allocation than subjects with intermediate levels of testosterone. As such, gender and recent past performance effects render subjects with intermediate levels of testosterone more risk averse than subjects with high or low testosterone levels during rebalancing investment tasks. These results support those of Stanton et al. (2011), which show that low and high testosterone subjects exhibit decreased aversion to economic risk. Their results, like those in this study, are also significant in the presence of significant nonspecific gender differences. Therefore, the results here show that the study of the relation between testosterone and investment decision making should consider the influence of gender, recent past performance, and whether financial decisions are made for the first time.

\subsubsection{Testosterone and Portfolio Investment Performance}

In order to better understand the role of testosterone on asset allocation decisions, including its role on rebalancing choices, it is necessary to analyze how the securities behave as a portfolio. In other words, I investigate whether the 
characteristics of the entire portfolio of assets provide additional information about subjects' financial preferences not otherwise evident by examining their preferences for individual assets. Table 3.5 displays the relation of Sal-T to several of these portfolio characteristics during DIV1, including the portfolio's expected return and volatility, and the value at risk. ${ }^{30}$

Table 3.5 shows significant linear relations between testosterone levels and the portfolio's expected return, volatility, VaR, shortfall and final wealth for the DIV1 task. Specifically, Sal-T has a strong negative relation to the expected return, volatility, and final wealth of the portfolio, and a strong positive relation with VaR and shortfall. These results are consistent with the results displayed in Panel A of Table 3.4, which shows that Sal-T has a negative relation with the proportion of funds invested in high-risk securities, and a positive relation with the proportion of funds invested in low-risk securities. As such, the results show that investors with higher levels of testosterone prefer low-risk securities and avoid high-risk securities. This results in portfolios with significant lower expected return, volatility and final wealth than the portfolios of subjects with lower levels of testosterone. Furthermore, the results show that the portfolios of subjects with lower levels of testosterone are subject to greater downside risk than the portfolios of subjects with higher levels of testosterone.

Table 3.5, also shows that Sal-T exhibits a significant positive relation to the portfolio Sharpe ratio, which measures the risk-adjusted performance. In

\footnotetext{
${ }^{30}$ Additionally, only results pertaining to DIV1 are displayed, because there are no significant results for DIV2. I find that subjects allow their DIV1 performance to significantly influence their decisions during DIV2, overwriting the influence of testosterone.
} 
other words, subjects with higher testosterone levels create portfolios with a greater return per level of risk undertaken, compared to subjects with lower testosterone levels. The fact that expected return and risk-adjusted return are negatively correlated has to do with the larger magnitude of the variance relative to that of the expected return. In terms of investment decisions, the results show that high testosterone subjects are mainly concerned with the mean and variance of the return distribution - therefore, their higher Sharpe ratios. Alternatively, low testosterone subjects consider higher moments of the return distribution (i.e., skewness), and therefore focus on avoiding extreme adverse events-therefore, lower VaR and shortfall.

The results also show that testosterone does not always have a linear relation to the predicted performance of the portfolio. In particular, Sal-T has a strong negative relation to the portfolio abnormal return. This result is interesting, considering that it is the only measure of portfolio performance in Table 3.5 to exhibit a curvilinear relation with testosterone. Unlike other measures analyzed, abnormal return is an atypical measure, in that it is both a measure of return and a measure of risk. This characteristic could explain the unique relation between abnormal return and Sal-T. Alternatively, it could also mean that abnormal return helps to capture a unique aspect of testosterone's role on financial decision making; namely, its combined influence on risk and reward preferences.

Interestingly, for DIV2 no relation exists between Sal-T and any of the measures of expected portfolio performance. Instead, a strong linear relation between the performance in DIV1 (i.e., net liquidity value) and the 
aforementioned portfolio characteristics is obtained. ${ }^{31}$ The strong influence of DIV1 performance on DIV2 allocation choices is further evidence that investors regard DIV2 as a rebalancing of their DIV1 portfolios, rather than as a new portfolio formation task. As such, the results show that portfolio rebalancing involves a different psycho-physiological mechanism of decision making than the initial portfolio formation-namely, one in which testosterone plays a much smaller role, and in which recent past performance is a key factor.

Overall, the results in Table 3.5 contrast with those of Coates and Herbert (2008), who show that higher morning levels of testosterone in a sample of floor traders is related to higher final wealth in the afternoon. A key important difference between their study and this one is the type of financial task. Floor traders engage in high-frequency trading, which requires constant attention to intraday price patterns and quick decision making. In this study portfolio formation is not as physically demanding as high-frequency trading, and decisions are made with less time constrains and for longer time horizons. In fact, Coates et al. (2009) propose that the positive correlation between testosterone and profitability during high-frequency trading "could even reverse sign among traders who adopt a more analytical and long-term approach to the markets." The results in this study are consistent with this view.

The results displayed in Table 3.5 also contradict Stanton et al. (2011), who show that Sal-T has a concave-up (U-shape) relation to risk aversion; meaning that individuals with intermediate levels of testosterone are more risk

31 These results are not shown because no relation between the performance measures during DIV2 and testosterone levels exists. The objective of this study is to address this relation. 
averse than individuals with low and high testosterone (relative to their gender). However, the results in Table 3.5 only support the risk-aversion difference found between low- and intermediate-testosterone level individuals; specifically, that low-testosterone individuals take greater risks, and achieve greater profits, than individuals with intermediate levels of testosterone. In order to corroborate the findings for high-testosterone individuals, the quadratic term in Table 3.4 would need to be significant and positive. Adding to the inconsistency in findings between this study and Stanton et al. (2011), other studies show that the relation between testosterone and risk aversion is linear and positive for men (Apicella et al. 2008), and linear and negative for women (Sapienza et al. 2009).

\subsubsection{Testosterone and the Efficient Frontier}

The last part of the analysis on investment decision making addresses the relation between testosterone levels and portfolio efficiency. As discussed in Appendix C, portfolio efficiency is measured as the horizontal distance between portfolios and the efficient frontier. Table 3.6 displays the results for DIV1 (Panel A) and DIV2 (Panel B).

The results displayed in Table 3.6 show that under different asset allocation tasks, testosterone creates a different relation with portfolio efficiency. During the initial portfolio-formation task (DIV1) a significant negative quadratic (concave down) relation exists between Sal-T and the horizontal distance of a portfolio to the efficient frontier. In other words, subjects with low and high testosterone levels create less efficient portfolios than subjects with intermediate levels of testosterone. Alternatively, during subsequent portfolio rebalancing, the 
relation between testosterone levels and portfolio efficiency is negative and linear, showing that subjects with higher testosterone levels create less efficient portfolios during reallocation decisions than subjects with lower testosterone levels. To my knowledge, this is the first study to show the relation between testosterone levels and portfolio efficiency. .

Overall, the results from the portfolio formation tasks (DIV1 and DIV2) show that testosterone has a complex relation to asset allocation during investment decisions. The memory of recent past performance and gender differences can significantly interfere with the influence of testosterone on subsequent asset allocation decisions. However, asset allocation choices (Table 3.4) and the resulting portfolio efficiency (Table 3.6) show the persistent influence of testosterone under portfolio rebalancing decisions.

\subsection{Testosterone and Options Trading Decisions and Outcome}

\subsubsection{Options Trading Performance Overview}

The relation between testosterone and trading decisions and outcomes is analyzed during an options trading task. Subjects could trade up to four different European option contracts written on the same non-dividend paying stock; namely two call options with strike prices of $\$ 25$ (25C) and $\$ 26$ (26C), and two put options with strike prices of $\$ 24(24 \mathrm{P})$ and $\$ 25(25 \mathrm{P})$. The stock was not tradable, but its price was observable. Table 3.7 summarizes the performance during the options trading task. All prices and profits and losses are in dollars.

At the end of the trading period, the stock had a value of $\$ 25.93$. As such, all but the 25C contract expired out-of-the-money. Therefore, the trading 
performance results in Table 3.7 show that the average subject incurred losses (negative P\&L's) in all but the $25 \mathrm{C}$ contract. However, the $25 \mathrm{C}$ gains were sufficiently large to result in a positive overall portfolio P\&L. Interestingly, 25C was the most traded contract, having the largest number of buy orders, sell orders, market orders, and limit orders. These results show that subjects had optimistic expectations for future stock prices in general. Moreover, the evident preference for $25 \mathrm{C}$ over the $26 \mathrm{C}$ contract shows a preference for risk taking, since at-the-money options (i.e., 25C) possess higher deltas than out-of-themoney options (i.e., 26C). Such preference for risk taking is evident in the large variability of the P\&L levels. Figure 3.1 , which shows the price path of the options contracts, confirms this conjecture.

Figure 3.1 shows that soon after trading starts, the prices of the options increase dramatically for all contracts except $24 \mathrm{P}$. In some cases, the price rises to surpass the price of the underlying stock. Such cases constitute violations of the theoretical upper price limit of the options, because they introduce arbitrage opportunities between the stock and the options. However, in this task, the stock is not tradable, and arbitrage is not possible. Therefore, the dramatic price increases are most likely due to the actions of speculators or naïve traders.

\subsubsection{Testosterone and Options Contract Choice}

In order to determine whether testosterone is related to trading choices and performance during the options trading task, I employ the three regression models introduced in section 3.4.1. Table 3.8 displays the significant relation 
between Sal-T and investor trading preferences among the four types of option contracts.

Table 3.8 provides several takeaways. First, testosterone is preferentially related to puts. Table 3.7 shows that the majority of put orders submitted are buy orders. As such, the results show that testosterone level is related to having a pessimistic view about future stock prices. If holding the stock was allowed (as in the real world), the results also could mean that the testosterone level is related to hedging a long position on stocks using put options. Overall, the results in Table 3.8 are supported by medical studies showing that brain areas involved in anticipation of uncertain gains (e.g., showing optimism by buying call options) and losses (e.g., showing pessimism by buying put options) are different (Knutson and Cooper 2005).

Second, testosterone is related to option moneyness. High and low testosterone subjects have lower preference for at-the-money options (i.e., 25P and $25 \mathrm{C}$ ) than subjects with intermediate levels of testosterone. At-the-money options are the least conservative of the four options contracts, because they undergo a greater change in price for a given change in stock price. Therefore, the results show that intermediate levels of testosterone are related to greater risk taking. Third, testosterone is negatively related to extreme risk taking. Specifically, the testosterone level has a negative relation to selling a naked call, which is the riskiest position attainable during the trading simulation. ${ }^{32}$ Therefore, the results show that testosterone levels do not have a linear relation to risk

32 Of the four possible combinations between buy/sell and put/call, selling a call without owning the stock (i.e. naked call) is the only one with unlimited potential losses. 
taking during trading. In fact, extreme and irrational risk taking (e.g., selling naked call options), takes place under low levels of testosterone. Overall, the results in Table 3.8 show that testosterone is related to trading risk, which contradicts Coates and Herbert (2008).

\subsubsection{Testosterone and Order Type}

The choice of submitting a limit or a market order is another important decision undertaken during trading. Table 3.9 shows that testosterone is significantly related to this choice. Specifically, testosterone level is negatively related to the submission of limit orders and positively related to the submission of market orders. The meaningful financial implications of the results in Table 3.9 are discussed below.

First, a preference for limit or market orders can be due to trader attitude on immediacy. According to Glosten's (1994) equilibrium model of the limit-order book, traders can be broadly defined as "patient" traders if they place limit orders and supply liquidity to the market or as "urgent" traders if they place market orders and consume liquidity. Under Glosten's (1994) framework, informed traders are more likely to be urgent traders. ${ }^{33}$ Therefore, according to the results in Table 3.9, informed/urgent traders are high testosterone traders, whereas uninformed/patient traders are low testosterone traders. These results provide a biological explanation for the theoretical models of order flow in the market microstructure literature (e.g., Handa and Schwartz 1996; Foucault 1999). Such models predict that asset volatility changes lead to changes in the proportion of

33 This is because the value of private information decreases over time. Therefore, informed traders are better off submitting market orders, which are executed immediately. 
limit orders submitted. Table 3.9 shows that an individual's testosterone level is also a powerful predictor of limit order placement. In fact, changes in testosterone levels could be driving the changes in asset volatility, as suggested in Apicella et al. (2014).

Second, the preference for limit or market orders can be due to risk and reward preferences. That is, limit orders have non-execution risk, whereas market orders are executed with certainty. Additionally, in the real world, traders submitting limit orders face adverse selection risk due to the arrival of informed traders (Ahn et al. 2001). Alternatively, when a limit order is executed, trade

occurs at a more favorable price than a market order. The results in Table 3.9 show that traders with high testosterone levels are more likely to submit market orders, whereas traders with low testosterone levels are more likely to submit limit orders. Therefore, the results show that testosterone is significantly related to decisions regarding the balance between trading risk and reward.

\subsubsection{Testosterone and Trading Time Preferences}

In addition to choosing which type of order to submit and what volume to trade, subjects must also decide when to trade-that is, time related choices. The results, displayed in Table 3.10, are as follows: First, subjects with high testosterone levels wait longer to initiate trading than subjects with low testosterone levels. Bosch-Domenech et al. (2014) reach a similar conclusion after showing that prenatal testosterone levels in a large sample $(n=623)$ predict 
scores on the Cognitive Reflection Test (CRT). ${ }^{34}$ Given the positive relation between testosterone levels and CRT scores, the results show that testosterone is related to deliberation and reflection of financial choices prior to engaging in trading. These results have obvious practical implications for real traders. For example, day traders could better understand why some of them commence trading precipitously, whereas others take more time.

Second, subjects with high testosterone levels submit their last order (i.e., stop trading) significantly sooner than subjects with low testosterone levels. This is congruent with high testosterone subjects having greater preference for market orders over limit orders (Table 3.9). Indeed, Garvey and Wu (2010) show that market orders benefit the most from higher trading speed. The literature also shows that greater speed of offset (i.e., how quickly trades are offset) is a fundamental aspect of trader discipline (Locke and Mann 2005). ${ }^{35}$ Therefore, the results show that subjects with higher testosterone levels possess greater trading discipline than subjects with lower testosterone levels. Note that for professional traders and aspiring average investors greater trading discipline is linked to future trading success (Locke and Mann 2005). Because traders can train to discipline themselves, such information will help them become more

\footnotetext{
${ }^{34}$ The Cognitive Reflection Test was developed by Frederick (2005). It measures the tendency to engage in deliberation and reflection to arrive at correct answers, rather than provide an intuitive and incorrect response.

35 Trading discipline is the tendency to cut losses short and let profits run. The opposite tendency is known as the disposition effect, in which traders hold on to losing positions for too long and sell winning positions too soon.
} 
accomplished traders. In particular, monitoring their levels of testosterone could help them ensure that they are achieving and maintaining discipline.

\subsubsection{Testosterone and Options Trading Performance}

Table 3.11 displays the relation between testosterone and trading performance. The results show that subjects with higher levels of testosterone achieve better risk adjusted performance (in terms of the coefficient of variation) than subjects with lower levels of testosterone. Note that subjects with high testosterone levels achieve superior risk adjusted performance on options contracts where the average subject realized large losses, namely $24 \mathrm{P}$ and $26 \mathrm{C}$ (Table 3.7). Furthermore, both of these contracts expired out-of-the-money. These facts show that a high level of testosterone provides a competitive advantage in predicting negative financial outcomes. Indeed, medical studies show that the amygdala, which is a main target of testosterone in the brain, is associated with the anticipation of negative outcomes (Schulkin et al. 1994). Additionally, the coefficient of variation is better at predicting risk sensitivity (i.e., the probability of choosing a riskier or less risky option) than normative risk

measures, such as variance (Weber et al. 2004). Therefore, the results support Coates and Herbert's (2008) hypothesis that testosterone influences trading profits via the role that it plays in setting risk preferences.

\subsection{Conclusions}

In this study, I analyzed the relation of testosterone to financial choices and performance during a portfolio formation task and an options trading task. I purposely selected these tasks to distinguish between carefully thought-out, long- 
term financial choices (i.e., investment choices) and high-speed, stressful financial choices (i.e., trading choices). Coates et al. (2009) postulate that the role of testosterone on financial decisions and outcome depends on the time pressures associated with financial tasks. However, the literature has not answered how testosterone's influence on financial decision making is different under investment and trading tasks. To my knowledge, this is the first study to address this distinction.

Overall, the results of this study show that under investment tasks, testosterone plays a crucial role during initial asset allocation decisions. Testosterone plays a lesser role during subsequent rebalancing choices, which are primarily driven by the memory of recent past performance. These results show that first-time investors can benefit from understanding the effect of testosterone on their financial decisions. Similarly, the results can be helpful to professional financial planners to better understand the financial choices of firsttime investors.

With the advent of online discount brokerage services, many naïve investors are making quick trading decisions similar to the decisions made during the options trading task. The results of this study show that testosterone is significantly related to many aspects of trading, including the choice of security, order type, and time related preferences. Additionally, risk adjusted performance is positively correlated with testosterone levels. This is good news for those who worry about the effects of "testosterone poisoning" on financial markets. Contrary to the popular notion that testosterone leads to excessive risk taking and 
suboptimal financial decisions, I find that subjects with relatively high testosterone levels display qualities of profitable traders, such as discipline and choice deliberation under pressure. Therefore, this study strongly advocates for the continuation of research on the role of testosterone on financial choices and outcomes. It is my view that financial markets could be made safer and more efficient if individual market players learn to harness the influence of testosterone on their financial decision making. 
Table 3.1

\section{Asset Allocation Choices}

The table displays the average proportion of funds allocated into each of the five risky securities (HOME, GROW, BOND, MINE, MMKT), or left uninvested (CASH) during DIV1 and DIV2. The historical return and volatility of each security is displayed below its name. Volatility is displayed in parentheses

\begin{tabular}{|cccc|ccc|} 
& HOME & GROW & BOND & MINE & MMKT & CASH \\
& $*$ & $*$ & $*$ & $*$ & & $* * *$ \\
& $\mathbf{8 . 5} \%$ & $\mathbf{1 3 \%}$ & $\mathbf{4 . 5 \%}$ & $\mathbf{6 . 0 \%}$ & $\mathbf{2 . 0 \%}$ & $\mathbf{0 \%}$ \\
& $\mathbf{( 1 8 \% )}$ & $\mathbf{( 3 0 \% )}$ & $\mathbf{( 8 \% )}$ & $\mathbf{( 1 6 \% )}$ & $\mathbf{( 1 \% )}$ & $\mathbf{( 0 \% )}$ \\
\hline DIV1 & $22.9 \%$ & $23.7 \%$ & $12.7 \%$ & $13.7 \%$ & $7.0 \%$ & $20.0 \%$ \\
& $(17.5 \%)$ & $(14.1 \%)$ & $(9.4 \%)$ & $(11.3 \%)$ & $(8.6 \%)$ & $(29.4 \%)$ \\
\hline DIV2 & $26.3 \%$ & $27.4 \%$ & $15.2 \%$ & $17.3 \%$ & $6.9 \%$ & $6.9 \%$ \\
& $(16.1 \%)$ & $(13.8 \%)$ & $(11.8 \%)$ & $(11.2 \%)$ & $(8.9 \%)$ & $(19.4 \%)$ \\
\hline
\end{tabular}

Notes: Mean differences between DIV1 and DIV2 are tested via a paired twosample t-test. Significance is displayed at the $10 \%\left(^{*}\right), 5 \%\left(^{* *}\right)$ and $1 \%\left(^{* * *}\right)$ levels. 


\section{Table 3.2}

\section{Portfolio Return and Volatility}

The table displays the expected and realized return and volatility of portfolios during DIV1 and DIV2. Standard deviations are shown in parentheses.

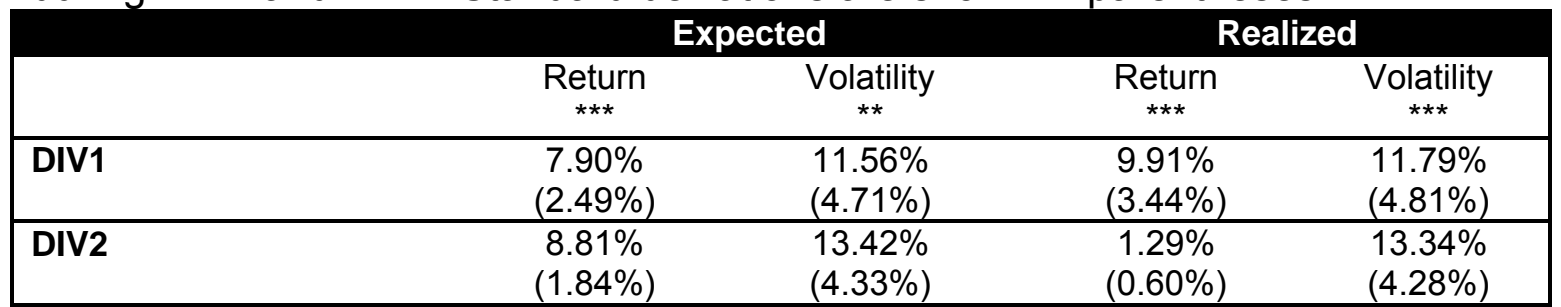

Notes: Mean differences between DIV1 and DIV2 are tested via paired twosample t-test. Significance is displayed at the 10\% (*), 5\% (**) and $1 \%\left({ }^{* \star *}\right)$ levels. 


\section{Table 3.3}

\section{Portfolio Performance}

The table shows various measures of expected and realized portfolio risk and return. The percentage shortfall represents the probability of falling short of reaching the investment objective of achieving a final portfolio value of $\$ 1.5$ million over 20 years. The final wealth is the portfolio value at the end of the investment period. The total portfolio return is the holding period return over the 20 years, computed from an initial wealth of $\$ 500,000$. The abnormal return is the yearly return in excess of the expected return predicted by the historical annual return of the securities. The Sharpe ratio is the difference between the annual return and the risk-free rate (which is zero for DIV1 and DIV2), divided by the return volatility. The value-at-risk $(\mathrm{VaR})$ is the maximum loss expected over one year, with a $95 \%$ confidence interval. Standard deviations are shown in parentheses.

\begin{tabular}{|lrr|} 
& DIV1 & DIV2 \\
\hline Shortfall $* * *$ & $51.53 \%$ & $45.45 \%$ \\
& $(18.09 \%)$ & $(12.60 \%)$ \\
\hline Final Wealth (Realized) *** & $\$ 3,799,634$ & $\$ 650,399$ \\
& $(\$ 1,653,338)$ & $(\$ 77,946)$ \\
\hline Final Wealth (Expected) *** & $\$ 2,478,087$ & $\$ 2,831,813$ \\
& $(\$ 835,455)$ & $(\$ 788,247)$ \\
\hline Total Return (Realized) *** $^{*}$ & $659.93 \%$ & $30.08 \%$ \\
& $(330.67 \%)$ & $(15.59 \%)$ \\
\hline Total Return (Expected) *** & $395.62 \%$ & $466.36 \%$ \\
& $(167.09 \%)$ & $(157.65 \%)$ \\
\hline Abnormal Return (Realized) *** & $3.35 \%$ & $-6.37 \%$ \\
& $(1.53 \%)$ & $(2.18 \%)$ \\
\hline Abnormal Return (Expected) * & $1.34 \%$ & $1.55 \%$ \\
& $(0.68 \%)$ & $(0.55 \%)$ \\
\hline Sharpe (Realized) *** & 0.88 & 0.11 \\
& $(0.18)$ & $(0.07)$ \\
\hline Sharpe (Expected) * & 0.74 & 0.70 \\
& $(0.15)$ & $(0.18)$ \\
\hline VaR *** & $-12.46 \%$ & $-14.43 \%$ \\
& $(5.33 \%)$ & $(5.17 \%)$ \\
\hline
\end{tabular}

Notes: Mean differences between DIV1 and DIV2 are tested via paired twosample t-test. Significance is displayed at the 10\% (*), 5\% (**) and $1 \%\left(^{* \star *}\right)$ levels. 
Table 3.4

\section{Testosterone Relation to Asset Allocation}

The table displays the coefficients for three regression models, where the proportion of funds allocated to each security or left uninvested (CASH) is the dependent variable. The proportion of funds allocated to Low Risk (CASH and MMKT), Medium Risk (BOND and MINE), and High Risk (GROW and HOME) is also analyzed. An additional fourth model is performed on DIV2 variables to control for the level of performance during DIV1. All tables only display the regression models with significant coefficients.

\section{Panel A: DIV1}

\begin{tabular}{|c|c|c|c|c|c|}
\hline & Model & Linear Sal-T & Quadratic Sal-T & Gender & Reg. $R^{2}$ \\
\hline \multirow[t]{2}{*}{ GROW } & 1 & ${ }^{* *}-47.19$ & & & 0.12 \\
\hline & 2 & *-39.69 & -14.89 & & 0.13 \\
\hline \multirow[t]{3}{*}{ BOND } & 1 & ${ }^{*}-27.67$ & & & 0.09 \\
\hline & 2 & ${ }^{*}-28.66$ & 1.96 & & 0.09 \\
\hline & 3 & ${ }^{*}-29.26$ & 2.18 & -35.49 & 0.12 \\
\hline \multirow[t]{3}{*}{ LOW RISK } & 1 & ${ }^{*} 77.43$ & & & 0.08 \\
\hline & 2 & ${ }^{*} 82.83$ & -10.72 & & 0.08 \\
\hline & 3 & ${ }^{*} 81.06$ & -10.07 & -103.87 & 0.11 \\
\hline \multirow[t]{3}{*}{ HIGH RISK } & 1 & ** -66.86 & & & 0.10 \\
\hline & 2 & *-66.27 & -1.16 & & 0.10 \\
\hline & 3 & ${ }^{*}-64.12$ & -1.95 & *126.78 & 0.18 \\
\hline
\end{tabular}

Panel B: DIV2

\begin{tabular}{|c|c|c|c|c|c|c|}
\hline & Model & Linear Sal-T & Quad. Sal-T & Gender & DIV1 NLV & Reg. $R^{2}$ \\
\hline BOND & 3 & ${ }^{*}-31.26$ & ${ }^{*} 24.89$ & $* *-108.76$ & & 0.28 \\
\hline MINE & 1 & $\star * 41.76$ & & & & 0.14 \\
\hline & 2 & **47.57 & -12.04 & & & 0.15 \\
\hline & 3 & ${ }^{* *} 47.63$ & -11.88 & -24.35 & & 0.17 \\
\hline & 4 & $* * * 57.53$ & -4.80 & -38.73 & **39.39 & 0.28 \\
\hline CASH & 4 & -39.06 & ${ }^{*}-38.12$ & *105.36 & ${ }^{* * *}-128.93$ & 0.41 \\
\hline
\end{tabular}

Notes: The explanatory variables are given by the model as follows:

Model 1 has salivary testosterone (Sal-T) as the single explanatory variable.

Model 2 introduces a quadratic term.

Model 3 introduces a dummy variable for gender (Female $=0$, Male $=1)$

Model 4 (DIV2 only) introduces the standardized Net Liquidation Value (NLV) of

DIV1 to control for DIV1 performance.

Regression coefficients are multiplied by 1,000 to show them more clearly.

Sample regression $R$-squared is displayed in the last column.

Significance is displayed at the $10 \%\left(^{*}\right), 5 \%\left(^{* *}\right)$ and $1 \%\left(^{* \star *}\right)$ levels. 


\section{Table 3.5}

\section{Relation of Testosterone to Expected Portfolio Performance}

The table displays the coefficients for three regression models, where the dependent variable is a measure of expected portfolio performance. These measures, which are computed via Monte Carlo simulations, include the portfolio annual return, annual volatility, value at risk $(\mathrm{VaR})$, final wealth, Sharpe ratio, percent shortfall and abnormal return.

\begin{tabular}{|c|c|c|c|c|c|}
\hline & Model & Linear Sal-T & Quadratic Sal-T & Gender & Reg. $\mathbf{R}^{2}$ \\
\hline \multirow{2}{*}{ Return } & 1 & ${ }^{* *}-8.34$ & & & 0.11 \\
\hline & 2 & ${ }^{*}-7.09$ & -2.48 & & 0.13 \\
\hline \multirow[t]{3}{*}{ Volatility } & 1 & ${ }^{* *}-15.75$ & & & 0.11 \\
\hline & 2 & ${ }^{*}-14.86$ & -1.78 & & 0.12 \\
\hline & 3 & ${ }^{*}-14.51$ & -1.90 & 20.16 & 0.16 \\
\hline \multirow[t]{3}{*}{ VaR } & 1 & **18.16 & & & 0.12 \\
\hline & 2 & ${ }^{*} 16.78$ & 2.73 & & 0.12 \\
\hline & 3 & ${ }^{*} 16.39$ & 2.88 & -22.99 & 0.16 \\
\hline \multirow[t]{3}{*}{ Final Wealth } & 1 & **-270,934 & & & 0.11 \\
\hline & 2 & ${ }^{*}-249,023$ & $-43,506$ & & 0.11 \\
\hline & 3 & ${ }^{*}-244,798$ & $-45,050$ & 248,908 & 0.13 \\
\hline Sharpe ratio & 1 & ${ }^{*} 54.50$ & & & 0.09 \\
\hline Shortfall & 1 & *50.57 & & & 0.08 \\
\hline \multirow{2}{*}{ Abn. Return } & 2 & 0.55 & ${ }^{* *}-2.27$ & & 0.17 \\
\hline & 3 & 0.49 & ** -2.25 & *-3.74 & 0.23 \\
\hline
\end{tabular}

Notes: The explanatory variables are given by the model as such:

Model 1 has salivary testosterone (Sal-T) as the single explanatory variable.

Model 2 introduces a quadratic term.

Model 3 introduces a dummy variable for gender (Female $=0$, Male $=1)$

Model 4 (DIV2 only) introduces the standardized Net Liquidation Value (NLV) of

DIV1 to control for DIV1 performance.

Regression coefficients (except those of Final Wealth) are multiplied by 1,000 to show them more clearly.

Sample regression $R$-squared is displayed in the last column.

Significance is displayed at the $10 \%\left(^{*}\right), 5 \%\left(^{* *}\right)$ and $1 \%\left(^{* \star *}\right)$ levels. 


\section{Table 3.6}

\section{Testosterone Relation to Portfolio Efficiency}

The table displays the coefficients for three regression models, where the dependent variable is the horizontal distance to the efficient frontier. This horizontal distance, labeled "SDiff" is the difference between the portfolio standard deviation, and the standard deviation of the efficient portfolio of same expected return.

\begin{tabular}{|ccrrrr|} 
& Model & Linear Sal-T & Quadratic Sal-T & Gender & Reg. $\mathbf{R}^{2}$ \\
\hline DIV1 SDiff & 2 & -0.75 & ${ }^{*}-2.73$ & & 0.11 \\
\hline & 3 & -0.74 & ${ }^{*}-2.74$ & 0.62 & 0.11 \\
\hline DIV2 SDiff & 1 & ${ }^{*}-2.84$ & & & 0.09 \\
\hline & 3 & ${ }^{*}-2.53$ & -0.71 & ${ }^{*} 5.67$ & 0.18 \\
\hline
\end{tabular}

Notes: The explanatory variables are given by the model as follows:

Model 1 has salivary testosterone (Sal-T) as the single explanatory variable. Model 2 introduces a quadratic term.

Model 3 introduces a dummy variable for gender (Female $=0$, Male $=1)$

Model 4 (DIV2 only) introduces the standardized Net Liquidation Value (NLV) of DIV1 to control for DIV1 performance.

Regression coefficients are multiplied by 1,000 to show them more clearly. Sample regression $R$-squared is displayed in the last column.

Significance is displayed at the $10 \%\left(^{*}\right), 5 \%\left(^{* *}\right)$ and $1 \%\left(^{* \star *}\right)$ levels. 
Table 3.7

\section{Options Trading Summary Performance}

The table displays several measures of performance during the options trading task for each of the four tradable option contracts and for the total portfolio. The name of the contract is the strike price (i.e., 24, 25, or 26) followed by the letter "P," for put, or the letter "C," for call. From top to bottom of column 1, the measures analyzed are: the realized profit or loss after trading stops (P\&L), the standard deviation of P\&L (SD P\&L), the average number of orders submitted (Avg. No. Orders), the average order size submitted (Avg. Order Size), the total number of market orders submitted (No. Market), the total number of limit orders submitted (No. Limit), the total number of buy orders (No. Buys), and the total number of sell orders (No. Sells). Where appropriate, standard deviations are displayed in parentheses.

\begin{tabular}{|lrrrrr|}
\hline P\&L & $\mathbf{2 4 P}$ & $\mathbf{2 5 P}$ & $\mathbf{2 5 C}$ & $\mathbf{2 6 C}$ & Total \\
& -660 & $-6,892$ & 14,673 & $-2,316$ & 4,805 \\
& $(6814)$ & $(243,651)$ & $(803,518)$ & $(691,388)$ & $(1,345,916)$ \\
\hline SD P\&L & 1,697 & 63,284 & 151,573 & 126,181 & 297,613 \\
& $(2,956)$ & $(98,890)$ & $(201,594)$ & $(277,131)$ & $(497,800)$ \\
\hline Avg. No. Orders & 4 & 4 & 8 & 5 & 21 \\
& $(7)$ & $(4)$ & $(12)$ & $(8)$ & $(23)$ \\
\hline Avg. Order Size & 47 & 58 & 65 & 60 & 77 \\
& $(49)$ & $(47)$ & $(43)$ & $(46)$ & $(34)$ \\
\hline No. Market & 130 & 133 & 180 & 138 & 581 \\
\hline No. Limit & 28 & 46 & 149 & 97 & 130 \\
\hline No. Buys & 124 & 136 & 226 & 139 & 625 \\
\hline No. Sells & 34 & 43 & 103 & 96 & 276 \\
\hline No. Orders & 158 & 179 & 329 & 235 & 901 \\
\hline
\end{tabular}




\section{Table 3.8}

\section{Testosterone, Number of Orders, and the Decision to Buy or Sell}

The table displays the coefficients for three regression models, where the dependent variable is the buy, sell and overall (i.e. buy plus sell) number of orders submitted per contract type as a percentage of the total number of orders submitted. From top to bottom of column 1, the dependent variables are: the number of 25P orders, number of put orders (both 25P and 24P), number of orders for at-the-money options (i.e. those with strike price $\mathrm{K}=25$ ), number of $24 \mathrm{P}$ buy orders, and number of $26 \mathrm{C}$ sell orders.

\begin{tabular}{|lrrrrr|} 
& Model & Linear Sal-T & Quad. Sal-T & Gender & Reg. $\mathbf{R}^{2}$ \\
\hline 25P Orders & 2 & ${ }^{*} 53.73$ & -18.12 & & 0.07 \\
\hline & 3 & ${ }^{*} 53.61$ & -17.87 & -40.25 & 0.08 \\
\hline Put Orders & 1 & ${ }^{*} 52.98$ & & & 0.07 \\
\hline Call Orders & 1 & ${ }^{*}-52.98$ & & & 0.07 \\
\hline 25K Orders & 2 & 32.65 & ${ }^{*}-55.46$ & & 0.07 \\
\hline & 3 & 32.78 & ${ }^{*}-55.71$ & 40.77 & 0.08 \\
\hline 24P Buys & 3 & 16.57 & ${ }^{*} 22.83$ & ${ }^{* *}-86.05$ & 0.25 \\
\hline 26C Sells & 1 & ${ }^{*}-30.02$ & & & 0.07 \\
\hline & 2 & ${ }^{* *}-37.16$ & 14.74 & & 0.09 \\
\hline & 3 & ${ }^{* *}-36.99$ & 14.39 & 56.96 & 0.15 \\
\hline
\end{tabular}

Notes: The explanatory variables are given by the model as follows:

Model 1 has salivary testosterone (Sal-T) as the single explanatory variable.

Model 2 introduces a quadratic term.

Model 3 introduces a dummy variable for gender (Female $=0$, Male $=1$ )

Sample regression $R^{2}$ is displayed in the last column.

Regression coefficients are multiplied by 1,000.

Significance is displayed at the $10 \%\left({ }^{*}\right), 5 \%\left({ }^{\star *}\right)$, and $1 \%\left(^{(\star \star}\right)$ levels. 


\section{Table 3.9}

\section{Testosterone and the Choice of Limit or Market Orders}

The table displays the coefficients for three regression models, where the dependent variable is the number of limit (Panel A) and market (Panel B) orders submitted for each option contract as a proportion of the total number of orders submitted by the subject. Additionally, "Limit Orders" and "Market Orders" (the last variable of each panel) is the total proportion of limit and market orders submitted, respectively.

Panel A: Limit Orders

\begin{tabular}{|c|c|c|c|c|c|}
\hline & Model & Linear Sal-T & Quadratic Sal-T & Gender & $\operatorname{Reg} R^{2}$ \\
\hline \multirow{3}{*}{ 24P Limit } & 1 & ** -30.27 & & & 0.12 \\
\hline & 2 & $* * *-38.78$ & 17.58 & & 0.18 \\
\hline & 3 & ${ }^{* * *}-38.76$ & 17.53 & 8.22 & 0.18 \\
\hline \multirow[t]{3}{*}{ 25C Limit } & 1 & ${ }^{* *}-75.15$ & & & 0.12 \\
\hline & 2 & ${ }^{*}-66.14$ & -18.60 & & 0.13 \\
\hline & 3 & ${ }^{*}-65.95$ & -18.98 & 62.09 & 0.15 \\
\hline \multirow[t]{3}{*}{ 26C Limit } & 1 & ${ }^{* * *}-78.85$ & & & 0.20 \\
\hline & 2 & ${ }^{* * *}-111.30$ & $* * * 66.98$ & & 0.40 \\
\hline & 3 & ***-111.02 & ${ }^{* * *} 66.41$ & ${ }^{* *} 94.21$ & 0.46 \\
\hline \multirow[t]{3}{*}{ Limit Orders } & 1 & ****-208.66 & & & 0.25 \\
\hline & 2 & ${ }^{* * *}-237.02$ & 58.54 & & 0.27 \\
\hline & 3 & $* * *-236.54$ & 57.56 & 161.84 & 0.31 \\
\hline
\end{tabular}

Panel B: Market Orders

\begin{tabular}{|rrrrrr|} 
& Model & Linear Sal-T & Quadratic Sal-T & Gender & Reg. $\mathbf{R}^{\mathbf{2}}$ \\
\hline 25P Market & 1 & ${ }^{*} 69.34$ & & & 0.14 \\
\hline & 2 & ${ }^{*} 674.52$ & -10.70 & & 0.14 \\
\hline & 3 & ${ }^{*} 74.41$ & -10.47 & -37.58 & 0.15 \\
\hline 26C Market & 1 & ${ }^{* *} 65.03$ & & & 0.11 \\
\hline & 2 & ${ }^{* *} 83.84$ & -38.84 & & 0.16 \\
\hline Market orders & 3 & ${ }^{* *} 83.80$ & -38.74 & -15.83 & 0.16 \\
\hline & 1 & ${ }^{* * *} 208.66$ & & & 0.25 \\
\hline & 2 & ${ }^{* * *} 237.02$ & -58.54 & & 0.27 \\
\hline
\end{tabular}

Notes: The explanatory variables are given by the model as follows:

Model 1 has salivary testosterone (Sal-T) as the single explanatory variable.

Model 2 introduces a quadratic term.

Model 3 introduces a dummy variable for gender (Female $=0$, Male $=1$ )

Sample regression $R^{2}$ is displayed in the last column.

Regression coefficients are multiplied by 1,000.

Significance is displayed at the $10 \%\left(^{(}\right), 5 \%\left(^{(*)}\right.$, and $1 \%\left(^{(\star \star}\right)$ levels. 
Table 3.10

\section{Testosterone and Trading Time Preferences}

The table displays the coefficients for three regression models, where the dependent variables are, from top to bottom of column 1: the time (in seconds) at which the first order was submitted, the time at which the last order was submitted, and the time difference between the last and first order submission (Trading Time).

\begin{tabular}{|lrrrrr|}
\hline & Model & Linear Sal-T & Quadratic Sal-T & Gender & Reg. $\mathbf{R}^{\mathbf{2}}$ \\
\hline First Order & 1 & ${ }^{* *} 15.34$ & & & 0.11 \\
\hline & 2 & ${ }^{* *} 16.56$ & -2.53 & & 0.12 \\
\hline Last Order & 3 & ${ }^{* *} 16.61$ & -2.62 & 14.87 & 0.14 \\
\hline & 2 & ${ }^{*}-12.16$ & 6.32 & & 0.10 \\
\hline Trading Time & 3 & ${ }^{*}-12.16$ & 6.31 & 1.66 & 0.10 \\
\hline & 1 & ${ }^{* * *}-24.44$ & & & 0.16 \\
\hline & 2 & ${ }^{* * *}-28.73$ & 8.85 & & 0.19 \\
\hline
\end{tabular}

Notes: The explanatory variables are given by the model as follows:

Model 1 has salivary testosterone (Sal-T) as the single explanatory variable.

Model 2 introduces a quadratic term.

Model 3 introduces a dummy variable for gender (Female $=0$, Male $=1)$

Sample regression $R 2$ is displayed in the last column.

Significance is displayed at the $10 \%\left(^{*}\right), 5 \%\left(^{(*)}\right.$, and $1 \%\left(^{(* *)}\right.$ levels. 
Table 3.11

Testosterone and Options Trading Performance

The table displays the coefficients for three regression models, where the dependent variables are measures of trading performance on individual option contracts. These are the final profit and loss value (P\&L), the coefficient of variation (CV), standard deviation of net liquidity value (SD NLV), and the range of net liquidity value.

\begin{tabular}{|c|c|c|c|c|c|}
\hline & Model & Linear Sal-T & Quadratic Sal-T & Gender & Reg. $R^{2}$ \\
\hline \multirow{3}{*}{ P\&L 24P } & 1 & ${ }^{* *}-2,164$ & & & 0.10 \\
\hline & 2 & ${ }^{*}-1,937$ & -467 & & 0.10 \\
\hline & 3 & ${ }^{*}-1,931$ & -480 & 1,969 & 0.12 \\
\hline \multirow[t]{3}{*}{ CV 24P } & 1 & ${ }^{\star \star} 0.12$ & & & 0.14 \\
\hline & 2 & ${ }^{* *} 0.13$ & -0.01 & & $\overline{0.14}$ \\
\hline & 3 & ${ }^{* \star} 0.13$ & -0.01 & * -0.18 & 0.20 \\
\hline \multirow[t]{3}{*}{ CV 26C } & 1 & ${ }^{*} 0.10$ & & & 0.08 \\
\hline & 2 & ${ }^{* *} 0.13$ & -0.06 & & 0.12 \\
\hline & 3 & ${ }^{* *} 0.13$ & -0.06 & -0.09 & 0.14 \\
\hline \multirow[t]{2}{*}{ SD NLV 25C } & 2 & 9,688 & ** $-54,044$ & & 0.10 \\
\hline & 3 & 9,798 & ${ }^{* *}-54,270$ & 37028 & 0.11 \\
\hline \multirow[t]{2}{*}{ Range NLV 25C } & 2 & 9,866 & ${ }^{* *}-177,483$ & & 0.10 \\
\hline & 3 & 10,150 & ${ }^{*}-178,069$ & 95,932 & 0.11 \\
\hline
\end{tabular}

Notes: The explanatory variables are given by the model as follows:

Model 1 has salivary testosterone (Sal-T) as the single explanatory variable.

Model 2 introduces a quadratic term.

Model 3 introduces a dummy variable for gender (Female=0, Male=1)

Sample regression $R$-squared is displayed in the last column.

Significance is displayed at the $10 \%\left(^{*}\right), 5 \%\left(^{* \star}\right)$, and $1 \%\left(^{* \star *}\right)$ levels. 
Figure 3.1

Option Price Path

The figure shows the price path followed by each option contract during the five minutes of trading. Time is expressed in seconds. The price displayed is the closing price for each second.

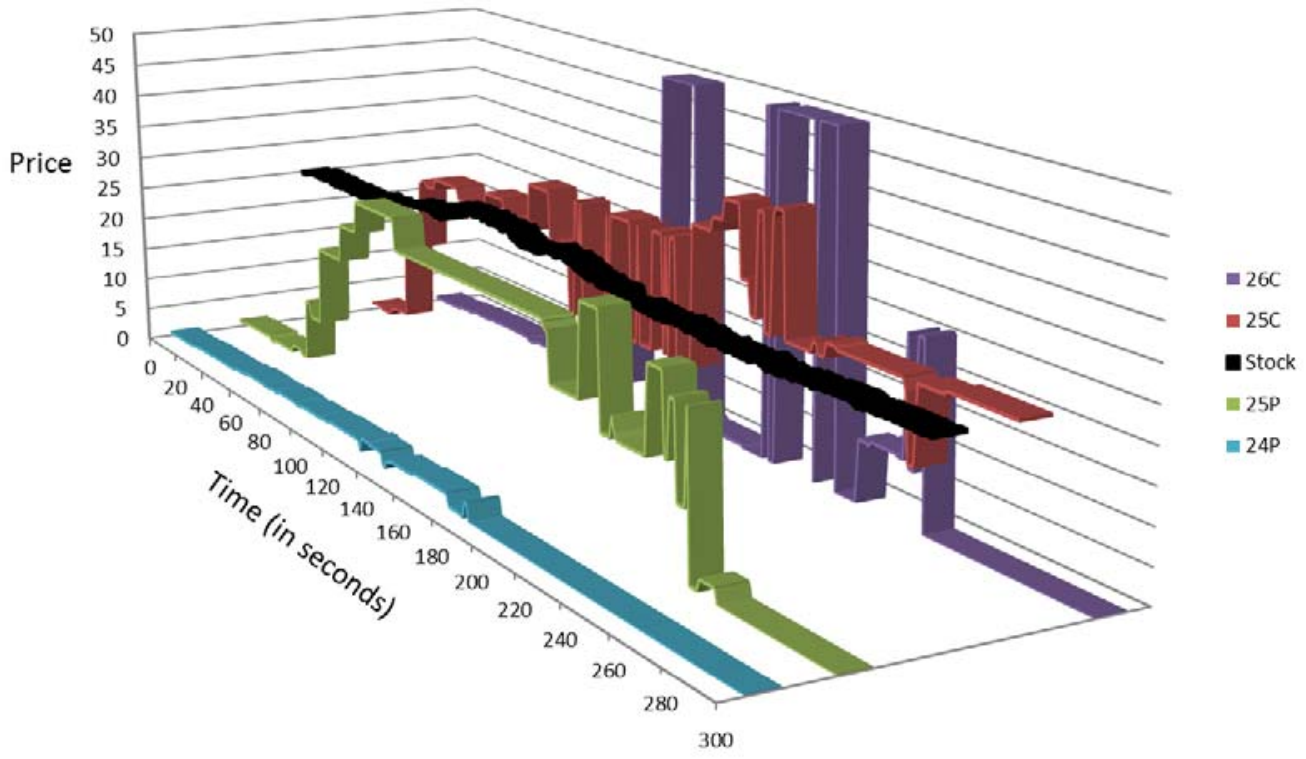




\section{CHAPTER 4: STRESS AND FINANCIAL CHOICES}

\subsection{Introduction}

In this essay, I examine the relation between cortisol levels (the biological barometer of stress levels) and financial decision making. ${ }^{36}$ It is widely held that stress is rampant among finance professionals, including traders and fund managers, and a clear connection exists between stress and cognitive processes. Yet the specific role of stress on financial choices and outcomes has only recently been addressed, and then only by a limited number of studies (the literature is summarized below). The present study represents one of the first comprehensive efforts to understand the role of stress on financial decision making. Specifically, this study is important to the literature because it 1) analyzes the role of stress under fundamentally different financial tasks (i.e., investing and trading), 2) considers a wide variety of investment choices, 3) examines both male and female subjects, and 4) takes place in a controlled environment, avoiding the confounds associated with field studies.

The present study differs from the financial literature in several important ways. First, it is one of the few studies in finance to measure the stress level of a financial task using its closest biological correlate (i.e., the individual's cortisol level). This is extremely important because stress is notoriously difficult to quantify objectively by other means (e.g., self-reports, psychological tests, etc.). Therefore, the measure of stress level used in this study is unbiased from

\footnotetext{
${ }^{36}$ In humans, cortisol is secreted by the adrenal glands into the blood in response to stressful stimuli. Therefore, the circulating level of cortisol (versus cortisol that is stored in the adrenal glands) is the primary biological marker of stress.
} 
personal observations. Second, it is the only study (known to the investigator) to examine the role of stress on both investment and trading decisions made by the same group of individuals. As such, it avoids many of the problems associated with fairly comparing the results of subjects across different tasks. Finally, this study employs realistic financial tasks with real world parallels. The majority of other studies make use of economic games, like the IGT and the Ultimatum Game, that have few real world analogs. Therefore, the results of the present study are more relatable than those of other studies.

Overall, the results show that the relation of stress to financial decisions and outcomes is distinct for investing and trading tasks. During investing decision making, the higher the stress level, the more subjects tend to avoid high-risk securities, and the more they tend to prefer low-risk securities. Ultimately, investment performance is optimal under moderate levels of stress. Alternatively, during trading decision making, the influence of stress on risk-taking behavior is modulated by the stress appraisal process -in particular, whether an optimistic or pessimistic view about future stock prices is held. Ultimately, trading performance is optimal under either high or low levels of stress. The resultant implications for financial decision makers, as well as the relevance for the finance literature, are discussed.

Financial decisions are stressful, and stressful stimuli cause the body to secrete cortisol into the bloodstream. Upon reaching the brain, cortisol plays a key role in the regulation of the cognitive processes necessary to deal with the financial task involved. The strength of the stress response depends primarily 
upon the amount of cortisol released and the brain areas involved. The more potent the stimuli, the greater the amount of cortisol released, and consequently the greater its influence on the brain. Therefore, cortisol, and therefore stress, has a direct influence on financial decision making.

Different types of financial tasks require different kinds of financial decisions. Such decisions activate different areas of the brain and employ different cognitive processes. Therefore, we can hypothesize that the role of stress on financial decision making may be related to the type of financial task being performed. For example, short-term investment decisions (i.e., trading), such as decisions made by day traders, require high alertness, responsiveness, and quick problem solving. Alternatively, long-term investment decisions (i.e., investing), such as retirement planning decisions, can involve unhurried deliberation, introspection, and scenario analysis. This study examines the role of stress under both short-term trading and long-term investing tasks in order to capture any differences resulting from the different cognitive processes involved during each task.

Because of the limited body of work examining the role of stress on financial decision making, it is not clear how stress and financial performance are related. A widely accepted hypothesis in the health sciences (Conrad et al. 1999) shows an inverted $\mathrm{U}$-shape relation between stress levels and cognitive function (sometimes known as the Yerkes-Dodson curve, in honor of the psychologists who first described it in 1908). According to this model, there is an optimal level of stress (neither too low nor too high) that maximizes performance on cognitive 
and behavioral tasks. Maximizing performance on financial tasks is of outmost consequence for finance professionals. However, it is not known whether performance on financial tasks also exhibits an inverted U-shaped relation with stress levels. Therefore, this essay examines the relation of stress to trading and investing performance.

In addition to examining financial performance, or outcomes, this study also examines the relation of stress to decision making during investing and trading tasks, including the choice of asset allocation preferences, volumes traded, and timing of trades. To the best of my knowledge, this is the first study to examine these aspects of financial decision making. Therefore, this essay provides important information that could help finance professionals identify and deploy the profit-enhancing qualities of "good" stress, as well as cautions about excessive stress.

\subsection{Literature Review}

Occupational stress is particularly high among finance professionals (Jones et al. 2003), and it can result in behavioral problems, such as mental disorders (Dias 1990) and elevated alcohol consumption (Kahn and Cooper 1990). Oberlechner and Nimgade (2005) surveyed a large sample of foreign exchange traders $(n=326)$, showing that "pressure to achieve the profit goal" is reportedly the greatest source of stress, followed by "long working hours" and "time pressure." These results are not unexpected, but they do not provide finance professionals with useful solutions. For one, the aforementioned sources of stress are part of the job requirements for traders; therefore they cannot be 
mitigated. Additionally, self-reported information fails to address stress sources that are outside of an individual's awareness. For example, Lo and Repin (2002) show that traders exhibit changes in heart rate, blood pressure, and skin conductance concurrently with transient market events. Such instinctual physiological responses to financial stimuli are consistent with the experience of stress. Therefore, biological markers of stress, such as cortisol levels, provide a superior method to study the relation between stress and financial decision making.

Salivary cortisol (Sal-CO) is the preferred method used by researchers for measuring circulating levels of cortisol in the body, due to the noninvasiveness of this approach. Coates and Herbert (2008) examine the relation of Sal-CO to financial performance in a small sample of male floor traders $(n=17)$. The authors find no evidence that cortisol levels are related to trading gains or losses (P\&L). Instead, they show that cortisol levels possess a significant positive linear relation to standard measures of risk, such as the variance of profits and the volatility of the market. In addition to the standard measures of risk, the present study considers various other risk measures and risky choices. I choose alternative measures because standard measures of risk are suboptimal predictors of risk preferences (Weber et al. 2004). Additionally, studies show the opposite relation between stress and risk taking as described by Coates and Herbert. For example, van Honk et al. (2003) show that cortisol levels correlate positively with risk aversion (instead of risk taking) in subjects playing the lowa 
Gambling Task (IGT).Therefore, one of the main objectives of the present study is to resolve such contradictory findings.

Due to the embryonic state of the literature on this subject, it is premature to draw any conclusions from Coates and Herbert (2008). However, their study is the closest available for comparison to the study here, although my study differs in the following key respects: I analyze the relation of cortisol to financial decisions made during trading and investing tasks. Moreover, I use a sample of male and female naïve financial decision makers, whereas Coates and Herbert employ a sample of male professional traders. Therefore, the results of the present study are easier to apply to a broader range of investors than the results provided by Coates and Herbert. Finally, this study is free of trader selection bias, as I do not exclude subjects on the basis of their (lack of) trading skills. Such bias occurs in the Coates and Herbert study because even the least experienced professional trader is carefully selected from a large pool of applicants on his/her merit as a "good" trader. ${ }^{37}$ Therefore, individual professional traders should be able to cope the best with trading-related stress. Also note that the lack of a relation between cortisol levels and trader P\&L levels in the Coates and Herbert sample could be the result of the superior stress-coping skills of individuals in their sample.

\subsection{Methodology}

The participants and procedure used is described in Section 3.2, "Testosterone and Financial Choices." However, the current study concerns the

${ }^{37}$ It is common practice to put applicants through trading simulations and trial periods before hiring them as traders. 
role of stress on financial decision making, and therefore is concerned with salivary levels of cortisol (Sal-CO). As described in Section 3.2, saliva collection occurs after provoking stress in subjects and prior to the financial tasks. Therefore, the resulting stress level observed is a "before the fact" measure that cannot be attributed to the financial decision making process. That is, the results obtained in this study show the influence of stress on financial choices and outcome, and not the other way around.

The mean Sal-CO concentration in the sample is $5.48 \mathrm{nmol} / \mathrm{L}(\mathrm{SD}=3.07)$ in men and $8.55 \mathrm{nmol} / \mathrm{L}(\mathrm{SD}=8.47)$ in women. There is no benchmark to compare these levels, since the Sal-CO measurement (as with many other saliva measurements) is strongly related to the particular technique employed. Even studies that measure Sal-CO at the same time of day present significantly different Sal-CO concentrations. For example, Laudat et al. (1988) measure Sal$\mathrm{CO}$ at the same time of day as the present study. However, their sample exhibits a mean Sal-CO level of $15.5 \mathrm{nmol} / \mathrm{L}(\mathrm{SD}=0.8)$, which is much higher than the mean Sal-CO of subjects in the present study. In fact, the Laudat et al. study shows that subjects with adrenal insufficiency (abnormally low levels of cortisol) have a mean Sal-CO level of $7.5 \mathrm{nmol} / \mathrm{L}(\mathrm{SD}=0.4)$, which is more congruent with the results of this study. ${ }^{38}$ Due to these inconsistencies in the literature, raw levels of cortisol are standardized (converted to z-scores) in this study for all participants. The z-scores are used in all the analyses, making it easier for other

\footnotetext{
${ }^{38}$ Therefore, if I compared the Sal-CO from this study with theirs would show the subjects in this study suffer from abnormally low levels of cortisol.
} 
studies to compare their results to this research (as long as they too standardize raw cortisol levels).

\subsection{Results}

\subsubsection{Stress and Investment Asset Allocation Decisions}

The asset allocation decisions of subjects provide "before the fact" evidence of the role of stress on financial decision making during investment tasks. Table 4.1 displays the significant relations of stress to asset allocation decisions in the first portfolio-formation task (DIV1) in Panel A, and the second portfolio-formation task (i.e., the rebalancing task, DIV2) in Panel B. ${ }^{39}$ Overall, the results show that current levels of stress (i.e., Sal-CO) affects investment allocation preferences (i.e., what people invest in). Furthermore, whether allocation choices are made for the first time or subsequent times is important. In other words, the influence of stress on first-time investment choices is different than on subsequent choices. This is because subjects allow the memory of recent past performance to influence subsequent investment choices. Therefore, the influence of stress on reallocation choices is changed by the influence of the recent past performance.

Specifically, Panel A of Table 4.1 shows that during initial portfolio formation, a higher stress level (i.e., Sal-CO) is related to a higher allocation to low-risk securities, and a lower allocation to high-risk securities. A higher proportion of funds not invested in risky securities (i.e., CASH) is also related

\footnotetext{
39 Only regression models with significant testosterone coefficients are displayed. Although adding explanatory variables changed the significance of individual variables, the sample Rsquared remains the same.
} 
positively to Sal-CO. These results are consistent with van Honk et al. (2003), who find that Sal-CO is correlated with risk aversion in the IGT. Therefore, the results show that stress plays an important role during initial investment decisions involving how much risk to undertake (or how much risk can be tolerated). Specifically, the higher the stress level, the more subjects tend to avoid high-risk securities, and the more they tend to prefer low-risk securities. Medical studies have addressed the mechanisms by which high stress can lead to risk aversion. In particular, sustained exposure to high cortisol levels can lead to anatomical changes in a primal part of the brain that deals with emotional responses (i.e., the amygdala), causing individuals to respond to stress with fear, anxiety (Davis 1992), and chronic anticipation of negative events (Schulkin et al. 1994). Therefore, the preferential allocation of funds to low-risk securities in highrisk subjects could be the result of amygdala overstimulation, which mutes the ability to tolerate uncertainty or willingness to accept uncertainty.

Table 4.1, Panel B shows that cortisol is involved with a shift in attitude towards risk during repeated exposure to the asset allocation task. That is, during DIV2 subjects with different cortisol levels revise their allocation choices in the low risk MMKT security. Specifically, subjects with low and high cortisol levels allocate lower amounts of funds to MMTK than subjects with intermediate stress levels. These results are consistent with performance optimization under moderate levels of stress, as described by the inverted U-shaped YerkesDodson curve. In fact, the results on investment performance (discussed later) show that subjects with intermediate stress levels achieve higher abnormal return 
than low and high-stress subjects. Therefore, the results show that subjects with moderate levels of stress learn from their recent past performance (i.e., the performance on DIV1) to make better allocation decisions during subsequent investment tasks (i.e., generating neither too little nor too much risk).

The reason why some subjects learn to make better allocation decisions after DIV1, whereas others do not make more optimal decisions, could be related to the ability to adapt to stressful tasks after repeated exposure. Medical studies show that repeated exposure to stressful stimulation results in attenuation of the stress response in some individuals, but not in others. For example, Kirschbaum et al. (1995) subject a sample of healthy male participants to a brief public speaking task once per day for five days. The study shows that while Sal-CO is high during the first day, it declines in some subjects during the subsequent days, but remains elevated in other subjects throughout the entire trial. The study also shows that subjects who are unable to habituate their stress response have characteristically low levels of self-esteem. Therefore, subjects who exhibit stress habituation after DIV1 could be better prepared to make rational asset allocation decisions during DIV2. Additionally, their study shows that subjects unable to habituate their response to stress have identifying personality traits.

\subsubsection{Stress and Expected Investment Performance}

Expected portfolio performance is a direct consequence of asset allocation decisions. Therefore, the influence of stress on asset allocation decisions is reflected in the expected portfolio performance. Table 4.2 displays the relation of Sal-CO to measures of expected portfolio performance during 
DIV1 ${ }^{40}$ Some of the results are obvious given the relation between stress and asset allocation choices discussed in the previous section. For example, subjects with higher levels of stress invest in low-yield, low-risk securities, so naturally their portfolios are expected to have lower return and volatility than the portfolios of subjects with lower levels of stress. As a consequence, the chance of achieving the minimum required holding period return is also lower for highstress subjects. Such facts confirm what was already suspected (from the previous section, and the results of van Honk et al. 2003): high stress during initial portfolio creation results in risk averting choices, which results in portfolios with low return, low volatility and high shortfall. These results are particularly useful for first-time investors (or finance professionals who deal with first-time investors), because it shows that under duress they could create portfolios that do not fulfill their future expected consumption needs.

Other results in Table 4.2 are not forgone conclusions from the previous section (i.e., they are less obvious given the asset allocation results). For example, the greater the Sal-CO, the higher the Sharpe ratio and VaR values. ${ }^{41}$ That is, subjects with greater levels of stress create portfolios with higher expected return-to-volatility ratios and higher expected loss under "extreme"

\footnotetext{
${ }^{40}$ As mentioned in the previous section, subjects allow their DIV1 performance to significantly influence their decisions during DIV2. As a result, the influence of stress on rebalancing performance is masked by the powerful influence of the memory of recent past performance.

${ }^{41}$ The $\mathrm{VaR}$ is the maximum loss expected with $95 \%$ confidence over one investment period (i.e., one simulated year in this case). The likelihood of an extreme adverse event occurring with $95 \%$ confidence is 1.645 standard deviations below the mean in a Normal distribution. Therefore, the $\mathrm{VaR}$ is equal to -1.645 multiplied by the standard deviation plus the mean.
} 
adverse events. ${ }^{42}$ At first, it may seem contradictory for subjects with high levels of stress to have high Sharpe ratio and high $\mathrm{VaR}$, yet low return and low volatility. However, as Table 4.2 shows, the magnitude of the volatility coefficient is larger than the magnitude of the return coefficient. This means that although volatility and return are both decreasing in relation to Sal-CO (i.e. both are negatively correlated), volatility decreases at a faster rate than return does. This results in the aforementioned high Sharpe ratio and high VaR values.

Overall, how is stress related to investment risk and return? The answer to this question relates to the measures of risk and return. Expected return is a measure of gross return, whereas the Sharpe ratio is a measure of risk-adjusted return. Therefore, regarding the relation between stress and return, the results show that high-stress subjects are risk-adjusted performance maximizers, whereas low-stress subjects are gross performance maximizers. Regarding the relation between stress and portfolio risk, note that volatility is a measure of dispersion and uncertainty, whereas VaR (as with Shortfall) is a measure of downside risk and adverse outcomes. Therefore, the results show that highstress subjects are uncertainty minimizers, whereas low-stress subjects are downside risk minimizers.

In fact, a large body of theoretical work describes the existence of "safetyfirst" investors who minimize the chance of extreme adverse outcomes (starting with Roy 1952). According to this literature, the allocation choices of safety-first

\footnotetext{
42 Technically the Sharpe ratio is the difference between the expected return and the risk-free rate divided by the standard deviation of returns. However, in this study the risk-free rate is zero in all tasks. Therefore, the Sharpe ratio is simply the expected return divided by volatility.
} 
investors are intended to maximize expected return, subject to a downside risk constraint. Similarly, portfolio theory predicts the existence of investors with quadratic preferences, who care only about the mean and variance of returns, and not about extreme losses (Levy and Markowitz 1979). The empirical literature shows that at times people's choices are consistent with Roy's framework, and at other times people's choices are consistent with Markowitz's framework. As such, the present study advances the literature by showing that: 1) biological correlates to Roy's and Markowitz's frameworks do exist—namely, safety-first investors have low levels of stress, whereas mean-variance investors possess high levels of stress, and 2) stress levels influence whether investors follow Roy's or Markowitz's framework of decision making.

Finally, the results in Table 4.2 show that Sal-CO has a unique (inverted U-shape) relation to portfolio abnormal return. That is, subjects with intermediate levels of stress achieve greater abnormal return than subjects with high or low levels of stress. Since both the Sharpe ratio and the portfolio abnormal return are risk-adjusted performance measures, one would expect them to possess a similar relation to stress levels. However, unlike the Sharpe ratio, abnormal return captures skewness and other higher-order moments of the return distribution (Leland 2002). In fact, the finance literature shows that investors do value higher-order moments (Kraus and Litzenberger 1976). Therefore, the results in Table 4.2 show that stress levels influence the value that investors place on higher-order moments of the return distribution. In particular, subjects with intermediate stress levels assign a greater value to positive skewness, 
achieving greater abnormal return than subjects with high and low stress levels. These results are congruent with performance maximization under moderate levels of stress, as predicted by the Yerkes-Dodson hypothesis. Furthermore, the results are supported by medical studies showing that variance and skewness are processed by two different brain areas, both of which are known targets of cortisol (Symmonds et al. 2011).

\subsubsection{Stress and Options Trading Performance}

Trading in options is generally more demanding than stock trading, or even futures trading. ${ }^{43}$ Therefore, options trading is a superior way to study the effect of stress on trading choices and outcomes. Table 4.3 displays the relation between Sal-CO and different trading choices available to subjects during the options-trading task. The results show that stress exerts a significant influence on trading choices, including the number of orders submitted, order type (i.e., limit versus market orders), trading position (i.e., selling versus buying), and trading time preferences. Lakonishok et al. (2007) shows that options trading is largely motivated by speculation on the direction of future stock price movements. As such, it is not surprising that the relation between stress and trading choices is significant at the contract level, and not at the portfolio level. In other words, by focusing on individual options subjects can speculate based on the risk profile of the different contracts.

The results in Table 4.3 create several important conclusions. First, stress exerts a more direct influence on selling decisions than buying decisions. Indeed,

\footnotetext{
${ }^{43}$ This is because option contracts are more difficult to understand, have more alternatives, and possess more leverage and positive payout skewness.
} 
selling is more stressful than buying, since even experienced traders have a hard time exiting losing trades (Odean 1998). Furthermore, medical studies show that the amygdala, which plays a central role in the stress response, is activated during selling decisions (of an owned asset), but not during buying decisions (Weber et al. 2007).

Second, the influence of stress on risk preferences is different for "optimists" and "pessimists." 44 This result is consistent with the Transactional Model of Stress, which emphasizes the importance of the appraisal process in the stress response (Lazarus and Folkman 1984). Table 4.3 shows that highstress optimists preferentially sell 25P, whereas low-stress optimists preferentially sell $24 \mathrm{P}$. The at-the-money $25 \mathrm{P}$ is riskier than the out-of-the-money 24P, due to the higher delta of the former. Therefore, the results show optimists with high stress levels take more risk than optimists with low stress levels. Additionally, Table 4.3 shows that high-stress pessimists sell more of the $26 \mathrm{C}$, whereas low-stress pessimists sell less of the $26 \mathrm{C}$. Selling a naked call, as is the case when one sells $26 \mathrm{C}$, is the riskiest alternative in options trading, because the potential losses are boundless. The associated results show that pessimists with high levels of stress take less (extreme) risk than pessimists with low levels of stress.

Third, the results show that stress possesses a U-shaped relation to order type (i.e., limit versus market orders) and to timing preferences. Specifically,

44 In the present study, "optimists" are identified as having a positive outlook about the future stock price, and their trading is characterized by buying call options and/or selling put options. Alternatively, pessimists are identified as having a negative outlook about the future stock price, and their trading is characterized by buying put options and/or selling call options. 
subjects with high or low levels of stress submit a greater proportion of $26 \mathrm{C}$ limit orders, begin trading earlier, and spend more time trading than subjects with intermediate levels of stress. Since $26 \mathrm{C}$ is the contract with the highest price, using limit orders can result in preferred transactions for high and low stress subjects. Furthermore, the fact that high and low stress subjects spend more total time trading (i.e., the time elapsed from first to last order submission) provides them with more opportunities to perform favorable trades. In fact, the performance results in Table 4.4 show that subjects with high or low stress levels have better $25 \mathrm{C}$ risk-adjusted performance than subjects with intermediate levels of stress. In terms of gross return (P\&L), subjects with low levels of stress achieve superior $24 \mathrm{P}$ performance. These results are opposite of what the Yerkes-Dodson hypothesis predicts about the stress-performance relation, showing that trading performance is not always optimal at moderate levels of stress.

\subsection{Conclusions}

Financial decisions often are perceived as being stressful. At times, they can invoke powerful emotional and cognitive processes that curb reason and performance. As such, it is critical to understand the role of stress on the decision-making process. This study provides one of the first comprehensive analyses of the relation between stress levels and financial choices under investing and trading frameworks. The tasks are realistic, and the measure of stress is unbiased. The results have important implications both for academic research and for financial decision making. 
The literature (described in Section 4.2) does not agree on the direction of the relation between stress and risk preferences during financial decision making. Some studies show that stress exhibits a positive correlation with risk aversion, whereas other studies show that stress has a positive correlation with risk taking. However, such incongruences reflect the very nature of stress as an adaptation mechanism. If all stress responses were equal, then there could be no adapting to new situations. Therefore, prior studies are simply capturing the proper stress response under the given circumstances.

The present study shows that the stress response is significantly different between investing and trading tasks. Furthermore, stress has a different relation to initial and subsequent investment choices. Specifically, stress has a significant positive linear relation to risk-aversion during initial investment decisions. Consequently, portfolios of high stress subjects are less risky and profitable than portfolios of low stress subjects. Alternatively, the relation of stress to subsequent investment decisions is greatly diminished by subjects' memory of their initial investment performance. Hence, stress is not significantly related to the performance of rebalanced portfolios. These results could be generalized to the population of naïve investors. However, the results might be different in a sample of professional investors for two main reasons: First, professional investors are less likely than naïve investors to allow their past performance to play a major role on their investment decisions. Second, professional investors make risky investment choices despite their overwhelming levels of stress. Therefore, future studies could examine the relation of stress and financial decision-making in 
professional investors. Regarding trading decisions, the results show that stress plays a pervasive role in many aspects of trading choices. One of the most interesting results is the modulating role of the stress appraisal process on the relation between stress and risk-taking. That is, the influence of stress during trading decisions is different for optimists and pessimists. Specifically, high stress optimists take more risk than low stress optimists, whereas high stress pessimists take less risk than low stress pessimists. Whether or not these results could be generalized to professional investors needs further research. However, modern psychology theory predicts that the stress appraisal process is an important modulator of the stress response. Therefore, professional investors might not be different from naïve investors in this regard.

Finally, this study could be expanded in several ways in order to address some important related questions. First and foremost, the present study is primarily a correlational study. Therefore, conclusions regarding the direction of the relation between stress and financial decisions and outcomes must be drawn with care. Future studies could address causality more appropriately via cortisol administration. Second, stress might work in conjunction with other endogenous factors, such as testosterone and personality traits, to exert an influence on financial decision-making. Future studies could address these factors together rather than separately. Third, given the almost universal focus on investment biases in the current behavioral finance literature, future studies could address the relation between stress and investment biases. Finally, this study stops at the level of the individual investor. Future studies could address the relation between 
stress and market behavior. Overall, it is my hope that the present study encourages other researchers to explore this new and exciting area of behavioral finance. 
Table 4.1

\section{Stress and Asset Allocation}

The table displays the coefficients for three regression models, where the proportion of funds allocated to the exchange-trade fund (ETF) securities (HOME, GROW, BOND, MINE, and MMKT) or not invested (CASH) is the dependent variable. An ETF is an investment fund traded on stock exchanges like a single stock. ETFs are composed of many assets, including stocks, commodities, and bonds. In addition to the five ETFs and CASH, the table displays the combined proportion of funds invested in low-risk securities (MMKT and $\mathrm{CASH}$ ) and high-risk securities (HOME and GROW). An additional, fourth model is performed on DIV2 variables to control for the level of performance during DIV1. Only the significant results are displayed in this table, and all subsequent tables. See the text for clarification.

\section{Panel A: DIV1}

\begin{tabular}{|lrrrrr|} 
& Model & Linear Sal-CO & Quadr. Sal-CO & Gender & Regression $\mathbf{R}^{2}$ \\
\hline CASH & 1 & ${ }^{*} 82.15$ & & 0.08 \\
\hline LOW RISK & 1 & ${ }^{*} 73.32$ & & & 0.07 \\
\hline HIGH RISK & 1 & ${ }^{*}-57.73$ & & & 0.07 \\
\hline & 2 & ${ }^{*}-74.89$ & 14.23 & 0.08 \\
\hline & 3 & ${ }^{*}-72.87$ & 13.55 & ${ }^{*} 127.75$ & 0.16 \\
\hline
\end{tabular}

Panel B: DIV2

\begin{tabular}{|rrrrrr|}
\hline Model & $\begin{array}{r}\text { Linear } \\
\text { Sal-CO }\end{array}$ & $\begin{array}{r}\text { Quadratic } \\
\text { Sal-CO }\end{array}$ & Gender & DIV1 NLV & $\begin{array}{r}\text { Regression } \\
\mathbf{R}^{\mathbf{2}}\end{array}$ \\
\hline MMKT & 2 & -15.03 & ${ }^{*} 18.25$ & & \\
\hline \\
\hline 3 & -15.03 & ${ }^{*} 18.25$ & -2.30 & & 0.09 \\
\hline 4 & -17.70 & ${ }^{*} 18.67$ & -0.14 & -8.79 & 0.09 \\
\hline
\end{tabular}

Notes: The explanatory variables are given by the model as follows:

Model 1 has salivary cortisol (Sal-CO) as the single explanatory variable.

Model 2 introduces a quadratic term.

Model 3 introduces a dummy variable for gender (Female=0, Male=1).

Model 4 (DIV2 only) introduces the standardized Net Liquidation Value (NLV) of

DIV1 to control for DIV1 performance.

Sample regression $R^{2}$ is displayed in the last column.

Regression coefficients are multiplied by 1,000 to show them more clearly.

Significance is displayed at the $10 \%\left(^{*}\right), 5 \%\left(^{* *}\right)$ and $1 \%\left(^{* \star *}\right)$ levels. 


\section{Table 4.2}

\section{Relation of Stress to Expected Portfolio Performance}

The table displays the coefficients for three regression models, where the dependent variable is a measure of expected portfolio performance during DIV1. There were no significant results for DIV2. Monte Carlo simulations of 2,000 iterations are performed for each subject, based on their asset allocation choices and the return distribution of the assets, in order to measure expected portfolio performance. These measures are: expected annual return, expected annual volatility of returns, expected Sharpe ratio, percent shortfall, expected abnormal return, and the $5 \%$ value at risk ( $\mathrm{VaR})$.

\begin{tabular}{|c|c|c|c|c|c|}
\hline & Model & Linear Sal-co & Quadr. Sal-CO & Gender & Regression $\mathrm{R}^{2}$ \\
\hline Return & 1 & ${ }^{* *}-8.04$ & & & 0.11 \\
\hline Volatility & 1 & ${ }^{*}-12.81$ & & & 0.08 \\
\hline Sharpe ratio & 1 & ${ }^{*} 42.28$ & & & 0.08 \\
\hline Shortfall & 1 & **59.56 & & & 0.11 \\
\hline & 2 & ${ }^{*} 62.71$ & -2.62 & & 0.11 \\
\hline & 3 & ${ }^{*} 61.67$ & -2.27 & -66.34 & 0.14 \\
\hline VaR & 1 & $\star 13.95$ & & & 0.07 \\
\hline Abn. Return & 2 & 0.88 & ${ }^{* *}-1.50$ & & 0.12 \\
\hline & $\frac{2}{3}$ & 0.82 & ${ }^{* *}-1.48$ & ${ }^{*}-3.76$ & 0.19 \\
\hline
\end{tabular}

Notes: The explanatory variables are given by the model as such:

Model 1 has salivary cortisol (Sal-CO) as the single explanatory variable. Model 2 introduces a quadratic term.

Model 3 introduces a dummy variable for gender (Female=0, Male=1).

Sample regression $R^{2}$ is displayed in the last column.

Regression coefficients are multiplied by 1,000 to show them more clearly.

Significance is displayed at the $10 \%\left(^{*}\right), 5 \%\left(^{(*)}\right.$ and $1 \%\left(^{* \star *}\right)$ levels. 


\section{Table 4.3}

\section{Cortisol and Options Trading Preferences}

The table displays the coefficients for three regression models, where the dependent variable is a measure of trading preferences for different options contracts. These measures are, from top to bottom in the first column: the proportion of orders submitted, the proportion of limit orders (Limit), the proportion of sell orders, the number of seconds elapsed before the first order is submitted, and the total trading time.

\begin{tabular}{|lrrrrr|}
\hline 25P Orders & Model & Linear Sal-CO & Quadr. Sal-CO & Gender & Regression $\mathbf{R}^{2}$ \\
\hline & 1 & ${ }^{*} 51.98$ & & & 0.08 \\
\hline & 2 & ${ }^{*} 71.95$ & -17.39 & & 0.09 \\
\hline 26C Limit & 3 & ${ }^{*} 71.76$ & -17.22 & -40.27 & 0.10 \\
\hline & 2 & ${ }^{* *}-69.60$ & ${ }^{* *} 41.92$ & & 0.13 \\
\hline 24P Sells & 3 & ${ }^{* *}-69.15$ & ${ }^{* *} 41.53$ & ${ }^{*} 95.13$ & 0.20 \\
\hline & 1 & ${ }^{* *}-27.08$ & & & 0.09 \\
\hline & 2 & ${ }^{*}-33.90$ & 5.94 & & 0.10 \\
\hline 25P Sells & 3 & ${ }^{*}-34.06$ & 6.08 & -33.13 & 0.13 \\
\hline 26C Sells & 1 & ${ }^{*} 24.98$ & & & 0.07 \\
\hline & 2 & ${ }^{* *}-47.43$ & 17.31 & 56.86 & 0.11 \\
\hline First Order & 3 & ${ }^{* *}-47.16$ & 17.07 & & 0.17 \\
\hline & 2 & ${ }^{* *} 22.36$ & ${ }^{* *}-11.07$ & 0.16 \\
\hline Trading Time & 3 & ${ }^{* *} 22.44$ & ${ }^{* *}-11.13$ & 15.18 & 0.19 \\
\hline & 2 & ${ }^{*}-21.43$ & ${ }^{*} 11.99$ & & 0.10 \\
\hline
\end{tabular}

Notes: The explanatory variables are given by the model as follows:

Model 1 has salivary cortisol (Sal-CO) as the single explanatory variable.

Model 2 introduces a quadratic term.

Model 3 introduces a dummy variable for gender (Female=0, Male=1).

Sample regression $R^{2}$ is displayed in the last column.

Regression coefficients are multiplied by 1,000 to show them more clearly.

Significance is displayed at the $10 \%\left(^{*}\right), 5 \%\left(^{* *}\right)$ and $1 \%\left(^{* * *}\right)$ levels. 


\section{Table 4.4}

\section{Cortisol and Trading Performance}

The table displays the coefficients for three regression models, where the dependent variables are the final profit and loss value (P\&L), and the ratio of average to standard deviation of Net Liquidity Value (coefficient of variation, CV).

\begin{tabular}{|lrrrrr|} 
& Model & Linear Sal-CO & Quadr. Sal-CO & Gender & Regression $\mathbf{R}^{\mathbf{2}}$ \\
\hline P\&L 24P & 1 & ${ }^{* *}-2314$ & & & 0.11 \\
\hline CV 25C & 2 & -0.26 & ${ }^{*} 0.15$ & & 0.08 \\
\hline & 3 & -0.26 & ${ }^{*} 0.16$ & -0.38 & 0.13 \\
\hline
\end{tabular}

Notes: The explanatory variables are given by the model as follows:

Model 1 has salivary cortisol (Sal-CO) as the single explanatory variable.

Model 2 introduces a quadratic term.

Model 3 introduces a dummy variable for gender (Female=0, Male=1).

Sample regression $R^{2}$ is displayed in the last column.

Regression coefficients are multiplied by 1,000 to show them more clearly.

Significance is displayed at the $10 \%\left(^{*}\right), 5 \%\left(^{* *}\right)$ and $1 \%\left(^{* * *}\right)$ levels. 


\section{REFERENCES}

Ahn, H. J., Bae, K. H., and Chan, K. (2001) Limit orders, depth, and volatility: Evidence from the stock exchange of Hong Kong. Journal of Finance, 56(2), 767-788.

Apicella, C. L., Dreber, A., Campbell, B., Gray, P. B., Hoffman, M., and Little, A. C. (2008) Testosterone and financial risk preferences. Evolution and Human Behavior, 29(6), 384-390.

Arnold, P. D., Zai, G., and Richter, M. A. (2004) Genetics of anxiety disorders. Current Psychiatry Reports, 6, 243-254.

Barber, B. M., and Odean, T. (2000) Trading is hazardous to your wealth: The common stock investment performance of individual investors. Journal of Finance, 55, 773-806.

Baker, H. K., and Nofsinger, J. R. (2002) Psychological biases of investors. Financial Services Review, 11, 97-116.

Bechara, A., Damasio, H., and Damasio, A. R. (2000) Emotion, decision-making and the orbitofrontal cortex. Cerebral Cortex, 10, 295-307.

Biais, B., Hilton, D., Mazurier, K., and Pouge, S. (2002) Psychological traits and trading strategies. Discussion Paper, Center for Economic Policy Research.

Blackburn, R. (1969) Sensation seeking, impulsivity, and psychopathic personality. Journal of Consulting and Clinical Psychology, 33, 571-574.

Bosch-Domenech, A., Branas-Garza, P., and Espin, A. M. (2014) Can exposure to prenatal sex hormones (2D: 4D) predict cognitive reflection? Psychoneuroendocrinology, 43, 1-10.

Bressan, R. A., and Crippa, J. A. (2005) The role of dopamine in reward and pleasure behaviour-review of data from preclinical research. Acta Psychiatrica Scandinavica, 111(s427), 14-21.

Coates, J. M., Gurnell, M., and Rustichini, A. (2009) Second-to-fourth digit ratio predicts success among high-frequency financial traders. Proceedings of the National Academy of Sciences, 106(2), 623-628.

Coates, J. M., Gurnell, M., and Sarnyai, Z. (2010) From molecule to market: Steroid hormones and financial risk-taking. Philosophical Transactions of the Royal Society B: Biological Sciences, 365, 331-343. 
Coates J.M., and Herbert, J. (2008) Endogenous steroids and financial risktaking on a London trading floor. Proceedings of the National Academy of Sciences, 105, 6167-6172.

Cohen, M. X., Young, J., Baek, J. M., Kessler, C., and Ranganath, C. (2005) Individual differences in extraversion and dopamine genetics predict neural reward responses. Cognitive Brain Research, 25, 851-861.

Conrad, C. D., Lupien, S. J., and McEwen, B. S. (1999) Support for a bimodal role for type II adrenal steroid receptors in spatial memory. Neurobiology of Learning and Memory, 72(1), 39-46.

Dabbs, J. M., Frady, R. L., Carr, T. S., and Besch, N. F. (1987) Saliva testosterone and criminal violence in young adult prison inmates. Psychosomatic Medicine, 49(2), 174-182.

Daniel, K. D., Hirshleifer, D., and Subrahmanyam, A. (1998) Investor psychology and security market under- and over-reactions. Journal of Finance, 53, 1839-1886.

Davis, M. (1992) The role of the amygdala in fear and anxiety. Annual Review of Neuroscience, 15(1), 353-375.

De Martino, B., Kumaran, D., Holt, B., and Dolan, R. J. (2009) The neurobiology of reference-dependent value computation. Journal of Neuroscience, 29, 3833-3842.

Dias, S. (1997). Analysis of mental disorder claims: Workers compensation statistics NSW. WorkCover New South Wales, 525(96), 1-8.

Durand, R. B., Newby, R., Peggs, L., and Siekierka, M. (2010) Personality. Journal of Behavioral Finance, 14(2), 116-133.

Durand, R. B., Newby, R., and Sanghani, J. (2008) An intimate portrait of the individual investor. Journal of Behavioral Finance, 9, 193-208.

Eckel, C. C., and Grossman, P. J. (2002) Sex differences and statistical stereotyping in attitudes toward financial risk. Evolution and Human Behavior, 23, 281-295.

Elifson, K. W., Klein, H., and Sterk, C. E. (2006) Predictors of sexual risk-taking among new drug users. Journal of Sex Research, 43, 318-327.

Epstein, L. G. (1999) A definition of uncertainty aversion. The Review of Economic Studies, 66(3), 579-608. 
Flory, J. D., Manuck, S. B., Matthews, K. A., and Muldoon, M. F. (2004) Serotonergic function in the central nervous system is associated with daily ratings of positive mood. Psychiatry Research, 129, 11-19.

Foucault, T. (1999) Order flow composition and trading costs in a dynamic limit order market. Journal of Financial markets, 2(2), 99-134.

Frederick, S. (2005) Cognitive reflection and decision making. Journal of Economic Perspectives, 19(4), 25-42.

Frye, C. A., Rhodes, M. E., Rosellini, R., and Svare, B. (2002) The nucleus accumbens as a site of action for rewarding properties of testosterone and its 5a-reduced metabolites. Pharmacology Biochemistry and Behavior, 74(1), 119-127.

Garvey, R., and Wu, F. (2010) Speed, distance, and electronic trading: New evidence on why location matters. Journal of Financial Markets, 13(4), 367-396.

Gladue, B. A., Boechler, M., and McCaul, K. D. (1989) Hormonal response to competition in human males. Aggressive Behavior, 15(6), 409-422.

Glosten, L. R. (1994) Is the electronic open limit order book inevitable? Journal of Finance, 49(4), 1127-1161.

Goetzmann, W. N., and Kumar, A. (2008) Equity portfolio diversification. Review of Finance, 12, 433-463.

Goudriaan, A. E., Lapauw, B., Ruige, J., Feyen, E., Kaufman, J. M., Brand, M., and Vingerhoets, G. (2010) The influence of high-normal testosterone levels on risk-taking in healthy males in a 1-week letrozole administration study. Psychoneuroendocrinology, 35(9), 1416-1421.

Graham, J. R., and Lowenfeld, B. H. (1986) Personality dimensions of the pathological gambler. Journal of Gambling Behavior, 2, 58-66.

Gregory, D. W. (2012) Deconstructing financial psychopaths: Culture, evolution, or opportunity? Working Paper, Bentley University.

Guiso, L., Sapienza, P., and Zingales, L. (2008) Trusting the stock market. Journal of Finance, 63, 2557-2600.

Handa, P., and Schwartz, R. A. (1996) Limit order trading. Journal of Finance, 51(5), 1835-1861. 
Holt, C. A., and Laury, S. K. (2002) Risk aversion and incentive effects. American Economic Review, 92(5), 1644-1655.

Horvath, P., and Zuckerman, M. (1993) Sensation seeking, risk appraisal and risky behavior. Personality and Individual Differences, 14, 41-52.

Ivkovich, Z., Sialm, C., and Weisbenner, S. (2008) Portfolio concentration and the performance of individual investors. Journal of Financial and Quantitative Analysis, 43, 613-656.

Jones J.R., Huxtable, C.S., Hodgson, J.T., and Price, M.J. (2003) Self-reported work-related illness in 2001/02: Results from a household survey. Norwich: Health and Safety Executive.

Kahn, H., and Cooper, C.L. (1990) Mental health, job satisfaction, alcohol intake and occupational stress among dealers in financial markets. Stress Medicine, 6, 285-298.

Kandasamy, N., Hardy, B., Page, L., Schaffner, M., Graggaber, J., S Powlson, A., Fletcher, P., Gurnell, M., and Coates, J. (2014) Cortisol shifts financial risk preferences. Proceedings of the National Academy of Sciences, 111(9), 3608-3613.

Kashkin, K. B., and Kleber, H. D. (1989) Hooked on hormones?: An anabolic steroid addiction hypothesis. Jama, 262(22), 3166-3170.

Kirschbaum, C., Prussner, J. C., Stone, A. A., Federenko, I., Gaab, J., Lintz, D., Schommer, N., and Hellhammer, D. H. (1995) Persistent high cortisol responses to repeated psychological stress in a subpopulation of healthy men. Psychosomatic Medicine, 57(5), 468-474.

Knutson, B., Adams, C. M., Fong, G. W., and Hommer, D. (2001) Anticipation of increasing monetary reward selectively recruits nucleus accumbens. Journal of Neuroscience, 21(16), 1-5.

Knutson, B., and Cooper, J. C. (2005) Functional magnetic resonance imaging of reward prediction. Current Opinion in Neurology, 18(4), 411-417.

Korniotis, G. M., and Kumar, A. (2013) Do portfolio distortions reflect superior information or psychological biases? Journal of Financial and Quantitative Analysis, 48(1), 1-45.

Kraus, A., and Litzenberger, R. H. (1976) Skewness preference and the valuation of risk assets*. Journal of Finance, 31(4), 1085-1100. 
Kuhnen C. M., and Chiao, J. Y. (2009) Genetic determinants of financial risktaking. PLoS ONE, 4(2), e4362.

Kuhnen, C. M., and Knutson, B. (2005) The neural basis of financial risk-taking. Neuron, 47, 763-770.

McEwen, B. S. (1998) Stress, adaptation, and disease: Allostasis and allostatic load. Annals of the New York Academy of Sciences, 840, 33-44.

Lakonishok, J., Lee, I., Pearson, N. D., and Poteshman, A. M. (2007) Option market activity. Review of Financial Studies, 20(3), 813-857.

Lane S. D., Tcheremissine, O. V., Lieving, L. M., Nouvion, S. O., and Cherek, D. R. (2005) Acute effects of alprazolam on risky decision-making in humans. Psychopharmacology, 181, 364-373.

Laudat, M. H., Cerdas, S., Fournier, C., Guiban, D., Guilhaume, B., and Luton, J. P. (1988) Salivary cortisol measurement: A practical approach to assess pituitary-adrenal function. Journal of Clinical Endocrinology and Metabolism, 66(2), 343-348.

Lazarus, R. S., and Folkman, S. (1984) Stress, appraisal and coping. New York: McGraw-Hill.

Leland, H. E. (1999) Beyond mean-variance: Performance measurement in a nonsymmetrical world. Financial Analysts Journal, 55(1) 27-36.

Levy, H., and Markowitz, H. M. (1979) Approximating expected utility by a function of mean and variance. American Economic Review, 69(3), 308317.

Lo, A. W., and Repin, D. V. (2002) The psychophysiology of real-time financial risk processing. Journal of Cognitive Neuroscience, 14, 323-339.

Locke, P. R., and Mann, S. C. (2005) Professional trader discipline and trade disposition. Journal of Financial Economics, 76(2), 401-444.

Mazur, A. (1995) Biosocial models of deviant behavior among male army veterans. Biological Psychology, 41(3), 271-293.

Mehta, P. H., Jones, A. C., and Josephs, R. A. (2008). The social endocrinology of dominance: Basal testosterone predicts cortisol changes and behavior following victory and defeat. Journal of Personality and Social Psychology, 94(6), 1078-1093. 
Middleman, A. B., and DuRant, R. H. (1996) Anabolic steroid use and associated health risk behaviours. Sports Medicine, 21(4), 251-255.

Oberlechner, T., and Nimgade, A. (2005) Work stress and performance among financial traders. Stress and Health, 21(5), 285-293.

Odean, T. (1998) Are investors reluctant to realize their losses? Journal of Finance, 53(5), 1775-1798.

Odean, T. (1999) Do investors trade too much? American Economic Review, LXXXIX, 1279-1298.

Rogers, R. D., Lancaster, M., Wakeley, J., and Bhagwagar, Z. (2004) Effects of beta-adrenoceptor blockade on components of human decision-making. Psychopharmacology, 172, 157-164.

Roy, A. D. (1952) Safety first and the holding of assets. Econometrica, 20, 431449.

Roy, A., Custer, R., Lorenz, V., and Linnoila, M. (1989) Personality factors and pathological gambling. Acta Psychiatrica Scandinavica, 80, 37-39.

Sapienza, P., Zingales, L., and Maestripieri, D. (2009) Gender differences in financial risk aversion and career choices are affected by testosterone. Proceedings of the National Academy of Sciences, 106(36), 15268-15273.

Schulkin, J., McEwen, B. S., and Gold, P. W. (1994) Allostasis, amygdala, and anticipatory angst. Neuroscience and Biobehavioral Reviews, 18(3), 385396.

Shefrin, H. (2000) Beyond greed and fear: Understanding behavioral finance and the psychology of investing. Boston: Harvard Business School Press.

Stanton, S. J., Liening, S. H., and Schultheiss, O. C. (2011) Testosterone is positively associated with risk taking in the lowa Gambling Task. Hormones and Behavior, 59(2), 252-256.

Stanton, S. J., O'Dhaniel, A., McLaurin, R. E., Kuhn, C. M., LaBar, K. S., Platt, M. L., and Huettel, S. A. (2011) Low- and high-testosterone individuals exhibit decreased aversion to economic risk. Psychological Science, 22(4), 447453.

Symmonds, M., Wright, N. D., Bach, D. R., and Dolan, R. J. (2011). Deconstructing risk: Separable encoding of variance and skewness in the brain. Neuroimage, 58(4), 1139-1149. 
Tarter, R. E. (1988) Are there inherited behavioral traits that predispose to substance abuse? Journal of Consulting and Clinical Psychology, 56, 189-196.

Thaler, R., and Johnson, E. J. (1990) Gambling with the house money and trying to break even: The effects of prior outcomes on risky choice. Management Science, 36, 643-660.

van Honk, J., Schutter, D., Hermans, E., and Putman, P. (2003) Low cortisol levels and the balance between punishment sensitivity and reward dependency. NeuroReport 14, 1993-1996.

van Honk, J., Schutter, D., Hermans, E., Putman, P., Tuiten, A., and Koppeschaar, H. (2004) Testosterone shifts the balance between sensitivity for punishment and reward in healthy young women. Psychoneuroendocrinology, 29(7), 937-943.

Weber, B., Aholt, A., Neuhaus, C., Trautner, P., Elger, C. E., and Teichert, T. (2007) Neural evidence for reference-dependence in real-markettransactions. Neuroimage, 35(1), 441-447.

Weber, E. U., Shafir, S., and Blais, A. R. (2004) Predicting risk sensitivity in humans and lower animals: Risk as variance or coefficient of variation. Psychological Review, 111(2), 430-445.

Widiger, T. A., and Mullins-Sweatt, S. N. (2009) Five-factor model of personality disorder: A proposal for DSM-V. Annual Review of Clinical Psychology, 5, 197-220.

Wright, P., He, G., Shapira, N. A., Goodman, W. K., and Liu, Y. (2004) Disgust and the insula: fMRI responses to pictures of mutilation and contamination. NeuroReport, 15, 2347-2351.

Zethraeus, N., Kocoska-Maras, L., Ellingsen, T., von Schoultz, B., Hirschberg, A. L., and Johannesson, M. (2009) A randomized trial of the effect of estrogen and testosterone on economic behavior. Proceedings of the National Academy of Sciences, 106(16), 6535-6538.

Zuckerman, M. (1979) Sensation seeking: Beyond the optimal level of arousal. New Jersey: Erlbaum.

Zuckerman, M. (1994) Behavioral expressions and biosocial bases of sensation seeking. New York: Cambridge University Press. 


\section{APPENDICES}

\section{Appendix A: Descriptions of Investment Measures}

Portfolio diversification (PDIV): The coefficient of determination (R-squared) of the linear regression between portfolio excess returns (the dependent variable) and market excess returns (the independent variable). ${ }^{45}$

Average return (AVE): The annualized arithmetic mean of the portfolio excess returns.

Holding period return (HPR): The annualized geometric mean of the portfolio excess returns.

Return volatility (SD): The annualized standard deviation of portfolio excess returns. In order to annualize the volatility, the weekly standard deviation is multiplied by the square root of 52 .

Sharpe ratio: The annualized arithmetic mean of portfolio excess returns divided by the annualized standard deviation of portfolio excess returns. ${ }^{46}$

Alpha: The intercept of the linear regression between portfolio excess returns and the market excess returns. As with the other measures of portfolio return, alpha is annualized.

\footnotetext{
${ }^{45}$ In all the calculations, the three-month Treasury bill rate is used as a proxy for the risk-free rate of return, whereas the Standard \& Poor's 500 index (S\&P500) is used as a proxy for the market rate of return.

${ }^{46}$ When ranking portfolios by the Sharpe or Treynor ratios it is necessary to make an adjustment to the traditional formulas when portfolios with negative average excess returns exist. For instance, suppose that we want to rank two portfolios with equal positive average excess returns; the one with the lowest return volatility (standard deviation) receives a higher Sharpe ratio. On the other hand, if the portfolios possess equal negative average excess returns, then the one with the highest volatility receives a higher (less negative) Sharpe ratio, a counterintuitive result. A way to correct this issue is to make an adjustment to the traditional Sharpe ratio formula by adding an exponent to the denominator. The exponent is excess return divided by the absolute value of the excess return. A similar adjustment is necessary for the traditional Treynor ratio formula.
} 
Beta: The slope of the linear regression between portfolio excess returns and market excess returns.

Treynor ratio: The annualized arithmetic mean of portfolio excess returns divided by the portfolio beta. When excess returns are negative, the Treynor ratio is modified in a similar fashion as the Sharpe ratio. 


\section{Appendix B: Abnormal Factor Score Descriptions}

\begin{tabular}{|c|c|c|}
\hline Low Score Description & Factor & High Score Description \\
\hline $\begin{array}{l}\text { Is happy, mind works well, does not find } \\
\text { ill health frightening } \\
\text { (Low hypochondriasis) }\end{array}$ & D1 & $\begin{array}{l}\text { Shows overconcern with bodily functions, } \\
\text { health, or disabilities } \\
\text { (High hypochondriasis) }\end{array}$ \\
\hline $\begin{array}{l}\text { Is contented about life and } \\
\text { surroundings, has no death wishes } \\
\text { (Zestfulness) }\end{array}$ & D2 & $\begin{array}{l}\text { Is disgusted with life, harbors thoughts or } \\
\text { acts of self-destruction } \\
\text { (Suicidal disgust) }\end{array}$ \\
\hline $\begin{array}{l}\text { Avoids dangerous and adventurous } \\
\text { undertakings, has little need for } \\
\text { excitement } \\
\text { (Low brooding discontent) }\end{array}$ & D3 & $\begin{array}{l}\text { Seeks excitement, is restless, takes risks, } \\
\text { tries new things } \\
\text { (High brooding discontent) }\end{array}$ \\
\hline $\begin{array}{l}\text { Is calm in emergency, confident about } \\
\text { surroundings, poised } \\
\text { (Low anxious depression) }\end{array}$ & D4 & $\begin{array}{l}\text { Has disturbing dreams, is clumsy in } \\
\text { handling things, tense, easily upset } \\
\text { (High anxious depression) }\end{array}$ \\
\hline $\begin{array}{l}\text { Shows enthusiasm for work, is } \\
\text { energetic, sleeps soundly } \\
\text { (High energy euphoria) }\end{array}$ & D5 & $\begin{array}{l}\text { Has feelings of weariness, worries, lacks } \\
\text { energy to cope } \\
\text { (Low energy depression) }\end{array}$ \\
\hline $\begin{array}{l}\text { Is not troubled by guilt feelings, can } \\
\text { sleep no matter what is left undone } \\
\text { (Low guilt and resentment) }\end{array}$ & D6 & $\begin{array}{l}\text { Has feelings of guilt, blames self for } \\
\text { everything that goes wrong, is critical of } \\
\text { self } \\
\text { (High guilt and resentment) }\end{array}$ \\
\hline $\begin{array}{l}\text { Is relaxed, considerate, cheerful with } \\
\text { people } \\
\text { (Low bored withdrawal) }\end{array}$ & D7 & $\begin{array}{l}\text { Avoids interpersonal contact, shows } \\
\text { discomfort with people } \\
\text { (High bored withdrawal) }\end{array}$ \\
\hline $\begin{array}{l}\text { Is trusting, not bothered by jealousy or } \\
\text { envy } \\
\text { (Low paranoia) }\end{array}$ & $\mathrm{Pa}$ & $\begin{array}{l}\text { Believes he is being persecuted, spied on, } \\
\text { poisoned, controlled, mistreated } \\
\text { (High paranoia) }\end{array}$ \\
\hline $\begin{array}{l}\text { Avoids engagement in illegal acts or } \\
\text { breaking rules, sensitive } \\
\text { (Low psychopathic deviation) }\end{array}$ & $\mathrm{Pp}$ & $\begin{array}{l}\text { Complacent towards own or others, anti- } \\
\text { social behavior, is not hurt by criticism } \\
\text { (High psychopathic deviation) }\end{array}$ \\
\hline $\begin{array}{l}\text { Realistically appraises himself and } \\
\text { others, shows absence of regressive } \\
\text { behavior } \\
\text { (Low schizophrenia) }\end{array}$ & Sc & $\begin{array}{l}\text { Retreats from reality, has uncontrolled and } \\
\text { sudden impulses } \\
\text { (High schizophrenia) }\end{array}$ \\
\hline $\begin{array}{l}\text { Is not bothered by unwelcome thoughts } \\
\text { and ideas or compulsive habits } \\
\text { (Low psychasthenia) }\end{array}$ & As & $\begin{array}{l}\text { Suffers insistent, repetitive ideas and } \\
\text { compulsive habits } \\
\text { (High psychasthenia) }\end{array}$ \\
\hline $\begin{array}{l}\text { Considers himself as good, } \\
\text { dependable, and smart as most others } \\
\text { (Low general psychosis) }\end{array}$ & Ps & $\begin{array}{l}\text { Has feelings of inferiority and } \\
\text { unworthiness, timid, loses head easily } \\
\text { (High general psychosis) }\end{array}$ \\
\hline
\end{tabular}

Notes: This table describes the twelve abnormal personality factors measured in Part II of Cattell's Clinical Analysis Questionnaire. The "Low Score Description" pertains to sten scores between 1 and 3, whereas the "High Score Description" pertains to sten scores between 8 and 10. Each description is followed by its clinical name shown in parenthesis. The lower the sten score, the greater the low score description applies to the individual. Similarly, the higher the sten score, the greater the high score description applies. This table is from the Manual for the Clinical Analysis Questionnaire. 


\section{Appendix C: Portfolio Efficiency}

The appendix figure shows the efficient frontiers and the individual portfolios formed during DIV1 (Panel A) and DIV2 (Panel B). The figures show that portfolios are more clustered together in DIV2 than in DIV1. This is consistent with the results provided in Table 3.1 (Chapter 3 ), which shows that portfolio return and volatility have lower standard deviations in DIV2. Thus, the figure supports the notion that the performance during DIV1 influenced the allocation choices during DIV2. The figure also shows that DIV2 portfolios lie closer to the efficient frontier than DIV1 portfolios. To test this notion, it is necessary to measure the distance between each portfolio and the efficient frontier.

Since investors could choose not to invest a portion of their allowance (CASH), their position is equivalent to having the choice to allocate their funds between the market portfolio (the efficient portfolio with highest Sharpe ratio) and a risk-free asset that pays zero return. As such, the "new" efficient frontier is the tangency line that connects the risk-free rate to the market portfolio (also known as the Capital Allocation Line $(C A L))$, together with the portion of the Markowitz efficient set of risky assets above the market portfolio

For a given level of return, modern portfolio theory predicts that the variance of a portfolio on the efficient frontier, excluding CAL, is a product of its expected return $\left(E\left(R_{p}\right)\right)$, the vector of asset returns $(\mu)$, and the matrix of covariances between the risky assets $(\mathrm{V})$, as shown in Equation 1: 


$$
\sigma_{p}^{2}=\left(E\left(R_{p}\right), 1\right)\left[(\mu, \mathcal{1})^{\prime} V^{-1}(\mu, \mathcal{1})\right]^{-1}\left(\begin{array}{c}
E\left(R_{p}\right) \\
1
\end{array}\right)
$$

Equation 1 can be employed to compute coordinate points on the efficient frontier above the tangency portfolio. Similarly, the equation for CAL (Equation 2) can be used to compute the coordinate points on the efficient frontier below the tangency portfolio. The CAL equation is a linear formula that relates the expected portfolio return and volatility $\left(\sigma_{p}\right)$ to the expected return and volatility of the market portfolio (shown with subscript "M"), and the risk-free rate (which is zero in this case)

$$
E\left(R_{p}\right)=r_{f}+\sigma_{p} \frac{\left[E\left(R_{M}\right)-r_{f}\right]}{\sigma_{M}}
$$

Together, Equations 1 and 2 can be used to calculate the horizontal distance between each portfolio and the efficient frontier — that is, the difference between the realized portfolio volatility, and the volatility of the efficient portfolio of equal expected return.

The appendix figure shows that four portfolios in DIV1 (Panel A) and one portfolio in DIV2 (Panel B) fall below the expected return of the tangency portfolio (two portfolios overlap in DIV1). For these five portfolios, Equation 2 is used to calculate the horizontal distance to the efficient frontier, whereas Equation 1 is used for the remaining portfolios. The average horizontal distance to the efficient frontier of DIV1 portfolios is $1.91 \%(S D=1.17 \%)$, whereas the average horizontal distance to the efficient frontier of DIV2 portfolios is $1.69 \% \quad(S D=0.93 \%)$. 
Nevertheless, this difference is not statistically significant, showing that portfolio efficiency is similar for both tasks.

\section{Appendix C Figure}

The Efficient Frontier and DIV1 and DIV2 Portfolios

The curves displayed in red represent the efficient frontiers in the absence of a risk-free rate instrument. Since investors could potentially leave a portion of their funds uninvested (in Cash), it is equivalent to having the option of investing in a risk-free asset with a return of zero. The efficient frontier then becomes the tangency line, displayed in black, plus the upper portion of the red curve. The dots displayed in blue represent the individual investor portfolios.
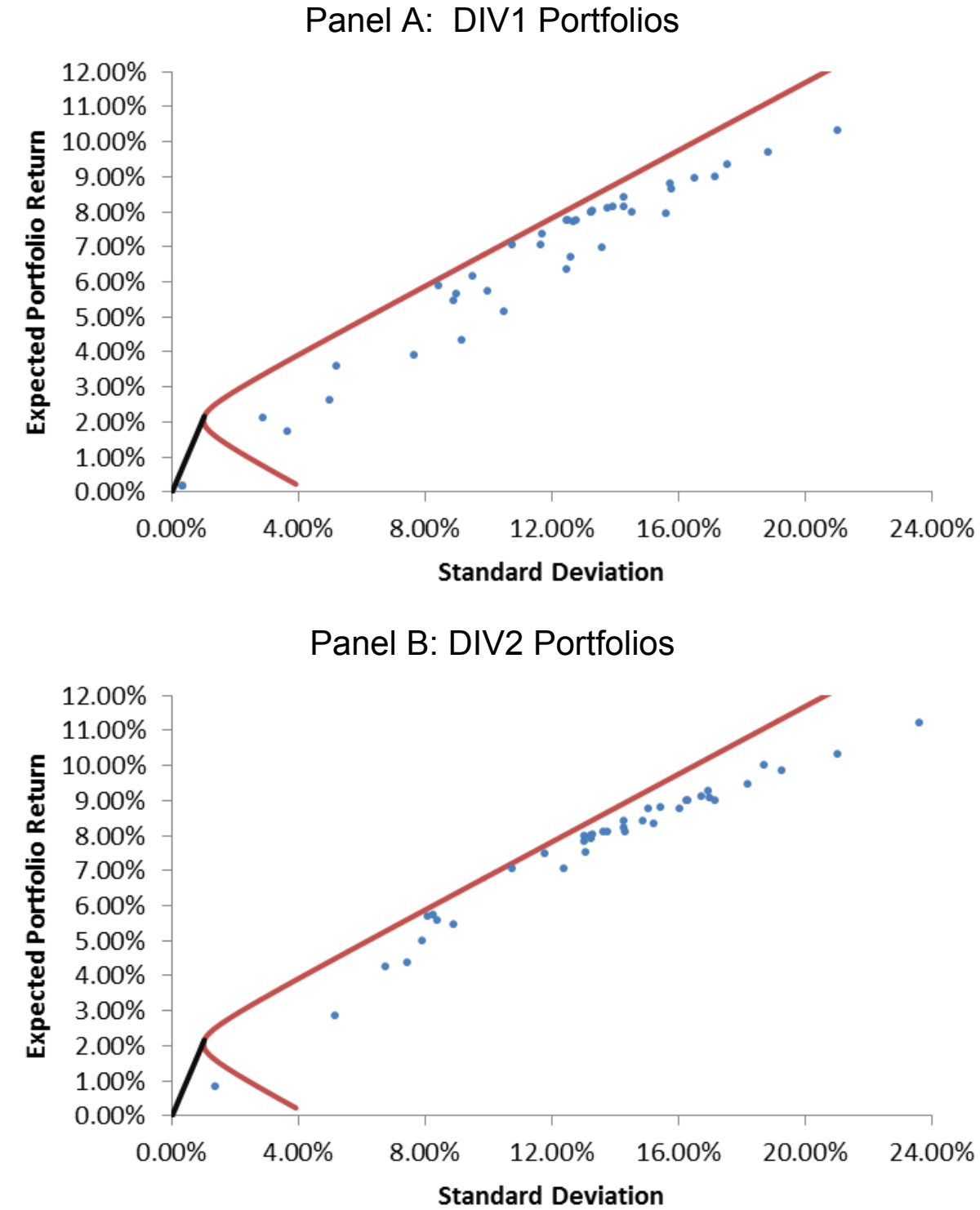
VITA

FERNANDO M. PATTERSON

Born, Havana, Cuba

1999-2003

B.S., Psychobiology

University of Miami

Coral Gables, Florida

2008-2009

M.S., Finance

Florida International University

Miami, Florida

\section{PUBLICATIONS AND PRESENTATIONS}

Patterson, F. M., and Daigler, R. T. (2014) The abnormal psychology of investment performance. Review of Financial Economics, 23(2), 55-63.

Patterson, F. M., and Daigler, R. T. (September 2012) The abnormal psychology of investment performance. Society for Neuroeconomics Annual Meeting, Key Biscayne, Florida. 